\title{
PATHFINDER ATOMIC POWER PLANT TECHNICAL PROGRESS REPORT JULY 1, 1959_SEPTEMBER 30, 1959
}

February 1960

[TIS Issuance Date]

Atomic Energy Division

Allis-Chalmers Manufacturing Company

Milwaukee, Wisconsin

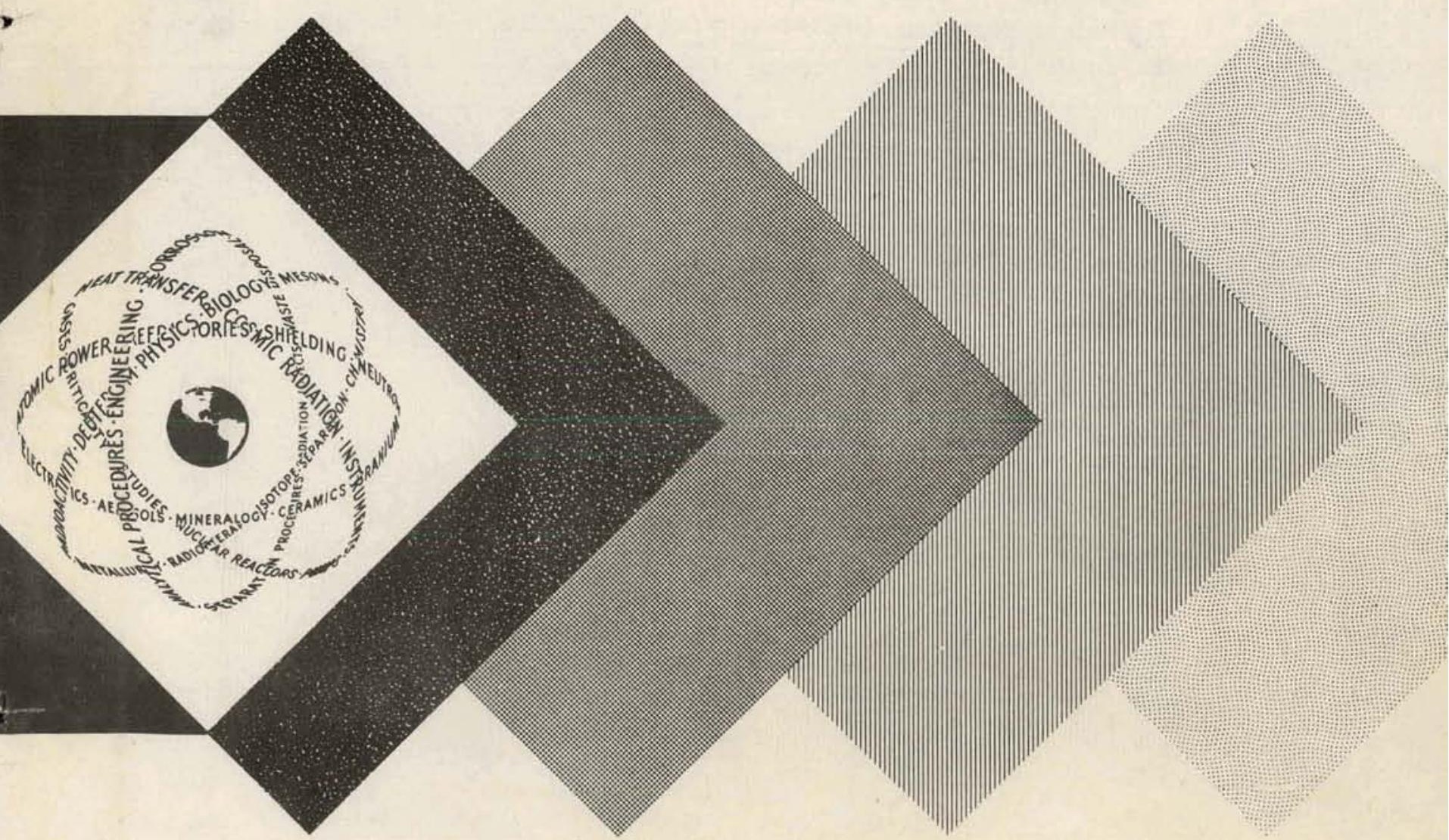




\section{DISCLAIMER}

This report was prepared as an account of work sponsored by an agency of the United States Government. Neither the United States Government nor any agency Thereof, nor any of their employees, makes any warranty, express or implied, or assumes any legal liability or responsibility for the accuracy, completeness, or usefulness of any information, apparatus, product, or process disclosed, or represents that its use would not infringe privately owned rights. Reference herein to any specific commercial product, process, or service by trade name, trademark, manufacturer, or otherwise does not necessarily constitute or imply its endorsement, recommendation, or favoring by the United States Government or any agency thereof. The views and opinions of authors expressed herein do not necessarily state or reflect those of the United States Government or any agency thereof. 


\section{DISCLAIMER}

Portions of this document may be illegible in electronic image products. Images are produced from the best available original document. 


\section{LEGAL NOTICE}

This report was prepared as an account of Government sponsored work. Nelther the Unitod States, nor the Commission, nor any person acting on behalf of the Commission:

A. Makes any warranty or representation, expressed or implied, with respect to the accuracy, completeness, or usefulness of the information contained in this report, or that the use of any information, apparatus, method, or process disclosed in this report may not infringe privately owned rights; or

B. Assumes any liabilities with respect to the use of, or for damages resulting from the use of any information, apparatus, method, or process disclosed in this report.

AB used in the above, "person acting on behalf of the Commission" Includes any employee or contractor of the Commission, or employee of such contractor, to the extent that such employee or contractor of the Commission, or employee of such contractor prepares, disseminates, or provides access to, any information pursuant to his employment or contract with the Commission, or his employment with such contractor.

This report has been reproduced directly from the best avallable copy.

Printed in USA. Price $\$ 2.75$. Available from the Office of Technical Services, Department of Commerce, Washington 25, D. C.

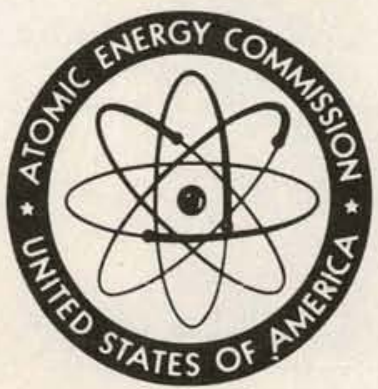


PATHFINDER ATOMIC POWER PLANT

TECHNICAL PROGRESS REPORT

JULY I, 1959 - SEPT. 30, 1959

Submitted to

U. S. ATOMIC ENERGY COMMISSION, NORTHERN STATES POWER COMPANY

and

CENTRAL UTILITIES ATOMIC POWER ASSOCIATES

Under

Agreement dated 2nd Day of May 1957 and Supplemental Agreement dated 22rd Day of November 1957 between NSP and A-C under AEC Controct No. AT (11-1)-589

by

ALLIS-CHALMERS MANUFACTURING COMPANY

BOX 512

MILWAUKEE 1, WISCONSIN

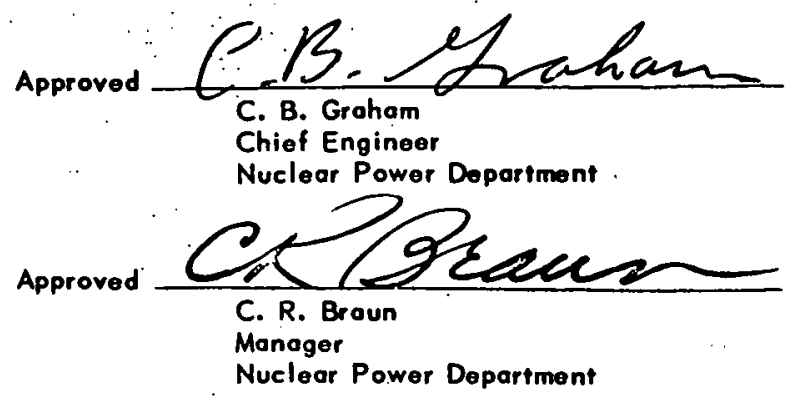

November 15, 1959 
THIS PAGE

\section{WAS INTENTIONALLY LEFT BLANK}


THIS PAGE

\section{WAS INTENTIONALLY LEFT BLANK}




\section{THIS PAGE}

\section{WAS INTENTIONALLY \\ LEFT BLANK}


TABLE OF CONTENTS

Page

List of Illustrations ............................. vii

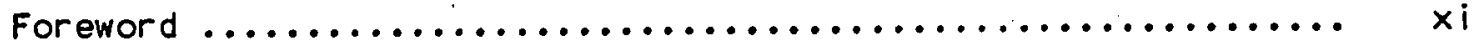

Design Data $\ldots \ldots \ldots \ldots \ldots \ldots \ldots \ldots \ldots \ldots \ldots \ldots \ldots \ldots \ldots \ldots \ldots \ldots \ldots \ldots \ldots \ldots$

1. Fuel Element Research and Development ................ I

1.1. Fuel Material Cladding, Bonding, and Irradiation Testing .................................. I

1.2 Heat Transter and Fluid Flow Investigations .......... 9

1.3 Fabrication of Fuel for the Critical Facility ......... 13

1.4 Fuel Element Manufacturing Research and Development .. 14

1.5 Nuclear Handling Tools, Cotfins, Shipping Containers . 21

1.6 Low-Enrichment Superheater Fuel Element ............. 22

2. Reactor Mechanical studies ......................... 27

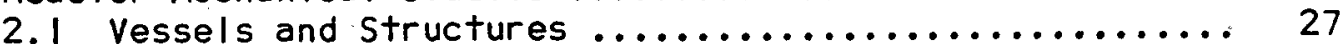

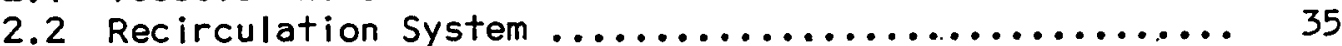

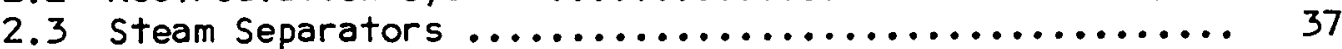

2.4 Control Rods, Guide Tubes and Control Rod Drives ..... 39

3. Nuclear Analysis .............................. 45

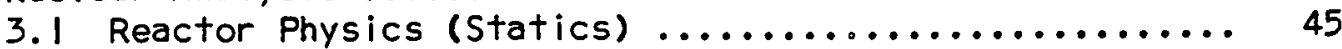

3.2 Reactor and System Dynamics .................... 59

3.3 Critical Experiments ........................ 61

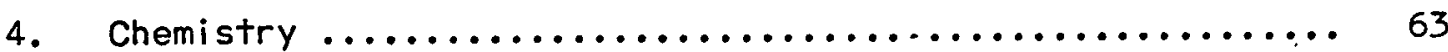

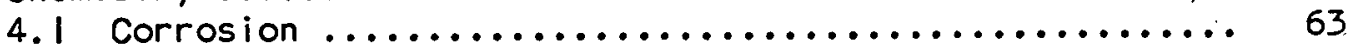

4.2 Recombiner, Radioactive Gas Removal and Storage

System, Ion Exchanger and Chemical Processing....... 63

5. Instrumentation and Control .................... 77

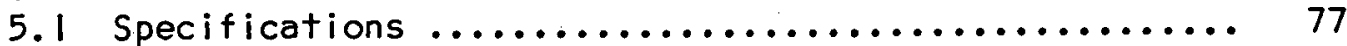

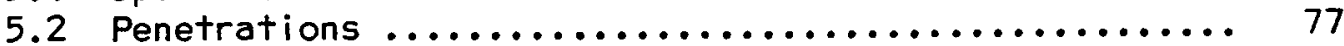

5.3 Water Level Tests .......................... 77

6. Plant Safety Analysis .......................... 79

7. Feasibility Studies ........................... 8 I

7.1 Elimination of Vapor Closure .................. 81

8. Steam Plant and Reactor Auxiliary Systems Design ........ 83 
Figure

Title

Source

1.1. Average Corrosion Rate of 8001 Aluminum Alloy in Dynamic Corrosion Tests

A-C Dwg. No. 43-023-995

1.2. Average Corrosion Rate of 8001 Aluminum Alloy in Static Corrosion Tests

A-C Dwg. No. 43-023-999

1.3. $3 \times 3$ Boiler Irradiation Element (Pin and Strap Construction)

A-C Dwg. No. 43-500-731

1.4. Boiler Irradiation Assembly

A-C Dwg. No. $43-500-738$

1.5. Superheater Test Section Piping

1.6. 10-8-6 Pin Test Section Assembly

1.7. Superheater Test Element

1.8. Heat Balance

A-C Dwg. No. 43-500-733

A-C Dwg. No. 43-500-748

A-C Dwg. No. 43-002-045

A-C Dwg. Nvo. 43-024-008

1.9. Heat Loss to Moderator

A-C Dwg. No. 43-023-993

1.10. Aluminum Clad Boiler Fuel Element Design 11

A-C Dwg. No. 43-002-054

1.11. Maximum Aster Geometry

A-C Dwg. No. 43-024-007

1.12. Aster Logical Flow Diagram

A-C Dwg. No. 43-024-007

1.13. Superheater Element Concept.

A-C Dwg. No. 43-301-347

2.1. Reactor Section

A-C Owg. No. 43-001-999

2.2. Typical Flow Distribution Pattern Through Grid Plate

A-C Dwg. No. 43-024-017

2.3. Reactor Cover Test Vessel

A-C Dwg. No. 43-001-963

2.4. Schematic of closure Test

A-C Dwg. No. 43-024-031

2.5. Full Scale Closure Test - Upper Head Tack Weld.

A-C Photo No. 204596

2.6. Full Scale Closure Test - Upper Head with Initial Tack Welds

A-C Photo No. 204597 
2.7. Butterfly Valve Test - Sigma vs

Valve Angle

A-C Dwg. No. 43-023-984

2.8. Control Rod Drive Water: Supply Test

A-C Dwg. No. 43-002-043

2.9. Drive Motor Test Rig

NP Photo 055-3

2.10. Latch Test Set-Up

NP Photo 052-14

2. I1. Latch

NP Photo 052-6

3.1. Neutron Flux vs.Lethargy

A-C Dwg. No. 43-024-033

3.2. Neutron Flux vs Lethargy

A-C Owg. No. 43-024-032

3.3. Dose Points (Containment Shel!, Sec. AA)

A-C Dwg. No. 43-0.02-024

3.4. Dose Points (Recirculation Pump Floor Containment Shell)

A-C Dwg. No. 43-002-024 Sheet 2 of 2

3.5. Gamma Dose in Shield Pool

A-C Dwg. No. 43-024-000

3.6. Gamma Dose along Inner Face Concrete Shield

A-C Dwg. No. 43-024-001

3.7. Neutron Flux Axially above the Core

A-C Dwg. No. 43-024-003

3.8. Gamma Flux and Dose Axially above Core

A-C Dwg. No. 43-024-004

3.9. Gamma Flux and Dose Axially below Core

A-C Dwg. No. 43-024-005

3.10. Neutron Flux Axially below Core

A-C Dwg. No. 43-024-006

3.11. Radial Gamma and Neutron Heating

Simulator

A-C Dwg. No. 43-024-002

3.12. System Block Diagram

A-C Dwg. No. 43-023-871-02

3.13. Reactivity Effect of Voids

A-C Dwg. No. 43-023-994

3.14. Control Rod Run-In

A-C Dwg. No. 43-023-977

3. 15. Control Rod Run-Out

A-C Dwg. No. 43-023-978

3.16. Starting and Stopping Recirculation Pump

A-C Dwg. No. 43-023-979

4.1. Reactor Water Purification System

A-C Dwg. No. 43-500-608-06

Sheet 2 of 3

4.2. Flash Tank for Pathfinder Station

A-C Dwg. No. 19-647-372 
4.3. Pressure Drop across Filters vs Operating Time, Filter Test - 39RIOCV - Cotton

A-C Dwg. No. 43-023-996

4.4. Pressure Drop across Filters vs Operating Time, Filter Test - 39RlOCV - Cotton A-C Dwg. No. 43-023-997

4.5. Pressure Drop across Filters vs Operating Time, Filter Test - 39RIOCV - Cotton A-C Dwg. No. 43-023-998

5.1. Reactor Building Electricol Cable

Penetrations

A-C Dwg. No. 43-024-029

5.2. Proposed Reactor Start-Up Inter locks

A-C Dwg. No. 43-024-030

5.3. Water Level Test Schematic for Steam Separator Loop

A-C Dwg. No. 43-500-708

8.1. Main Steam and Feedwater System for Patht inder CRBR

A-C Dwg. No. 43-500-608-06 Sheet 1 of 3 
FOREWORD

This is the eighth of a series of reports covering technical progress on the research and development program being performed in connection with the design of the Pathfinder Atomic Power Plant. This plant will be located at a site near Sioux Falls, South Dakota, and is scheduled for operation in June 1962. Owners and operators of the plant will be the Northern States Power Company of Minneapolis, Minnesota.

The U.S. Atomic Energy Commission, through Contract No. AT(11-1)-589, with Northern States Power Company, and Central Utilities. Atomic Power Associates (CUAPA), are sponsors of the research and development program.

Allis-Chalmers Manufacturing Company of Milwaukee, Wisconsin, under contract with Northern States Power Company; is performing the research, development and design, and will construct the plant, including the reactor, which is designated as the Controlled Recirculation Boiling Reactor (CRBR). Pioneer Service and Engineering Company of Chicago, IIlinois, is providing the architect-engineer services to Allis-Chalmers. Portions of the $R \& D$ program, particularly in connection with fuel development, have been subcontracted by Allis-Chalmers.

Conceptual engineering and component research and development is well under way at Allis-Chalmers Greendale Laboratories. Erection of a number of major experimental facilities have been completed which will provide important design data. Construction of the Critical Experiment facility is progressing satisfactorily and will be ready for operation about November 1, 1959.

*CUAPA Member Companies:

Central Electric and Gas Company Interstate Power Company lowa Power and Light Company lowa, Southern Utilities Company Madison Gas and Electric Company Wisconsin Public Service Corporation
Mississippi Valley Public Service Company Northern States Power Company Northwestern Public Service Company Otter-Tail Power Commany St. Joseph Light and Power Company 


\section{DESIGN DATA}

CRBR WITH NUCLEAR SUPERHEATER

\section{$\underline{\text { Plant }}$}

Power, boiler region.................................64,000 kw

Power, superheater region.................................. $700 \mathrm{kw}$

Steam flow at rated power........................615,000 lbs/hr

Total core power...............................203,700 kw

Gross electrical capability..........................66,000 kw

Net electrical output...............................62,000 kw

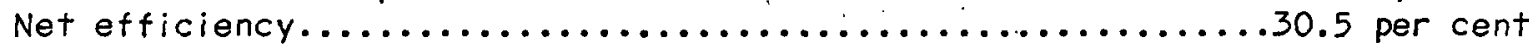

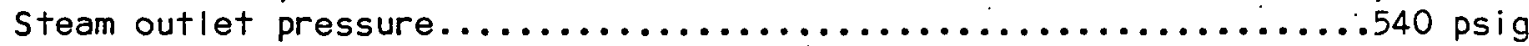

Reactor operating pressure...........................600 psig

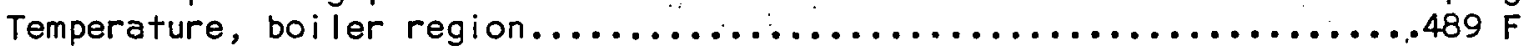

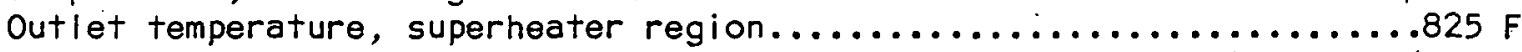

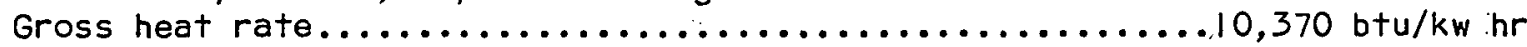

Reactor buil.ding size............................... ft dia $\times 120 \mathrm{ft}$

\section{Reactor}

Vessel size..............................ll-1/2 ft $\times 31-1 / 2 \mathrm{ft}$ Total core dimensions............................... $6 \mathrm{ft} \times 6 \mathrm{ft}$ Dimensions of superheater region....................... ft $\times 30$ in Fuel, boiler (Al clad)............................. per cent enriched $\mathrm{UO}_{2}$

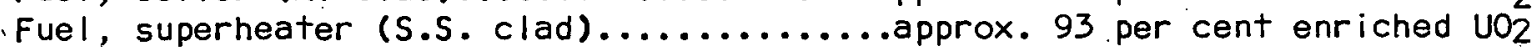

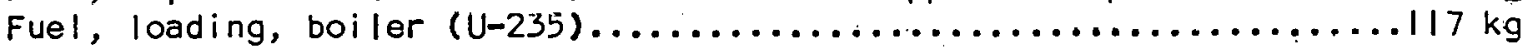

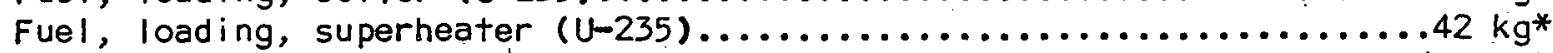
Power density (boiler core coolant)......................87 kw/liter* Average heat $f l u x$, boiler region.................... 30,000 btu/hr/ft $2 *$

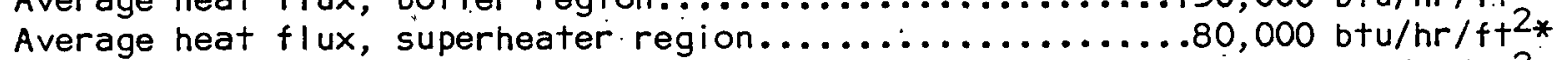
Maximum heat flux, boiler region................462,000 btu/hr/ft2*

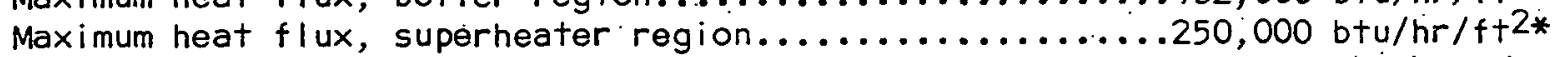
Recirculation rate............................60,000 gpm Recirculation pump power..............................794 kw*

*Value was changed during the quarter. 


\section{FUEL ELEMENT RESEARCH AND DEVELOPMENT}

\subsection{FUEL MATERIAL CLADDING, BONDING, AND IRRADIATION TESTING}

$1.1 .1 . \quad$ Cladding

1.1.1.1. 8001 Aluminum. Dynamic Corrosion Tests. The second tests of 8001 aluminum in Loops 2 and 3 were completed. Eight sample coupons were tested in each loop. The samples in Loop 2 were inspected after exposures of $8.2,17.9,33.0,44.8,57.7$, and 69.7 days. The samples in Loop 3 were inspected after exposures of $10.8,26.3,36.3,47.2,60.2$, and 73.1 days. The eddy-current gage was used to measure the corrosion rate during the first half of the tests, and the less accurate weighing method was used for the remainder of the test run. (Use of the eddy-current gage was discontinued' because of performance difficulties. The repairs and modifications which are presently being made are discussed in Section 4.1.)

The initial corrosion rate during these two tests was considerably lower than the initial rates during the first tests in Loops 2 and 3 . After a period of 25 to 45 days, however, the corrosion rates approached the rates obtained in the first tests. The average overall corrosion rates (including the initial period) for these tests were 7.1 and $10.3 \mathrm{mils} /$ year. The average corrosion rates after the initial period were 14.6 and $16.6 \mathrm{mils} /$ year. Detailed results of the tests are given in Figure 1.1 .

The second test of 8001 aluminum samples in Loop 1 , a test involving an excess aluminum section, was resumed. The test was discontinued after only 1.7 days because of a short circuit in the stator of the canned-rotor pump. The test was then run as the third test in Loop 2. The test conditions were as follows: eight sample coupons were used; the aluminum area in the system. 
was increased to $5850 \mathrm{sq} \mathrm{cm}$ yielding a total area-to-volume ratio of

$2620 \mathrm{sq} \mathrm{cm} / \mathrm{liter}$. (The area-to-volume ratio in the Pathfinder is expected to be $134 \mathrm{sq} \mathrm{cm} / \mathrm{liter}$.$) The excess aluminum was placed in the$ ion exchanger vessel, since this modification could be easily made. The samples were inspected after $8.0,18.9,28.9$, and 41.9 days.

The test is not completed, but preliminary evaluation indicates that. the corrosion rate was not reduced. This confirms the report by Chalk River to the Aluminum Alloy Task Group in September that these unexpected results may be obtained in tests operated under these conditions. The possibility exist, however, that extraneous but only temporary reactions are nullifying the effect of the excess aluminum section and that continued exposure would produce more satisfactory results.

After the third test in Loop 2 is completed, a fourth test will be conducted with the excess aluminum section in the main stream and upstream from the aluminum samples.

Loop 3 was provided with preconditioned samples of aluminum for the third test; other test conditions remained the same. Preconditioning consisted in exposure of the samples in an autoclave for 7.1 days at $500^{\circ} \mathrm{F}$, 681 psia, and pH 7.0 (approximate). The samples were inspected after 7.1 , $17.1,27.0$, and 39.0 days.

This test is also not completed, but preliminary evaluation of data indicates that the corrosion rate may be somewhat reduced by the preconditioning. The test was interrupted because of pump failure and will be resumed as soon as repairs are made. 
Static Corrosion Tests. A static test on 8001 aluminum was completed. The test conditions were as follows: $500^{\circ} \mathrm{F}, 681$ psia, $\mathrm{pH} 5.4$ (approximate), and total exposure time of 36.9 days. The samples were inspected after $7.8,11.6,13.9,22.8,30.9$, and 36.9 days. The corrosion rates indicated during the final test period were in the range of .35 to $.80 \mathrm{mils} /$ year while the overall rates (including the initial period) were between 3.6 and $4.0 \mathrm{mi} / \mathrm{s} /$ year. Details of the tests are given in Figure 1.2.

Aluminum-Base Double-Alloy Annealing Tests. Annealing tests of a fuelelement cladding tube consisting of an outer tube of a corrosion resistant aluminum alloy and an inner tube of a strong aluminum alloy continued. The particular combinations under study are 1100 cladding on 5083 and M400 cladding on $\times 2219$.

Annealing tests were conducted at $500^{\circ} \mathrm{F}$ for exposure times as long as 120 days and results are presently being evaluated. Results of tests for 83-day exposures were previously reported and reference was made to precipitated M95AL8 in the 1100-5083 bond. Positive identification of this precipitate was not previously possible because its fine structure made response to various etching reagents difficult to interpret. Samples were sent to Reynolds Metals Company, fabricators of the tube, and the precipitate was identified by them as $\mathrm{Mg}_{2} \mathrm{Si}$.

Extruded Tube-Plate Aluminum Alloy Cladding. Investigation continued on the feasibility of producing $\times 8001$ aluminum alloy cladding in the form of tube-plates by the extrusion process. A difficulty previously described was that the material in the extrusion reweld areas was particularly susceptible to corrosion. Corrosion tests and metallographic analyses were 
conducted on additional samples, and the following tentative conclusions were made.

The microstructure of tube-plate coming from the beginning of any particular billet extruded at $900^{\circ} \mathrm{F}$ does not appear the same in samples from subsequent sections. The entire cross section of the extrusion exhibits a . fine and uniform dispersion of the nickel complex compounds, $\mathrm{NiAL}_{3}$ and FeniAlg, normally present. As the billet progresses in extrusion, however; the band of what appears to be matrix aluminum appears in the cross section of samples. The band is small at first and becomes progressively larger as the extrusion proceeds to the end of the billet.

Samples with only a small band were subjected to corrosion tests. Corrosion progressed exceedingly fast until the band was consumed. The corrosion behavior of the remaining sample, in which a normal distribution of nickel-compsund particles appeared, was that of normal $\times 8001$ aluminum alloy.

Since there is a normal temperature build-up due to friction and pressure as the extrusion of a billet progresses, the higher temperature of the extrusion may cause formation of the band of matrix aluminum in the reweld. To investigate the causes and to determine a possible solution to the problem, the following controls and techniques should be investigated in one or more combinations:

1) Shorter billets to decrease the temperature build-up by decreasing extrusion time,

2) the extrusion of billets beginning at lower temperatures ( 750 to $800^{\circ} \mathrm{F}$ ), 
3) the extrusion of larger billets ( 8 to 9 inches in diameter),

4) scalping of billets to remove any skin defects or segregation,

5) removal of one half-inch sections from each billet for

metallographic analysis of the cast structure,

6) periodic determination of the temperature of the extrusion as it leaves the die, and

7) removal of the butt end of each billet from the die and sectioning and evaluation to determine flow through the die.

1.1 .2 . Bonding

A draw bonding process is used by $M$ \& C Nuclear Corporation to obtain the bond between the uranium dioxide pellets and aluminum cladding. Destructive tests of these fuel pins show an excellent mechanical bond.

The mechanical bond between aluminum and sintered uranium dioxide does not lend itself to testing by ultrasonic techniques, since the noise level resulting from travel of sound around the clad is so great that the signal from the bond cannot be detected. Further non-destructive tests of the bond by this process were therefore discontinued:

The effect of reactor operating conditions on the bond-is being considered from the standpolnt of the cyclic strains and thermal fatigue produced in the cladding. This work is described in Section 1.4.

\subsubsection{Irradiation Testing}

1.1.3.1. Boiler Fuel Elements. Capsule Tests. Twenty-eight 3-inch long irradiation samples were fabricated by $M$ \& $C$ Nuclear Corporation and shipped to Valecitos Atomic Laboratory for encapsulation. The samples consisted of four uranium dioxide pellets and a stainless steel, fission-gas 
thimble, all clad in $\times 8001$ aluminum by a draw bonding process. Destructive tests show an excellent bond between the pellets and cladding.

Radiographs of end-cap welds show some porosity at. both ends of some samples. Porosity could be detected in the weld at the fission gas end in nearly all samples.

Typical welds were sectioned and macrographed. Upon examination, porosity was apparent in both welds, and oxide stringers were found within 0.010 to 0.015 inch of the surface. It was decided that conditions of the capsule (i.e. the non-corrosive environment) were not stringent enough to warrant rejection of the samples, however. The samples appeared to be well made from all other standpoints.

Assembly of a prototype irradiation capsule indicated certain modifications to be necessary. Capsules were fabricated with these modifications. During assembly, leaky thermocouples were found in some of the capsules; new thermocouples' were ordered and extensive quality checks were made before installing them. The delays involved in the modifications and replacement of the faulty thermocouples delayed the insertion of capsules for one GETR cycle. Present planning calls for capsule insertions the first part of October.

The test schedule is as follows:

\begin{tabular}{cccc}
$\begin{array}{c}\text { Capsule } \\
\text { Ser. No. }\end{array}$ & $\begin{array}{c}\text { Location } \\
\text { in GETR }\end{array}$ & $\begin{array}{c}\text { No. of } \\
\text { Cycles }\end{array}$ & $\begin{array}{c}\text { Burn-up } \\
\text { mwd/ton }\end{array}$ \\
\hline 1 & $\times 5$ & 4 & 5,000 \\
2 & $\times 6$ & 9 & 10,000 \\
3 & $\times 7$ & 14 & 15,000 \\
4 & $\times 8$ & 21 & 20,000 \\
\hline
\end{tabular}


Subassembly Tests. An assembly consisting of nine fuel pins in a 3-by-3 square array is scheduled to be irradiated in the GETR boiling water loop to gain more information on the behavior of an aluminum-clad, uranium dioxide fuel element operating under the conditions present in the pathfinder reactor. Test results should reveal the operating characteristics of the element and its component parts.

Fuel enrichment calculations by Vallecitos Atomic Laboratory showed that 12 per cent enrichment is required to obtain the maximum desired heat flux of $450,000 \mathrm{Btu} / \mathrm{hr} / \mathrm{sq} \mathrm{ft}$ within the first 10 inches of the test assembly. Approximately 13 months of exposure is required to obtain an average fuel burn-up of $10,000 \mathrm{mwd} / \mathrm{ton}$.

The test fuel element will consist of three subassemblies of three pins each. A support grid welded Into an aluminum box will corinect the bottom ends of the three pins comprising a subassembly. Every $10-1 / 2$ inches a formed strap will be fusion spot welded to a $\times 8001$ spacer plug that is welded between the pin sections (Figure 1.3.). The ends of the straps will be captured in slots in the aluminum box in such a way that axial expansion of the pins will be allowed. Blisters will be welded over the expansion slots to form a water tight box. Stainless steel end fixture will complete the nine-pin subassemblies (Figure 1.4.).

Orifice holes will be drilled in the nozzle to meter by-pass flow between the facility tube and the assembly.

A prototype assembly will be fabricated to evaluate design and construction problems. Flow tests will be made at Allis-Chalmers Greendale Laboratories 
to determine pressure drop across the assembly and the amount of by-pass flow around the assembly. These tests are designed to substantiate flow calculations and to insure sufficient cooling for the inside of the facility tube without starving the fuel element.

Eighteen-hundred dished-end, 12 per cent enriched, uranium dioxide pellets were received by $M$ \& $C$ Nuclear Corporation for fabrication of the irradiation assembly. Fabrication will not start until all welds are qualified.

Because an alternate design of the Pathfinder fuel element is considered, a different end closure was studied. It is felt that consistently good welds can be made with the new geometry. Closures on the extreme ends are made before the pellets are inserted, and the tubes are drawn. Individual pin sections are then loaded and draw bonded. Caps are inserted into the end of a tube section and welded in place while the inside of the rod is being evacuated through the hole provided. Appropriate pin sections are then screwed together under a vacuum and seal-welded using the tungsten inert-gas shielded arc.

Work has started on the closure welds for the prototype irradiation assembly. No particular difficulty was encountered with the end caps on the extreme ends and with the male and female caps at the intermediate joints. These welds were qualified after a minimum of work on uranium dioxide. The final weld, which seals the screwed joints, was satisfactory with $\mathrm{AL}_{2} \mathrm{O}_{3}$ pellets but has not yet been qualified with uranium dioxide. Sectioned samples of the final weld with uranium dioxide pellets showed porosity of 0.020 inch below the weld surface. It is expected that the technique will 
be improved to drive this porosity 0.050 to 0.060 inches below the surface.

A welding dry box was fabricated that permits control of atmospherepressure during the weld cycle. Installation and wiring of this box has not yet been completed.

The test loop in the GETR will be modified to accommodate the assembly, i.e. a 3-inch diameter loop will replace the 3/4-inch diameter loop previously available. The new loop is scheduled for completion in late November: Insertion of the subassembly is scheduled for early December.

1.1.3.2: Superheater Fuel Elements. Cermet Irradiation Studies. A literature study of irradiation effects on uranium dioxide stainless steel cermets to determine the maximum allowable burn-up of fuel was continued. Battelle Memoria! Iristitute and an AEC Laboratory were visited to obtain more detailed information on fabrication procedures, irradiation test conditions, and test results. Much of the data is still classified and cannot be reported here, but it appears that with correct fabrication practice and careful control of particle size, particle shape, fuel concentration, and cermet density, a high burn-up fuel is obtainable. Failures can be limited to simple longitudinal cracks with only a modest amount of swelling. The blister type failure sometimes seen can be virtually eliminated by careful control of fabrication processes.

\subsection{HEAT TRANSFER AND FLUID FLOW INVESTIGATIONS}

\subsubsection{Heat Transfer Loop}

The primary loop of the neat transfer test set-up was subjected to five hot pressurizing tests during July and August. Each test was shut do::n 
because of equipment malfunctions. The first test was shut down because the seal in the circulating pump siezed. The second test was shut down because the unipolar generator malfunctioned. The third test was shut down because of cooling water difficulties. Clogging of the filters caised the fourth shut down. The unipolar generator malfunctioned in the fifth test. The maximum pressure attained in the loop during these tests was 740 psi at 5090F.

Modifications of the unipolar generator were made, and tests will resume in October.

The low-flow loop addition was constructed and cold tested. Hot tests will be made during the next hot pressurizing test of the primary loop. Design of the superheater loop addition was completed (Figure 1.5.). All of the material for the loop was ordered, and about 20 per cent has been received. Quotes were requested of prospective fabricators.

A one-pin test section that will be used for burn-out studies was received and is being assembled.

Design of the 10-8-6--pin test section was completed (Figure 1.6.). All of the material was ordered and 90 per cent was received.

The conceptual design of the 80-64-49--pin test section was completed, and a layout was drawn.

The layout design (Figure 1.7.) of the superheater test section was completed, and detail drawings are being cómpleted.

\subsubsection{Low Pressure Air-Water Flow Tests}

To better understand the flow phenomena associated with two-phase flow and to better predict the flow characteristics through a boiler fuel element, 
low-pressure, air-water flow tests are planned. The hydraulic hold-down test loop', was modified to accommodate the tests.

The tests will be conducted at room temperature and atmospheric pressure. Simulated fuel elements will be inserted in the loop and tested to determine single-phase and two-phase (air-water) pressure drops and flow distributions. The gamma-attenuation void-measuring device will be used to determine bubble population and slip within the test sections.

The effects of various end-cap configurations, fuel-pin and tube-plate spacer arrangements, end-support designs, and transitional regions between fuel bundles in a subassembly will be evaluated. Tests will begin during the next quarter.

\subsubsection{Heat Loss from Superheater Fuel Element to Moderator}

The heat losses through the double-walled superheater support tube, are shown graphically in Figure 1.8. The losses were previously calculated without ' considering the radiation losses, $\left(\frac{0}{A_{23}}\right)_{R A D}$, and the heat loss was therefore calculated again.

The temperature drop across the stainless steel walls is assumed to be insignificant, and the walls are therefore represented by $T_{2}$ and $T_{3}$. The temperature gradient in the stagnant steam, ' $g^{\prime}$ ', is assumed to be 1 inear. Values for $T_{1}$ and $T_{g}^{\prime}$ are an output of the ASTER code (Section 1.4.2.2.). The value of $T_{3}$ is constant. The only unknown quantity on which the heat loss, $Q_{L}$, is dependent is $T_{2}$.

Values for $T_{2}$ were chosen to satisfy the heat balance equation,

IPathfinder Atomic Power Plant Technical Progress Report August 1957 March 1958, ACNP-5803, p. 6, 1958. 


$$
\left(\frac{Q}{A_{12}}\right)_{R A D}+\left(\frac{Q}{A_{2}}\right)_{F I L M}-\left(\frac{Q}{A_{23}}\right)_{C O N D}-\left(\frac{Q^{\prime}}{A_{23}}\right)_{R A D}=0 \quad \text { (1.1) }
$$

where

$$
\begin{aligned}
& \left(\frac{0}{A_{12}}\right)_{R A D}=\quad\left[\left(1-9_{1}\right) T_{1}{ }^{4}-\left(1-1 g_{1}\right) T_{2}{ }^{4}\right], \\
& \left(\frac{Q}{A_{2}}\right)_{F I L M}=h\left(T_{g I}-T_{2}\right) \text {, } \\
& \left(\frac{\rho}{A_{23}}\right)_{\text {CONs }}=\frac{k}{x}\left(T_{2}-T_{3}\right) \text {, } \\
& \left(\frac{Q^{\prime}}{A_{23}}\right)_{\text {RAD }}=\epsilon \sigma\left[\left(1-\alpha g_{2}\right) T_{2}{ }^{4}-\left(1-\alpha^{\prime} g_{Z_{2}}\right) T_{3}{ }^{4}\right] \text {, } \\
& h=.0214 \frac{k}{D e}(\operatorname{Re})^{\prime \prime}(\operatorname{Pr})^{1 / 3}\left(1+\frac{2.3}{L / D}\right),
\end{aligned}
$$

and where,

$$
\begin{aligned}
& Q=\text { heat transfer rate }-B+u / h r \\
& A=\text { heat transfer area }-f t^{2} \\
& T=\text { temperature }-O_{R} \\
& \epsilon=\text { emissivity } \\
& \alpha=\text { absorptivity } \\
& Q_{L}=\text { heat loss to moderator } \\
& \sigma=\text { Stefan-Boltzmann constant - Btu/ft }-h r-{ }^{\circ}{ }^{4} \\
& h=f i l m \text { heat transfer coefficient - Btu/hr-ft }{ }^{2}-O_{F} \\
& k=\text { thermal conductivity - Btu/hr-ft-of } \\
& \text { De = equivalent diameter }-f t \\
& R e=\text { Reynolds number } \\
& \operatorname{Pr}=\text { PrandtI number } \\
& L=\text { length - vt } \\
& x \text { - stagnant steam gap - } t+
\end{aligned}
$$

12 
The equation,

$$
Q_{L}=A_{23}\left[\left(\frac{Q^{\prime}}{A 23}\right)_{R A D}+\left(\frac{Q}{A 23}\right) \text { COND }\right]
$$

could then be used to calculate the heat loss: All values of $T_{2}$ that

satisfied Equation (1.1.) were equal to $\mathrm{Tg}^{\prime} \pm 10^{\circ} \mathrm{F}$. Therefore, as an approximation, the heat loss was correlated with the bulk fluid temperature of the outer flow channel. The correlation obtained is given in Figure 1.9 and is in a form that may be included in ASTER.

\subsection{FABRICATION OF FUEL FOR THE CRITICAL FACILITY}

\subsubsection{Boiler Fuel Elements}

By the end of the quarter, 27,900 rods of a $28,400-$ rod order were delivered by Mallinckrodt; 3,048 rods of a 3,200-rod order were delivered by Syivania-Corning Nuclear Corporation; and 7,879 rods of a 11,800-rod order were delivered by American Lava. The precise status of the Sylcor delivery is not known at this.time since some fuel material was diverted for use in the fuel element for irradiation in the EBWR. At present, about 94 per cent of the boiler fuel rods have been del ivered.

\subsubsection{Superheater Fuel Elements}

The manufacturer, $M$ \& $C$ Nuclear Corporation, 'received all fuel materials, one haif of the cladding material, and all of the nardware. The steel strike is delaying delivery of the remaining cladding material. The final developmental tuel tubes will be produced by late October, and production of superheater tubes containing enriched fuel will begin at that time. Complete delivery is expected by the latter part of December. 


\subsection{FUEL ELEMENT MANUFACTURING RESEARCH AND DEVELOPMENT}

\subsubsection{Boiler Fuel Element}

1.4.1.1. Mechanical Design. Alternate Design. An alternate design of the boiler fuel element was studied. The extruded tube-plate subassembly has been eliminated from consideration. The alternate design consists of nine subassemblies welded into an aluminum box at the bottom end only. Each subassembly will consist of $n$ ine fuel pins connected together by formed straps as shown in Figure 1:10. The ends of the straps will be captured in slots in the aluminum box.

The new design, is expected to provide greater lateral rigidity but less axial rigidity than the previous extruded-plate design. Increased lateral rigidity is required to decrease vibration in the nine-pin subassemblies. The reduction in axial rigidity is required to reduce the resistance of the subassemblies to differential expansion between fuel rods. Differential expansion would be caused by neutron fiux gradients across a fuel element. The slots that secure the end of the formed straps allow each subassembly to expand freely, and differential expansion should not appreciably affect the shape and straightness of the aluminum box.

The new design was simulated in the subassembly test described in Section 1.1.3.1. The degree to which vibration will be decreased will be determined by tests described below.

Fuel Pins. The fuel pins used are of three diminishing diameters all in a 9-by-9 square array. The diminishing diameters are expected to compensate for increased steam content in the upper area of the core in essentially the same manner as the $8-b y-8$ and $7-b y-7$ square arrays of the reference design. 
It was decided that the fuel element should be designed so that the cladding is always collapsed on the fuel pellets. This arrangement is required to eliminate hot spots that would develop as a result of poor heat transfer across the pellet-clad interface.

There is a considerable difference in the temperatures of the clad and the center of the uranium dioxide pellets. Although the expansion coefticient of uranium dioxide is much lower than that of aluminum, the axial and radial thermal expansion of the pellet is greater than that of the cladding because. of the temperature difference. Gross plastic strains in the cladding may therefore result.

Cyclic strains induced by pellet expansion and external pressure were calculated and were found to be well within the plastic range of the cladding material. Thermal fatigue in the plastic region is a function of the cyclic plastic strains and a material constant that must a.lso be evaluated. The plastic strain range will be determined by the Dehavior of the uranium dioxide pellets. The material constant is a property peculiar to the cladding material and the temperature variations.

Data from which the cyclic strain range may be determined should be forthcoming from the capsule and subassembly irradiation tests discussed in Section 1.1. Tests to determine the material constants required for a precise thermal fatigue analysis are being pianned. In addition an out-ot-reactor test of an aluminum-clad uranium dioxide bushing heated by an axial tungsten wire to determine thermal fatigue is planned.

Nozzle Spring. The spring that supports each boiler fuel element at the. grid plate was tentatively designed. Space limitations demand a spring with 
a relatively high spring rate and a minimum wire size. Inçonel was chosen for its negligible creep rate below $600^{\circ} \mathrm{F}$ and its high allowable stress in torsion $(55,000$ to 80,000 psi).

Conventional equations were used to make the necessary calculations. The loads on the spring consist of the sum of the boiler fuel weight, the pre-compression when the hold-down grid is lowered into place, and the load resulting from the differential thermal expansion between the boiler fuel element and the reactor vessel. Assuming that the modulus in torsion is $11 \times 10^{6} \mathrm{psi}$, the allowable stress of inconel is $60,000 \mathrm{psi}$, the thermal expansion is 0.375 inches, the weight of the boiler fuel element is 200 lbs, and the load due to pre-compression is 35 lbs, a spring with the following dimensions is necessary: 2.5 active coils and 4.5 total coils (with ends squared and ground), a spring rate of $171 \mathrm{lb} / \mathrm{in}$, a free length of 3.520 inches, a total capacity of 300 lbs, a mean diameter coil of 4.269 inches, and a wire diameter of .394 inch (4-0 gage W\&M). The maximum stress for which the spring is designed is 59,200 psi.

A tolerance investigation based on data published by the spring Manufacturer's. Association, Inc. indicates that the spring will require special quality control to obtain the uniformity required.

1.4.1.2. Tests. Experimental Stress Analysis. A test program was formulated to determine experimentally the stresses in the straps and the stresses in the rod sections of the alternate fuel element subassemblies. A group of rods and a strap will be mounted in a fixture, and sträins of a known magnitude will be imposed with set screws.

Water-Logged Fuel Pin. If the cladding of a fuel pin developes a pinhole defect, the pin would probably become filled with water (water-logged) 
after a shut-down. When the reactor is started up, two things may happen to the fuel rod: 1) the steam formed may escape before building up a pressure sufficient to rupture the cladding, or 2) the hole may become plugged, and the rod may rupture.' A preliminary calculation shows that power generation during start-up increases slowly enough to allow the steam to escape through a hole as small as 0.005 inches in diameter, and this alternative should present no problem. The magnitude of the problem presented by clogging of the pin hole after shut-down is not known. However, a test is being designed to determine what might happen during start-up if the pin hole becomes plugged.

Boiler Fuel Rod Vibrations. Vibration of the boiler fuel-element rods are particularly important in the Pathfinder reactor. Excessive amplitudes may contribute to flaking off of the protective corrosion film on the aluminum cladding. The strains caused by high amplitudes may be intolerable when combined with others. When the fuel rods are vibrating with a high amplitude, the nuclear characteristics of the reactor could be affected. Burgreen, ef.ad.2 have outlined the variables and expected vibrations induced in rods by a singlephase fluid flowing parallel to the rods. In the Pathfinder a two-phase fluid will be flowing parallel to the fue! rods.

A test program was formulated to determine the effect of two-phase parallel flow on the vibration of the rods and to determine if the frequency and amplitude of the vibration can be predicted by the equations presented by 0 . Burgreen, et. al or by some other means. A particularly helpful analytical tool would be a relationship between the vibration characteristics and the void fraction for various fluid velocities.

2 0. Burgreen, J. J.Byrnes, and D. M. Beuforadd, Vibrations of Rods Induced by Water in Para.llel Flow, ASME Paper No, 57-A-94, 1957. 
The correlations presented by Burgreen, et. al. are

$$
f=\frac{\pi}{2}-\sqrt{\frac{g}{\operatorname{Pr}}-\frac{E l}{A L^{4}}}
$$

and

$$
\frac{\delta}{D}^{1.3}=0.83 \times 10^{-10} \mathrm{~K}_{1} \Gamma^{1 / 2} \Omega
$$

where,

$$
\begin{aligned}
& f=\text { frequency cps } \\
& g=\text { acceleration of gravity } \\
& E=\text { Young's modulus } \\
& I=\text { moment of inertia } \\
& \operatorname{Pr}=\text { rod density } \\
& A=\text { cross sectional area } \\
& L=\text { length between support } \\
& \hat{\delta}=\text { amplitude of vibration } \\
& D=\text { hydraulic diameter } \\
& K I=\text { load-defiection end-fixity factor } \\
& \Gamma=\text { non-dimensional vibration parameter }=P_{w} v^{2} L^{4} / E_{I} \\
& \Omega=\text { non-dimensional vibration parameter } .
\end{aligned}
$$

The following results were obtained when Equations $(1.3,1.4)$ were applied to the geometry and conditions present in the Pathfinder: $\begin{array}{cc}\text { Fuel Rod Type } & \begin{array}{c}\text { Frequency } \\ \text { (cps) }\end{array}\end{array}$

18 inch long, .040-inch AL ciad

18 inch long, solid $\mathrm{AL}$

18. inch long, 0.025-inch Zirc clad

36 inch long, 0.025-inch Zirc clad
52

71.5

48

12
Amplitude (mils)

\section{2}

2.7

3.2

26.8 
The experimental program currently proposed includes three phases. Phase 1 consists in formulating methods to measure vibration with strain gages and determining the rod El product and end fixity. During Phase 2, the most accurate method of measuring void fraction and water velocity wi!l be determined. (This is currently a most important problem.) Phase 3 will consist of basic tests using a single rod and a two-phase parallel fluid flow.

\subsubsection{Superheater Fuel Element}

1.4.2.1. Design Status. Reference Design. The reference design for the superheater fuel element is an annular-type fuel element with three parallel flow channels and two cylindrical fuel-cladding sandwiches. The fuel material considered for use is a uranium dioxide, stainless steel cermet. Irradiation studies of this fuel were discussed in Section.1.1. At present, work is continuing in optimizing this design by ùse of an IBM 704 EDPM code. This work is discussed below. Work began on development of a low-enrichment. superheater fuel element. This work is discussed in Section 1.6.

\subsubsection{Allis-Chalmers Superheater Temperature Evaluating Routine} (ASTER). Description. The IBM 704 EDPM code, which was previously designated the Nuclear Power Superheater Thermal Code (NPSHTC), is now designated the Allis-Chaimers Superneater Temperature Evaluating Routine (ASTER). ASTER was designed to obtain the bulk coolant temperatures, wall temperatures, and pressure drop in a superheater type fuel element. The code was designed for an annular-type fuel element with a maximum of five parallel flow channels and four cylindrical fuel-cladding sandwiches. The geometry of such an element is shown in Figure 1.11 . The code with appropriate modification may also be applied to a flat-plate fuel element. 
ASTER includes the following special features:

1) Allowance is made for heat losses from the outer flow channel.

2) Allowance is made for the effect of a helical wire spacer.

3) The effect of the temperature at both sides of the sandwiches on the heat release from each side is considered.

4). All properties, both nuclear and thermal, although included in the code, may be conveniently altered or replaced.

Operation. The operation of ASTER is shown in Figure 1.12 and may be described as follows:

1) The operator initially selects the fuel element geometry and makes a rough approximation of the flow rate in each channel. The geometry selected in. the present application is the geometry of the Pathfinder superheater fuel element.

2) ASTER calculates the fluid bulk temperature, wall temperatures, and pressure drop for each flow channel.

3) The pressure drops for each channel are compared. It the difference between pressure drops is greater than 0.033 per cent of the maximum channel pressure drop; ASTER calculates new channel flow rates until these conditions are satisfied.

4). The tinal pressure drop is compared with a data input pressure drop which is the calculated pressure drop for an average fuel element. If the two values are not within 0.033 per cent, the total flow rate is adjusted and steps 2,3 , and 4 are repeated.

5) Results are printed out when these conditions are satisfied. 
Program Input Data. The following input data is required:

1) all geometrical factors,

2) total fuel element heat generation,

3. total bulk hot channel factor,

4) total film hot channel factor,

5) inlet fluid properties,

6) conduction parameters,

7) flow channel length,

8) mass flow above and below the fuel element,

9) film heat transfer coefficient correction factors,

10) initial fllow estimates, and

(1) miscellaneous program specification information.

Program Output Data." The following data may be obtained from ASTER:

1) all input flow rates considered except for the initial

est imates of flow rate,

2) bulk and wall temperatures for all channels at various positions along the length of the channel,

3). maximum bulk and wall temperature for each flow channel,

4) channel filow rates and total flow rates, and

5) pressure drop in each channel.

1.5. NUCLEAR HANDLING TOOLS, COFFINS, SHJPPING CONTAINERS

The one-eighth core mock-up is 95 per cent complete and most components were inspected. The 40-foot handing tank that will contain the mock-up is now filled with reactor-grade demineralized water and is ready for insertion of the test unit. 
A one half ton crane for handling boiler fuel elements was ordered, and construction of a prototype set of tools for handling both the boiler and superheater fuel elements is nearly complete.

\subsection{LOW-ENRICHMENT SUPERHEATER FUEL ELEMENT}

\subsection{1: Design Status}

A research and development program was initiated for tow-enrichment superheater fuel elements for the Pathfinder. A fuel element with the following characteristics is desired: a low-enrichment fuel, high heat transfer properties, good mechanical strength, high corrosion resistance; good irradiation stability, containment for fission gases, and simple fabrication processes.

Since considerable data is available on uranium dioxide ceramic tuels with stainless steel cladding, a superheater fuel element using these materials should require the least time to develop. The development of such a fuel element will therefore be emphasized. At least three different fuel configurations appear promising and will be investigated to determine ease of fabrication and heat transfer characteristics. The configurations are shown in Figure 1.13 with the reference design of the Pathfinder superheater fuel element.

The $R \& D$ program is planned in two sections. The first section is a six-month introductory study of material properties and fabrication processes. The second section is a two-year advanced research and. development program.

The first section of the program consists of two phases. The first phase is a programmatic data survey to determine general material properties, 
the uranium dioxide products available, uranium dioxide suppliers, fabrication processes and equipment, and characteristics of various fuel element configurations. Methods of increasing thermal conductivity and mechanical strength of ceramic fuel materials will be studied.

The second phase includes a fabrication study of uranium dioxide fuel elements using known data and proven technology. The study includes studies of powder preparation, compaction and consolidation, sintering and densification, cladding studies, testing, and evaluation.

The programmatic data survey and ceramic fabrication studies were initiated during the report period.

\subsubsection{Tests and Studies}

1.6.2.1. Programmatic Data Survey. A literature survey was initiated. The initial studies were limited to evaluation of reports on methods of fabricating uranium dioxide fuel bodies using proven ceramic fabrication processes. Data on uranium dioxide powder characteristics, lubricants, selection and use of organic binders, selection and use of density improving additives, methods of compaction and consolidation, sintering cycles and atmospheres, and fabrication procedures were obtained. The survey is continuing.

1.6.2.2. Ceramic Fabrication Studies. Stainless Steel Powder. Initial results of the data survey are being used to make fabrication studies. Prior to working with uranium dioxide powder, however, personnel are being trained in laboratory techniques and handling procedures for radioactive materials. Cylindrical pellets of the uranium dioxide type were made from 302 stainless steel powder for this purpose. 
The procedure used to make the pellets was as follows: as-received stainless steel powder is sieve-analyzed to obtain powder particles of -325 to +400 mesh size ( 34 to 44 microns in diameter). The powder is then mixed with a solution of 0.4 to $2.0 \mathrm{w} / 0$ sterotex in acetone. The sterotex acts as a die lubricant. The mixture is blended to effect proper distribution of the Sterotex; the mixture is pressed into pellets in hardened steel dies. Pressures between 30 to 100 tsi are used to compact pellets 0.388 inches in diameter by 0.500 inches in length.

About thirty pellets were made. The green or as-pressed density of the pellets ranged from 60 to 66 per cent of the theoretical density. A pellet pressed at 140 tsi had a green density of 67 per cent of the theoretical density.

An attempt was made to sinter the green pellets in a hydrogen-atmosphere furnace. The sintering cycle consisted in exposure at 1650 to $1700^{\circ} \mathrm{C}$ for periods of one to tive hours. High-density, clean pellets were not obtained. This shortcoming may have been due to the presence of excessive water vapor in the hydrogen gas and/or to characteristics of the furnace itself. Visual dimensional inspection was made to evaluate the pellets for swelling, shrinkage, laminations, warpage, etc. Work is continuing with more careful control of the sintering cycle.

Uranium Dioxide. Some uranium dioxide fabrication studies were initiated. The initial investigations were made on powder characteristics and fabrication procedures. Depleted uranium dioxide from Shattuck Chemical Company was used. The powder was analysed to determine mesh fraction and particle sizc and distribution. About 80 per cent of the lot was found to be less than -325 in 
size, i.e. less than $44 \mathrm{microns}$ in diameter. The powder appeared to consist of ceramic-type material. The particles were agglomerated structures made up of several attached crystallites rather than of single crystals.

Two five-batch lots of powder were prepared for compaction, sintering, and density studies. One lot was made of the as-received uranium dioxide powder, and the second lot was made of ball-milled uranium dioxide powder. The lot of ball-milled powder was made as follows: 600 grams of as-received uranium dioxide of -325 mesh were placed in a one quart container with 500 grams of high-density alumina balls. The powder was blended for. 24 hours. A batch from each lot was blended with the following lubricants and/or binders: 0.2 w/o sterotex, $2.0 \mathrm{w} / 0$ Carbowax, $2.0 \mathrm{w} / 0$ polyvinyl alcohol, $0.2 \mathrm{w} / \mathrm{o}$ Sterotex - 2.0 w/o Carbowax, and 0.2 w/o Sterotex -2.0 w/o polyvinyl alcohol. The Sterotex is added as a solution in acetone; the Carbowax and polyvinyl alcohol are added as a solution in water. The powders blended with lubricants in acetone could be pressed immediately, but the powders containing the water solutions are first dried at $60^{\circ} \mathrm{C}$ for 24 hours.

Seven pellets will be pressed from each of the ten batches. Pressures between 30 and 80 tsi, in lo-gm increments, will be used. After the pellets are formed, they will be sintered in a dry hydrogen furnace at 1650 to $1700^{\circ} \mathrm{C}$. The best combinations of lubricant, binder, and forming pressure will be selected on the basis of lamination, density, shrinkage, and other physical aspects. 


\section{THIS PAGE}

\section{WAS INTENTIONALLY \\ LEFT BLANK}




\section{REACTOR MECHANICAL STUDIES}

Upon initiation of the mechanical design studies of the reactor, Allis-Chalmers decided to use the design criteria provided by Section VIII of the ASME Pressure Vessel Code. This section, entitled "Unfired Pressure Vessels," was adopted over Section 1, "Power Boilers," for reasons given previously. ${ }^{3}$ The Hartford Steam Boiler Inspection and Insurance Company, ASME Inspection Agency to All is-Chalmers for design approval, suggested that an opinion be obtained from the state of South Dakota regarding this matter.

The state of South Dakota concurs with Allis-Chalmers that Section VIll is more applicable than Section 1 for the design of the Pathfinder reactor vessel. The State Engineer approved ${ }^{4}$ use of these. 'design criteria subject to the approval of the AEC Hazards Evaluation Branch and the Advisory Committee on Reactor Safeguards.

The conceptual and final design phases are proceeding on the basis that approval will be granted. The conceptual designs of most components is complete. The final designs are well underway.

\subsection{VESSELS AND STRUCTURES}

\subsubsection{Vessel Shell and Nozzles}

2.1.1.1. Design Status. Conceptual Design. Conceptual design of the vessel shell and nozzles is complete pending results of the

${ }^{3}$ Pathfinder Atomic Power Plant Technical Progress Report, April 1959 June 1959, ACNP-5915, p. 20, 1959.

${ }^{4}$ Ltr. , State of South Dakota, Office of the State Engineer to W. N. Marx, Manager, Northern States Power Co., July 30, 1959. 
radiographic proof tests discussed below. All'vessel nozzles (Figure 2.1) with exception of the support sieeves of the control rod drives and the recirculation discharge nozzles are of the saddle type.

The control rod drives are spaced in such a way that saddle-type nozzles cannot be used. Therefore, 3-1/2 inch diameter schedule 80 inconel pipes will be used as mounting sleeves and will be welded into the upper reactor head with full penetration welds. This type of nozzle design is permitted under conditions cutlined in special code case 1273N, paragraph (6). The we! ds will be insfected by the best radiographic methods. The welds will also be examined by liquid-penetrant and magnetic-particle methods to further prove their soundness.

The complex shape of a saddle-type nozzle makes the nozzle forging for a large opening in a cylindrical shell very expensive. In an effort to reduce the cost, the recirculation discharge nozzles in the lower section of the vessel will be fabricated of rolled ASTM A212-B plate. A 10-degree taper at the weld preparation should facilitate radiographic examination.

Final Design. Final design of the vessel shell is proceeding on the basis that approval of the AEC Hazards Evaluatlon Branch and the Advisory Committee on Reactor Safeguards will be granted. Major items remaining in the final design include thermal and hydraulic shock analysis of the vessel shell.

Final design of the nozzles depends on the outcome of the radiographic proof tests as interpreted by the Hartford Steam Boiler Inspection and Insurance Company. Final design and fabrication of the 
nozzles will proceed as soon as the tests are completed and approval is. granted.

Fabrication. The vessel neck and lower head were ordered. Final quotes are being obtained for the forgings for the instrument nozzle, liquid-level contro! nozzle, recirculation discharge nozzles, main flange forging and the flue ring. Final quotes are also being obtained for the bottom head and the plate materials.

2.1.1.2. Tests and Studies. Soddle-Type Nozzle. The connection weld for a saddle-type nozzle is in the vessel shell well away from the outer wall of the nozzle. This type of design lends itselt to unquestionable radiographic examination.

Mounting Sleeve of Control Rod Drives. A full-scale radiographic test of the mounting sleeve using ceramic inclusions is in progress to determine the validity of radiographic inspection of the full penetration welds. The welds will also be examined by liquid-penetrant and magneticparticle methods to further prove their soundness.

Recirculation Discharge Nozzles. The All is-Chalmers Non-Destructive Test Department reviewed the design of the recirculation discharge nozzle. The department believes that meaningful radiographs of the welds are possible'with its excellent betatron facilities. Radiographic tests are in progress using a full-scale mock-up of the recirculation discharge nozzle. Simulated ceramic inclusions will be placed at various positions and orientations in the welds.

Hard Model Test. Due to recent changes in the design of the recirculation suction nozzles (Figure 2.1.), the lower section of the vessel lends itself more readily to analytical analysis, In the light 
of these changes, the test of a quarter-scale aluminum model cannot be justified. This test was therefore cancelled.

Coolant Distribution Test. Tests of the new quarter-scale wooden model of the reactor inlet section were completed. A tinal report was written. 5

Flow distribution patterns through the simulated fuel element nozzles show a variation of \pm 5 per cent from the average flow with all three blowers operating and variations of \pm 10 per cent from average with one of the blowers shut-down. A typical flow pattern with three blowers operating is shown in Figure 2.2.

The energy loss through the plenum was approximately 1.8 times the velocity head in the inlet pipes. This gives an expected loss for the inlet section of the reactor of 10.6 teet of water.

Thermal Shock Studies. Thermal shock studies of the vessel shell are now in progress. A large part of the analysis is being done with an IBM 704 digital computer.

\subsubsection{Bolted Flange Closure}

2.1.2.1. Design Status. Conceptual Design. Conceptual design of the bolted flange closure is complete pending results of the full-scale closure tests deseribed below.

2.1.2.2. Tests. Full-Scale Closure Test. A full-scale closure test of the bolted flange closure will be conducted. The test vessel will consist of two, flanged, pressure vessel heads bolted together. The

5J. Wilson and R. Stiles, Pathfinder Atomic Power Plant Final Report on Coolant Distribution Test, ACNP-5920, 1959. 
top head is designed to the specifications for the Pathfinder reactor vessel head, and the lower head is designed to simulate the pressure vessel. An assembly drawing of the vessel is shown in Figure 2.3. A schematic diagram of the instrumentation is shown in Figure 2.4. The cover is a hemispherical spun head welded to a flange machined from a ring forging. This head is $2-1 / 2$ inches thick -- 2-3/8 inches of carbon steel with 1/8 inch of 304 stainless steel cladding. The lower head is a 2-to-i elliptical spun head made of carbon steel and welded to a carbon steel flange machined from a ring forging.

The flanges for both the upper and lower head are 7-1/4 inches thick with a 91 inch 1.0. and a 105-1/2 inch 0.D. Forty-eight 3-inch nominal diameter studs are used to bolt down the cover. The studs are made from 422 stainless steel and are heat treated to a BHN 285/347 to give an ultimate tensile strength of 140,000 psi and a minimum yield strength of 120,000 psi.

of the twenty control-rod drive tubes located in the upper head, sixteen are capped, and four are flanged. Two safety valves, set at 600 psig and 720 psig, are bolted to two of the flanges. The other two flanges provide lead wire exits for strain gages located inside the vessel. Both safety-valve discharge outlets are connected to an exhaust stack that extends through the roof. All control rod tubes are vented at the top through small tubes that are connected to a venting valve. The test vessel is supported on a stand made from wide flange channels and reinforced with pipe. A set of Lubrite plates at each of the four support columns allows the vessel to expand thermally. without stressing the support stand. 
An electric immersion heater, flange-connected to the lower head is used to generate steam. This heater may be operated at output levels up to $50 \mathrm{kw}$ in approximately 4-kw increments. A pressure switch installed in the vessel piping will shut off power to the heaters when the pressure in the vessel exceeds 660 psig.

Three thermocouple probe holes are located in the upper flange. Each probe accommodates six thermocouples spaced one inch apart. Another thermocouple well located in the lower vessel indicates vessel water temperature. All nineteen thermocouples are connected to a twenty-channel temperature recorder at the control panel. A cam-operated controller operated from one channel of the temperature recorder (the water temperature thermocouple) maintains a constant water temperature. A full length magnetic type i iquid-level indicator is mounted alongs lde the control panel.

For heat-up rates higher than those obtainable from the immersion heater, steam from the heat-transfer test loop will be used. A blow-off located between the vessel and steam supply valve is used for cooling-rate tests. The exhaust from this valve passes into the exhaust stack extending through the roof of the laboratory. A l0-gpm reciprocating pump is used to maintain a water level above the upper flange for cooling tests and may be used to provide additional cooiing when required.

Provision is made for measuring flange rotations by using dial indicator gages mounted on long rods that in turn are rigidly fastened to the flanges. A smal! angular ratation of the flanges will produce relatively large displacements at the free ends of the rods carrying the 
dlal gages. Dial gages will be mounted on the flanges to measure gasket compression and radial differential expansion of the flanges.

The piping system was designed to conform to the ASA code for power piping. All welds will be made and inspected according to requirements of the ASME code for unfired pressure vessels. After assembly, the vessel and piping will be subject to a pressure test for leaks.

Before commencing any high temperature tests, the vessel and piping will be insulated. A major portion of the vessel will be insulated with 3-inch thick calcium silicate blocks. A blanket insulation will be provided in areas where access to the vessel is necessary. An insulated 1/4-inch thick by 36 -inch wide carbon-steel ring surrounds the parting joint of the flanges and acts as a safety shield in case the gasket ruptures.

Nearly all the component parts of the test apparatus were ordered. Fabrication of the test vessel is now in progress. Views of the welding operation are shown in Figures 2.5 and 2.6 .

Preliminary tests designed to check out instrumentation and stress analysis techniques were initiated. A computer program was formulated for: computing stresses from strain rosette data. This program will be checked out with data from the preliminary tests. 2.1.3. Entrainment Separators and Support Shelf

2.1.3.1. Design Status. Results of the moisture entrainment tests indicate that either of two types of commercially available moisture separators are suitable for use with the. Pathfinder. Layouts were completed for the support shelf for both types. Before the final designs can be established, the type that will operate best under reactor conditions must be determined. Further tests are planned for this purpuse. 
2.1.3.2. Tests. Moisture De-Entrainment Tests. Testing of the 2-and 4-inch diameter test sections was completed, and results were reported. $^{6}$ Results indicate that under present reactor operating conditions, steam of 99 per cent quality or better will enter the moisture separators. This leaves approximately 0.9 per cent moisture to be removed by mechanical separators to obtain. steam of 99.9 per cent quality for the superheater.

Since these tests were conducted on relatively small test sections, the accuracy of extrapolating the results to predict the steam quality of the Pathfinder may be questioned. Further tests on a larger test section are therefore planned to further verify these results.

\subsubsection{Baffies}

Final design of the boiler-core baftle was completed. Fabrication is being discussed with shop personnel.

Stresses and deflections in the superheater-core baffle due to pressure differences between the boiler and superheater core were investigated.

\subsubsection{Superheater}

2.1.5.1. Mechanical Design. An investigation of the placement and orificing of the tube sheets is being conducted to minimize the pressure difference between the boiler-core and the superheater-core moderator and thereby reduce the stresses and deflections in the superheater baffle.

The possibility of container-tube vibration due to parallel and cooss flow of the moderator is being considered.

${ }^{6}$ Moisture De-Entrainment Tests in 2-and 4-inch Diameter Test Sections, ACNP-5921, 1959. 
2.1.5.2. Tests. Superheater Tube Weld Test. Welding of test semples of the superheater tube were completed, and preliminary indications are that all. welds investigated were successful. After completing laboratory examination of the welds, the optimum type weld will be selected from an economic as well as structural standpoint.

\subsubsection{Grid Plate}

Final design drawings are peing prepared.

\subsection{RECIRCULATION SYSTEM}

\subsubsection{Recirculation Pumps}

The finol designs were completed. Manufacture of the prototype is proceeding on schedule. The pump casing castings were poured, and preliminary radiographic tests indicate sound castings.

Specifications covering the hot loop testing of the prototype pump under design pressure and temperature conditions were completed.

\subsubsection{Recirculation Piping Loops}

2.2.2.1. Design Status. The recirculation piping configuration is essentially the same as previously described. 7 Minor changes were necessary as a result of the redesign of the recirculation discharge nozzles to normal penetration of the lower hemispherical head. The changes were sufficient to require another stress analysis of the loop, however.

2.2.2.2. Studies. Stress analysis of the present design of the recirculation piping loops was begun. The new design is not appreciably

7 Pathfinder Atomic Power Plant Technical Progress Report for October 1958 December 1958, ACNP $=5904$, i. 63, 1959. 
different than the previous design, and the forces and'moments are expected to be of the same order of magnitude as those previously reported. 8

\subsubsection{Recirculation Loop Valves}

2.2.3.1. Design Status. Conceptual design of the valves is complete. Preliminary design specifications for the valves have been written and transmitted to the Allis-Chalmer's York Works. Tests to determine the operating characterisitics of the valves are continuing. Final design specifications will be written as soon as these tests are completed.

\subsubsection{Tests. Eight-Inch Butterfly Valve. The eight-inch} diameter butterfly valve was tested to determine the value of sigma 9 (cavitation constant) at the throttling limit. The conservative definition of the throttling limit is the point of incipient (first-detectable) cavitation.

Sigma for the $20-1 / 2$ inch 1.0 . recirculation valve was calculated at reactor conditions and is shown in Figure 2.7 with the experimentally determined sigma for the 8-inch valve. The variation of sigma for a given valve angle at incipient cavitation is due in part to the air content of the water. The experimentally obtained curve was obtained with water that appeared to be relatively free of entrained and dissolved, air, but this was not substantlated. Varlous methods of determining the amount of entrained and dissolved air in water are being investigated.

8 lbid., pp. 12-16.

9 Pathfinder Atomic Power Plant Technical Progress Report for April 1959 June 1959, ACNP-5915, PP. 26 and 27, 1959. 
Test results indicate that the sigma-vs-valve-angle curve should coincide or be lower than the minimum-average-value curve of Figure 2.7. A control range of $21,167 /$ tio $15,600 \mathrm{gpm}$ would then be possible for each Pathfinder recirculation loop.

Tests were run to determine the point where a definite break-off in the flow coefficient occurs as cavitation develops. The break-off points were expected to be a function of sigma. Each test was run with a fixed valve angle and constant flow rate. The back pressure was varied to develop cavitation.

The flow coefficient is constant for a given valve angle when there is no cavitation in the system, but decreases only slightly as cavitation develops. No consistent correlation was found between sigma and the points at which the slight decreases occurred. Tests will continue to determine if a more definite break-off point can be obtained.

\subsection{STEAM SEPARATORS}

After the steam separator loop was completed, the loop was tested for leaks. The instrumentation to measure air and water flow rates and pressure drops throughout the loop was then installed.

The steam separator is required to meet certain design requirements. Among these requirements are a prescribed total pressure drop of $3 \pm 1 / 2$ fiol of water and a prescribed efficiency. The efficiency of the separator is defined in terms of the carry-under of air in the water that passes through the separator and the carry-over of moisture in the separator exhaust. A maximum carry-under rate of 1 per cent of air by volume is required. This value is based on the effect of vapor on the net positive suction 
head (NPSH) of the recirculation pumps. It mote vapor is present in the recirculated water, the NPSH is lowered and the pumps will not operate satisfactorily.

The steam separator loop was operated at reactor flow conditions to determine the total pressure drop through the model separator. The tests indicated that the total drop through the separator was too high. The size of the inlet and outlet nozzles of the separator were both increased to decrease the total pressure drop. The increases in the size of both nozzles was made without affecting the processes by which the separation of air and water is effected.

Tests of the modified model separator indicate that the average total pressure drop through the separator is 3.3 feet of water at the required flow rate of air and water. Pressure drops through the inlet and outlet nozzles were 1.9 and 1.4 of water, respectively. The carry-under rate was .2 per cent of air by volume. This value was obtained by passing water through the separator into a long horizontal diffusion tank. The velocity of the water decreases in the tank, and the air that has been carried under rises and displaces water in a collection drum mounted on the top of the tank. The volume, temperature, and pressure of the air collected was periodically measured, and the carryunder rate could then be calculated.

Tests are presently being run to determine the amount of steam that will be carried into the separator. This data will be necessary to specify the capacity of the separators that will be used on the Pathfinder. The open pool area around the inlet of the model separator is sized to simulate the pool area adjacent to which each separator will be 
installed in the reactor. Of interest is the fact that the steam-water mixture from the inner' part of the boiler core will travel a longer distance to enter the separator, then the air-water mixture travels to enter the inlet of the model separator. Therefore, more time will be available for steam to escape, and the capacities that will be indicated by the tests with the model separator should be slightly larger than the capacity that will be required of an operating separator in the Pathfinder.

Results thus far indicate that the carry-under rate is practically indeperident of the amount of air passing into the separator.

Under reactor conditions, the steam separators exhaust to the steam dome area. This area is at the same pressure as the surface of the pool around the separators. To duplicate reactor conditions, attempts were made to obtain equal pressures in the pool area and separator exhaust of the test loop by using a throttling valve in the exhaust, but the pressures were found to fluctuate considerably. Methods of damping out the pressure fluctuations in the test loop instrumentation are currently being investigated.

\subsection{CONTROL RODS, GIJIDE TUBES, AND CONTROL ROD DRIVES}

\subsubsection{Control Rods}

A prototype rod of boron stainless steel was manufactured and inspected. The rod was found to be well within the straightness tolerance required of the reactor control rods. The rod will be used in the critical facility.

Design of a split control rod, that can be removed from the reactor in sections was started. The removal of these rods in two sections would 
considerably reduce the radiation level at the top of the shield pool.

Control rod material studies are continuing. Samples of $2 \mathrm{w} / 0$ boron stainless steel were welded and brazed and are undergoing tensile strength tests at ambient and elevated temperature. The test results will be reported in the next quarterly report.

\subsubsection{Guide Tubes}

The design of split guide tubes incorporating the fuel element hold-down device and water turning baffle has undergone design changes and is still being considered for use in the Pathfinder reactor.

\subsubsection{Control Rod Drives}

2.4.3.1. Design Status. Conceptual Design. The conceptual design for all components of the control rod drives is complete with the following exceptions. Design of a suitable water supply system for the control rod rack housing is not complete. Formulation of a pinning and assembly procedure to correctly locate the latch with respect to the turning mechanism and drive housing is not finalized. Layouts for the cables, tubing and supporting structures that are attached to the drives and that must be disconnected when the vessel cover is removed must be completed. Further changes will be incorporated where results of tests and studies show them to be necessary.

A mechanical method was devised to hold the rack and latch in the up-position during reactor cover removals and was incorporated in the design. This device eliminates the necessity of energizing the scram clutch during cover removal. 
A study to determine. it the stiffening rings are necessary to support the slotted turning tube was completed. The study indicates that the rings are not required to handle the required torque but are needed to eliminate separation of the two tube halves due to bending.

The critical frequency of all shafting was calculated and found to be well above that which the drives will encounter. The critical frequency of the rack housing was also calculated and was found to be very low. The horizontal deflection of the rack housing due to various loads was also studied and does not appear to be a source of trouble.

The radial and longitudinal thermal expansions of the control-rod drive system with respect to the reactor core was analyzed. In the stainless superheater core erroneous position readings of as much as 3/4 inch may be obtained. In an aluminum boiler core a false indication of almost $1 / 2$ inch may be obtained when the reactor is heated to operating temperatures. These errors are at a maximum when the rods are fully withdrawn and are expected to be tolerable.

Control-Rod Drive Water-Supply Study. For normal withdrawal and insertion of the control rods, sufficient steam or water may enter or leave the rack housing through the radial clearance between the rack and bushing. Even if a large pressure drop developed across the clearance, the control system would not be affected because the rods are positively driven in both directions. On scram, however, the rods are disengaged and are required to drop the full stroke in. less than one second. During this drop a large pressure differential would develop across the clearance and could be sufficient to slow the drop and prevent proper shutdown of the reactor. A water supply for the rack housing is therefore necessary 
to reduce the pressure differential and allow an unimpeded drop of the control rods during scram.

Both external and interhal water supply systems were studied. The external water supply systems are characterized by various accumulator arrangements. A difficulty with such systems is that a large number of auxiliary components and connections, which could be a source of trouble, are required.

In the internal water supply systems under study, reactor steam is introduced into the rack housing and will reduce the pressure ditferential that developes during a scram. Two methods of accomplishing this are proposed. Steam may be released into the housing just above the bushing level, or steam may be guided through a tube to the top of the rack housing. If steam is released above the bushing and is allowed to rise in the rack housing, it would impinge on various components and raise their surface temperatures. The thermal stresses that are thus produced in the stainless steel components may be excessive. The use of a tube that introduces steam in the top of the housing would el iminate this problem.

The two systems that are proposed would both allow thermal circulation during normal operation. Since the amount of heat loss that would result from use of either of the proposed internal supply systems is difficult to evaluate analytically, a heat transfer test of the control-rod rack housing will be conducted. The test will be made to determine the amount of heat loss that may be expected with various internal supply arrangements. The test apparatus is being erected and is described in detail below. 


\subsubsection{Tests. Control Rod Rack-Housing Heat Transfer Tests.}

Heat transfer tests will be conducted to evaluate the heat loss to the shield pool when various internal water supply arrangements are used. The test apparatus is shown in Figure 2.8 and is presently being erected.

The autoclave that was used to test self-energizing seals is used to simulate the reactor vessel. The test loop is welded into the cover of the autoclave. The 3/8-inch tube represents one of the proposed methods of introducing steam to the top of the rack housing. The steam tube may be cut out of the system by closing the shut-off valve at the top of the loop. Various steam entry ports through the bushing may be tested. These ports are held in the bushing by a set screw.

The heat loss to the shield pool will be evaluated by measuring the flow rate and temperature rise of water passing through the cooling jacket. Dropping of a control rod will be simulated by opening the solenoid valve at the top of the column. Opening of the valve will allow some water to drain from the system and steam to enter the loop.

A 3/4-inch stainless steel bar will be suspended in the column so that it will be bathed by steam rising through the column. If severe thermal stresses are produced, checkering, may result which can be visually observed.

Prototype Control-Rod Drive. A prototype control rod drive will be tested to evaluate the conceptual design. Detail drawings for the prototype wére completed, and one prototype drive was ordered from the West Allis shops. A final check of the drawings will be made before manufacturing begins. 
The shop is in the process of scheduling the fabrication of the mechanism. Most of the items requiring a long lead time were ordered. Recently ordered items include the 440 C stainless steel turning tube bearings, turning tube material, all drive housing material, and the servo drive motor. Proposals for position indication were received, and one of the proposed systems will be incorporated in the prototype. As soon as conceptual design of the water supply system is completed, this system will also be incorporated in the prototype.

A flanged adapter section was designed for the prototype and will be used in final hot tests with conventional flanges simulating the vessel cover joint. At a later date, a quick disconnect coupling may be tested. The drive-motor test $r i g$ was completed and is shown in Figure 2.9. The test rig will be used to evaluate the two types of drive motors that are being considered for use.

Cold and Hot Latch Tests. The cold and hot latch tests were completed. After a total of 800 cycles, the latch proved to be satisfactory from both the materials standpoint and the operation standpoint. The latch and latch test stand are shown in Figures 2.10 and 2.11 . 


\section{NUCLEAR ANALYSIS \\ 3.1. REACTOR PHYSICS (STATICS)}

\subsubsection{Nuclear Constants}

A comparison was made between fast constants obtained with the Muft-4 code, 10 and the "fitted" constants"l. used heretofore. From the comparisons, the following conclusions can be made:

1) Results of the Muft-4 code agreed quite well with the slowing down properties for the boiler region calculated using the Deutsch equivalence method.

2) Hand calculations using Muft fast constants and Sofocate thermal constants in the equation,

$$
k_{\text {eff }}=\frac{1}{1+T B^{2}}\left[n f_{\text {fast }}+\frac{n f_{\text {SIOw }} P}{\left(1+L^{2} B^{2}\right)}\right]
$$

agreed quite closely with hand calculations using the present experimentally fitted constants when an adjustment is made to account for the fast absorption.

An example of the fast neutron spectrum obtained for the Muft-4 code and the differences that exist in the various core regions can be seen in Figure 3.1. and 3.2. Figure 3.1. makes a comparison between the fast spectrums in the boiler and superheater cores for cold core conditions. The main differences are at the high energy levels due to

10 pathfinder Atomic Power Plant Technical Progress Report, April 1959-June 1959, ACNP-5915, P. 35, 1959.

IIH. Bohl, Jr., E. Gelbard, G. Ryan, Muft-4--Fast Neutron Spectrum Code for the 18M 704, WAPD-TM-72, 1957.

${ }^{12}$ R. Deulsch, Computing 3-Group Constants for Neutron Diffusion, Nucleonics, Vol 15, No. I, 1957. 
differences in the inelastic scattering properties of the two regions; and at the U-238 resonance energy level where the spectrum. in the boiler is somewhat depressed.

Figure 3.2. shows little change in the spectrum within the boiler core due to boiling. Curves $A$ and $B$ show the change in the 64 fuel-rod region from the cold core condition to the operating condition with 34 per cent of the moderator voided.

\subsubsection{Stainless Steel Baffle Plate Analysis}

A series of one-dimensional diffusion theory calculations were made to determine the superheater loading that could give the desired power distribution and reactivity with a stainless steel baffle plate between' the boiler and superheater regions.

Superheater loadings of 39,42 and $45 \mathrm{~kg} \mathrm{U}-235$ were considered.

A 15-per cent increase in water was also considered for the superheater. The core was divided axially into six regions for each superheater loading to determine the effect of fuel and void changes in the boiler core.

Thermal group constants were obtained with the Sofocate program. Fast groúp constants were obtained by the water equivalence method. 1.3 Calculations were also made using fast group constants from the Muft-4 code.

The power fraction trom the superheater for the various cases is given in Table 3.1. The data is for the entire core and is obtained

13 Reactor Physics Constants, ANL-5800, p. 165. 
by weighting the superheater power for each radial slice against the power produced in previous RZ-geometry calculations.

From these results a fuel loading of $42 \mathrm{~kg} \mathrm{U}-235$ with a 15 -per cent increase in water was selected. A series of two-dimensional RZ-geometry calculations were then made to determine the gross coefficients and precisely determine the power distribution.

Table 3.1

SUPERHEATER POWER FRACTION FOR VARIOUS CORE LOADINGS AND AMOUNTS OF WATER

\begin{tabular}{l|c|c|c}
\hline \multirow{2}{*}{ Moderator } & \multicolumn{3}{|c}{ U-235 } \\
\cline { 2 - 4 } & $39 \mathrm{~kg}$ & $42 \mathrm{~kg}$ & $45 \mathrm{~kg}$ \\
\hline $\begin{array}{l}\text { Reference } \\
\text { Water }\end{array}$ & 0.16 & 0.18 & 0.208 \\
$\begin{array}{l}\text { 15-per cent. } \\
\text { Increase }\end{array}$ & 0.188 & 0.206 & 0.239 \\
\hline
\end{tabular}

3.1.3. Comparison of Core Representations

Representation of the core in three dimensions was in terms of

$R-\theta-Z$ coordinates with the $\theta$ dependence removed by some approximation. Some comparisons are being made that will indicate the effect of this simplifying assumption.

A two-dimensional diffusion theory calculation was made of a crosssectional slice of the core at the level corresponding to the 64-pin boiler section. The cold clean core with flooded superheater was calculated in $X-Y$ geometry. The superheater was represented by two irregular homogeneous regions. 
The same case was calculated in one dimension as a set of homogeneous, concentric, cylindrical regions with the two inner regions corresponding to the superheater. The transformation to cylindrical regions is such that the area remains the same. This type of transformation characterizes the $R-\theta$ representation in all the $R-\theta-Z$ calculations made.

The comparison of calculated results for the two representations is as follows:

$$
\text { keff }
$$

Integrated source, Superheater Integrated source, Boiler

$\frac{X-Y \quad \text { Radial }}{1.053 \quad 1.056}$

0.160

0.153

0.840

0.847

The comparison indicates that the one-dimensional radial representation is adequate for predicting reactivity and gross power distributions for surveys or parameter studies.

\subsubsection{Calculation of the Delayed Neutron Fraction}

The calculation of an average delayed neutron fraction, $\bar{\beta}$, was undertaken for various core configurations to be used in the critical facility. During reactor experiments, the period, $T$, will be measured, and the reactivity will be determined with the inhour equation. Since the inhour equation relates reactivity directly with $\overline{\mathcal{P}}$, the correct value of $\bar{S}$ is necessary to obtain an accurate reactivity measurement.

The calculation of the effective $\bar{\beta}$ is performed in the following manner.

1) Prompt-neutron fast constants (3-Group) are obtained by using the Muft-4 code; thermal constants are obtained from the Sofocate code. 
2) A transverse Wanda 4-Group diffusion calculation is made with a buckling criticality search specified.

3). Delayed neutron fast constants are obtained with Muft-4 by use of a special fission source deck that places all fission neutrons in the twelfth energy group (approximately the average energy of the delayed neutron groups).

4) By using the results from Step 2, a pointwise source, S, is calculated for each mesh point through the slab by the equation,

$$
S=\sum_{i=2}\left(\gamma \Sigma_{i} \phi_{i} \beta^{25}\right)+\sum_{i=1}^{1}\left(\nu \sum_{i}^{25} \phi_{i} \beta^{25} \quad \sum_{f}^{2 \delta} \phi_{i} \beta^{28}\right)
$$

5) The pointwise source from Step 4, the critical buckling from Step 2, and the delayed neutron fast constants from Step 3, are used to run a final Wanda problem in which the first Eigenvalue (first iteration) is the average delayed neutron fraction, $\bar{\beta}$.

A value of $\bar{\beta}$ was obtained for a 20-by-20-by-72-inch slab-core configuration containing a 9-by-9 pin array per 5 inch square assembly under cold clean conditions. For this case, $\bar{\beta}$ was found to be 0.00686 representing an increase of 7.2 per cent over the uncorrected $\bar{\beta}$. for U-235 fission of 0.0064 .

For this calculation, it was assumed that all of the delayed neutrons were due to U-235 fissioning. More refined calculations are in progress to determine the U-238 fission contribution to the delayed fraction. for the $\bar{\beta}$ calculation.

3.1.5. Reactor Shielding -- Shielding Analysis of the Reactor Building 3.1.5.1. Activity Sources. The sources of activity that exist in the reactor containment building. during power operation are 1) the primary 
gammas and fast neutrons originating in the core, 2) secondary gammas, gammas produced by capture of thermal neutrons in reflector and shield materials, 3) decay gammas from the $\mathrm{N}-16$ that is carried by the water and steam in the system, and 4) the gammas originating in system crud that was activated by the core neutron flux.

Primary Gammas and Fast Neutrons. The primary gammas are composed of prompt and delayed fission gammas, capture gammas from neutron capture in the core materials (aluminum, steel, water, uranium), and inelastic scattering gammas that are caused by the inelastic scattering of neutrons by various core materials. For purposes of analysis, all components of primary gammas are combined and related to the number of fissions that occur in the core. By knowing the number of fissions that take place in each core volume, a volume source of gamma rays within the core may be obtained directly.

The primary gammas were divided into five energy groups, and the average energy for each group, the number of primary gammas per fission, and the core volume source for the operating Pathfinder core are given in Table 3.2. The volume source, $S_{V}$, was calculated from the equation,

$$
S_{v}=\frac{P}{v} \times \frac{\text { gammas }}{\text { fissions }}
$$

where,

$$
\begin{aligned}
& P=\text { average power (watts) } \\
& V=\text { Core volume (cc) }
\end{aligned}
$$


Table 3.2.

PRIMARY GAMMA ENERGY GROUPS AND VOLUME SOURCES

FOR CORE AT FULL POWER OPERATION

\begin{tabular}{ccccc}
\hline Group & $\begin{array}{c}\text { Energy } \\
\text { Range } \\
\text { (Mev) }\end{array}$ & $\begin{array}{c}\text { Average } \\
\text { Energy } \\
(\text { Mev })\end{array}$ & $\begin{array}{c}\text { Gammas } \\
\text { per } \\
\text { Fission }\end{array}$ & $\begin{array}{c}\text { Average } \\
\text { Volume } \\
\text { Source } \\
(\text { r } / \text { cc-sec })\end{array}$ \\
\hline 1 & $0-1$ & 1 & 10.5 & $1.5 \times 10^{13}$ \\
11 & $1-3$ & 2 & 4.12 & $5.8 \times 10^{12}$ \\
111 & $3-5$ & 4 & 0.70 & $9.9 \times 10^{11}$ \\
IV & $5-7$ & 6 & 0.10 & $1.4 \times 10^{11}$ \\
V & $7-7.3$ & 7.3 & 0.055 & $7.7 \times 10^{10}$ \\
\hline
\end{tabular}

The volume sources of fast neutrons within the operating core based on a release of 2.5 neutrons per fission is $3.5 \times 10^{12} \mathrm{n} / \mathrm{cc}-\mathrm{sec}$.

Secondary Gammas. The prompt capture gammas formed outside of the core that are of importance in this analysis are those produced in the water surrounding, the core and in the steel vessel wall. The secondary water gammas are of the same energy and produce dose rates of the same order of magnitude as the primary Group II gammas. The steel secondary gammas are in gamma groups $11,111,1 V$, and $V$ with respective source strengths of 0.1 , $0.24,0.22$; and 0.50 gammas per thermal neutron capture. Considering the capture rate in steel, the dose rates are also found to be of the same order of magnitude as the primary gammas. Secondary gammas are produced in the concrete shield, but their contribution to the dose rates are much smaller than the primary gammas, and they are therefore neglected.

The activation of the main steam line by the thermal neutron flux at the elbow below the reactor core produces volume sources of $3.4 \times 10^{7}$, 
$9.5 \times 10^{5}$, and $6.3 \times 10^{7}$ gammas/cc-sec. with respective energies of 0.3 , 1.0, and 3.0 Mev. These sources are at saturation.

$\mathrm{N}-16$ Activation. The analysis of the $\mathrm{N}-16$ activation problem was made as follows. The number of $\mathrm{N}-16$ atoms, $\mathrm{N}$, at a point above the core is calculated by the equation,

$$
N=\frac{\sum \phi}{\lambda} \frac{\left(1-e^{\left.-\lambda t_{c}\right)}\right.}{\left(1-c \theta^{-\lambda\left(t_{c}+t_{0}\right)}\right.}
$$

where,

$$
\begin{aligned}
& t_{c}=\text { the resident time of water in the core } \\
& t_{0}=\text { the resident time of water outside the core. } \\
& \Sigma=\text { the } \mathrm{N}-\mathrm{i} 6 \text { activation cross section } \\
& \phi=\text { the activation } \mathrm{flux} \\
& \lambda=\text { the } \mathrm{N}-16 \text { decay constant, and } \\
& c=\text { the ratio of steam evaporation to recirculation }
\end{aligned}
$$

This yields a value of $1.6 \times 10^{10}$ atoms of $N-16$ per pound of steam above the core and $4 \times 10^{6}$ atoms of N-16 per cc in the water outside the core. When this activity is distributed to various components of the system, volume sources of $3 \times 10^{5}$ and $5.6 \times 10^{4}$ gammas/cc-sec. are found for the volumes occupied by the recirculating water (pumps, piping, etc.) and. the steam dome, respectively. The gamma energy of these sources is 6 Mev:

Active Crud. The system crud that is activated by the core neutron flux and subsequently deposited on components within the containment building presents a shielding problem. The assumptions and analysis is as follows. The source strength is given by the equation,

$$
s_{v}=\operatorname{DF}\left(1-e^{-\lambda+1}\right)
$$


where,

$D=$ the deposition rate of active material

$F=$ the removal fraction of active material

$\lambda=$ the decay constant of the active material

$t^{\prime}=$ the build-up time

The volume sources caused by the build-up of active crud based on a $3 \mathrm{mil}$ /year plate-out reaching a maximum of $5 \mathrm{mils}$ are given in Table 3.3 .

Table 3.3

VOLUME SOURCES FROM ACTIVE CRUD

\begin{tabular}{ccc}
\hline Gamma Energy (Mev) & $\begin{array}{c}\text { Recirculation Pump } \\
\text { Volume Source* }(\gamma / c c-s e c)\end{array}$ & $\begin{array}{c}\text { Recirculation Pump } \\
\text { Volume Source* }(r / c c-s e c)\end{array}$ \\
\hline 0.3 & $3.8 \times 10^{6}$ & $1.9 \times 10^{9}$ \\
1.0 & $4.8 \times 10^{6}$ & $2.0 \times 10^{9}$ \\
2.0 & $2.8 \times 10^{5}$ & $2.7 \times 10^{6}$ \\
3.0 & $4.0 \times 10^{3}$ & $1.6 \times 10^{6}$
\end{tabular}

* Based on total volume of component.

**Based on crud volume.

Sources after Shutdown. Substantial activity will be encountered when the core is in a shutdown condition. The sources attributed to crud and metal activation will remain essentially the same for a period of time. The sources caused by prompt capture gammas, $\mathrm{N}-16$, and the core primary gammas will be reduced substantially at shutdown. The major decáy sources at shutdown will be from the spent fuel, structural material in the core, and control rods. The magnitude at shutdown, however, is small enough to be neglected since shielding is provided for the operating core. 
Since fuel and control rods will be removed periodically, the determination of their source strengths is important for fuel-handling considerations. These volume sources are presented for the intinte exposure case and 10-hour decay in Table 3.4.

Table 3.4

VOLUME SOURCE FOR SPENT FUEL AND CONTROL RODS

\begin{tabular}{ccc}
\hline Gamma Energy (Mev) & $\begin{array}{c}\text { Spent Fuel } \\
\text { Volume Source }(\gamma / c c-s e c)\end{array}$ & $\begin{array}{c}\text { Control Rod } \\
\text { Volume Source }(\gamma / c c-s e c)\end{array}$ \\
0.3 & $7 \times 10^{11}$ & $8.2 \times 10^{11}$ \\
0.6 & $3.7 \times 10^{11}$ & - \\
1.0 & $7 \times 10^{11}$ & $3.8 \times 10^{11}$ \\
2.0 & $2 \times 10^{9}$ & $9 \times 10^{11}$ \\
3.0 & & \\
\hline
\end{tabular}

34.5:2. Radiation Levels. The radiation levels at representative dose points throughout the containment shell were calculated, assuming the physical characteristics given in Table 3.5 . 
Table 3.5

PHYSICAL CHARACTERISTICS DF SCURCES

\begin{tabular}{|c|c|c|c|}
\hline Component & Source & $i z e^{*}$ & Integral Shielding \\
\hline Core & $\frac{\text { Diameter }}{5-2 / 3} \frac{\text { feet }}{\text { for }}$ & $\frac{\text { Length }}{6}$ & - \\
\hline Recirculation pump & 6 feet & 4 teet & 3 inch steel. casing \\
\hline Recirculation piping (2) & 22 inch & 10 feet & $3 / 4$ Inch steel casing \\
\hline Steam dome & 10 feet & 7 teet & 3 inch steel wall \\
\hline Main steam line & 18 inch & 10 teet & 3/4, inch steel casing \\
\hline Control rod** & 3.5 inch & 6 teet & - \\
\hline Spent fuel element** & 5.7 inch & 6 feet & - \\
\hline
\end{tabular}

* All sources are right cylinders.

* These two items are located in the shield pool for the analysis of the shutdown case.

The location of the dose points are given in Figures 3.3 and 3.4 . The contribution of each component and the total dose for each point during full power operation are given in Table 3.6. The same information for the shutdown case is given in Table 3.7. In the shutdown case, the reactor is shutdown, the vessel is flooded with water, and the vessel lid is removed.

The gamma and neutron flux, both axially and radially from the core, are plotted for the operating case in Figures 3.5 through 3:10. The gamma flux given includes the primary gammas from the core and the secondary gammas produced by neutron capture in the various shielding materials. 
3.1.5.3. Gamma Heating. Gamma heating, $H_{\text {, }}$, was calculated in the radial direction from the core. The heat generation is given by the equation,

$$
H_{r}=H_{e} \phi E(\text { Mer/cs-sec })
$$

where,

$$
\begin{aligned}
& H e=\text { gamma ray energy absorption coefficient }\left(\mathrm{cm}^{-1}\right) \\
& \phi=\text { gamma ray flux }\left(/ \mathrm{cm}^{2}-\mathrm{sec}\right) \\
& E=\text { gamma ray energy (Mev). }
\end{aligned}
$$

The gamma flux includes the primary gammas and the secondary gammas produced in the shield.

Fast neutron heating, $H_{n}$, was calculated similarly. The heat generated is obtained by the expression,

$$
H_{n}=\sum_{R} \phi
$$

where,

$$
\begin{aligned}
& \Sigma_{R}=\text { fast neutron removal cross section }\left(\mathrm{cm}^{-1}\right) \\
& \phi=\text { fast neutron } \mathrm{flux}\left(\mathrm{n} / \mathrm{cm}^{2}-\mathrm{sec}\right) \\
& E=\text { fast neutron energy }(\mathrm{Mev})
\end{aligned}
$$

Although equation (3.7) gives a conservative approximation, the fast neutron heating is small compared to the gamma heating, and a more accurate analysis is not warranted.

The heat generation at full power operation was calculated using equation $(3.6,3.7)$ and results are plotted as a function of radial distance in Figure 3.11. The total heat deposited in the primary concrete shield due to gamma heating was calculated to be $15 \mathrm{kw}$. 
Table 3.6

\section{DOSES IN ROENGENS PER HOUR IN THE CONTAINMENT SHELL DURING FULL POWER OPERATION \\ (Refer to Figures 3.3 and 3.4 for dose point locations.)}

\begin{tabular}{|c|c|c|c|c|c|c|c|}
\hline $\begin{array}{l}\text { DOSE } \\
\text { POINT }\end{array}$ & CORE & $\begin{array}{c}N^{16} \text { IN } \\
\text { STM.DOME } \\
\end{array}$ & $\begin{array}{c}\text { PUMP (A) } \\
\text { NO. } 1 \\
\end{array}$ & $\begin{array}{c}\text { PUMP (A) } \\
\text { NO. } 2 \\
\end{array}$ & $\begin{array}{c}\text { PUMP (A) } \\
\text { NO. } 3 \\
\end{array}$ & MSL & TOTAL \\
\hline 1 & $1.6 \times 10^{4}$ & - & 5 & 5 & 5 & 760 (B) & $1.7 \times 10^{4}$ \\
\hline 2 & $1.5 \times 10^{4}$ & 4 & - & - & - & - & $1.5 \times 10^{4}$ \\
\hline 3 & $6 \times 10^{-3}$ & $5.2 \times 10^{-7}$ & - & - & - & - & $6 \times 10^{-3}$ \\
\hline 4 & $1 \times 10^{-3}$ & - & - & - & - & - & $1 \times 10^{-3}$ \\
\hline 5 & $7 \times 10^{-4}$ & - & - & - & - & - & $7 \times 10^{-4}$ \\
\hline 6 & $1.9 \times 10^{4}$ & - & 10 & 10 & 10 & 80 (B) & $1.9 \times 10^{4}$ \\
\hline 7 & $3.6 \times 10^{4}$ & - & $8.3^{\prime}$ & 8.3 & 8.3 & 30 (B) & $3.6 \times 10^{4}$ \\
\hline 8 & $2.3 \times 10^{4}$ & - & 4.5 & 4.5 & 4.5 & - & $2.3 \times 10^{4}$ \\
\hline 9 & $3.5 \times 10^{5}$ & - & 1.1 & 1.1 & 1.1 & - & $3.5 \times 10^{5}$ \\
\hline 10 & $1.2 \times 10^{5}$ & - & - & - & - & - & $1.2 \times 10^{5}$ \\
\hline 11 & $7.9 \times 101$ & 4 & - & - & - & - & $8.3 \times 10^{1}$ \\
\hline 12 & $1.2 \times 10^{4}$ & 4 & - & - & - & - & $1.2 \times 10^{4}$ \\
\hline 13 & $2.4 \times 10^{-3}$ & - & - & - & - & - & $2.4 \times 10^{-3}$ \\
\hline 14 & $6 \times 10^{-5}$ & - & $4.5 \times 10^{-2}$ & 6.5 & $4.5 \times 10^{-2}$ & - & 6.6 \\
\hline 15 & $1 \times 10^{-3}$ & - & $2.3 \times 10^{-2}$ & 1.5 & $2.3 \times 10^{-2}$ & - & 1.6 \\
\hline 16 & $6 \times 10^{-5}$ & - & - & $1.2 \times 10^{-2}$ & - & - & $1.2 \times 10^{-2}$ \\
\hline 17 & $1.2 \times 10^{-5}$ & $1 \times 10^{-3}$ & - & - & - & - & $1 \times 10^{-3}$ \\
\hline 18 & $9 \times 10^{-6}$ & - & - & - & - & - & $9 \times 10^{-6}$ \\
\hline 19 & $1.2 \times 10^{-8}$ & - & - & - & - & - & $1.2 \times 10^{-8}$ \\
\hline 20 & $3.2 \times 10^{-7}$ & - & - & - & - & - & $3.2 \times 10^{-7}$ \\
\hline 21 & - & - & $7 \times 10^{-2}$ & 27 & $7 \times 10^{-2}$ & - & 27 \\
\hline 22 & - & - & - & $1.7 \times 10^{-1}$ & - & - & $1.7 \times 10^{-1}$ \\
\hline 23 & - & - & - & $6 \times 10^{-3}$ & - & - & $6 \times 10^{-3}$ \\
\hline 24 & - & - & - & - & - & - & - \\
\hline 25 & - & - & - & - & - & - & - \\
\hline 26 & - & - & - & $8 \times 10^{-2}$ & 27 & $1.3 \times 10^{-3}(\mathrm{c})$ & 27 \\
\hline 27 & - & - & - & - & $6 \times 10^{-2}$ & $2.2 \times 10^{-1}(\mathrm{C})$ & $2.8 \times 10^{-1}$ \\
\hline
\end{tabular}

(A) Includes recirculation pump and related piping. Dose is from both crud deposition and $\mathrm{N}^{16}$.

(B) Due to activated pipe wall by thermal neutrons.

(C) Due to $\mathrm{N}^{16}$ carried by the steam. 
Table 3.7

DOSES IN ROENTGENS PER HOUR IN THE CONTAINMENT SHELL 10 HOURS AFTER SHUTDOWN

(Refer to Figures 3.3 and 3.4 for dose point locations.)

\begin{tabular}{|c|c|c|c|c|c|c|c|}
\hline $\begin{array}{l}\text { DOSE } \\
\text { POINT }\end{array}$ & $\begin{array}{c}\text { CORE } \\
\text { SHUTDOWN }\end{array}$ & $\begin{array}{l}\text { FUEL(C) } \\
\text { ELEMENT } \\
\text { IN POOL }\end{array}$ & $\begin{array}{c}\text { CONTROL }(C) \\
\text { ROD IN } \\
\text { POOL }\end{array}$ & $\begin{array}{l}\text { PUMP(A) } \\
\text { NO. } 1\end{array}$ & $\begin{array}{l}\operatorname{PUMP}(A) \\
\text { NO. } 2\end{array}$ & $\begin{array}{l}\operatorname{PUMP}(A) \\
\text { NO. } 3\end{array}$ & TOTAL(B) \\
\hline 1 & $2 \times 10^{-4}$ & - & - & 3 & 3 & 3 & $7.7 \times 10^{2}$ \\
\hline 2 & $3 \times 10^{-4}$ & $1.7 \times 10^{5}$ & $1.6 \times 10^{5}$ & - & - & - & $3.3 \times 10^{5}$ \\
\hline 3 & - & $4 \times 10^{-3}$ & $9.7 \times 10^{-2}$ & - & - & - & $1 \times 10^{-1}$ \\
\hline 4 & $. \quad-$ & $1 \times 10^{-3}$ & $2.4 \times 10^{-2}$ & - & - & - & $2.5 \times 10^{-2}$ \\
\hline 5 & - & $4.6 \times 10^{-4}$ & $1.1 \times 10^{-2}$ & - & - & - & $1.2 \times 10^{-2}$ \\
\hline 6 & $1.10^{-1}$ & - & - & 6 & 6 & 6 & 98 \\
\hline 7 & $8.9 \times 10^{1}$ & $=$ & - & 5.3 & 5.3 & 5.3 & $1.35 \times 10^{2}$ \\
\hline 8 & $6.9 \times 10^{1}$ & - & - & 2.8 & 2.8 & 2.8 & $7.7 \times 10^{1}$ \\
\hline 9 & $1.4 \times 10^{3}$ & - & - & .7 & .7 & .7 & $1.4 \times 10^{3}$ \\
\hline 10 & $6.9 \times 10^{1}$ & $\therefore$ & - & - & - & - & $6.9 \times 10^{1}$ \\
\hline 11 & $1.2 \times 10^{-1}$ & - & - & - & - & - & $1.2 \times 10^{-1}$ \\
\hline 12 & $4.8 \times 10^{-3}$ & - & - & - & - & - & $4.8 \times 10^{-3}$ \\
\hline 13 & - & $1 \times 10^{-4}$ & $1.6 \times 10^{-3}$ & - & - & - & $1.6 \times 10^{-3}$ \\
\hline 14 & - & - & - & $3 \times 10^{-3}$ & 3.6 & $3 \times 10^{-3}$ & 3.6 \\
\hline 15 & - & - & - & $1.10^{-3}$ & 1.5 & $1 \times 10^{-3}$ & 1.5 \\
\hline 16 & - & - & -2 & - & - & - & -2 \\
\hline 17 & - & $1 \times 10^{-4}$ & $1.6 \times 10^{-2}$ & - & - & - & $1.6 \times 10^{-2}$ \\
\hline 18 & - & $5 \times 10^{-5}$ & $8 \times 10^{-3}$ & - & - & - & $8 \times 10^{-3}$ \\
\hline 19 & - & - & - & - & - & - & - \\
\hline 20 & - & - & - & - & - & $-{ }_{-3}$ & - \\
\hline 21 & - & - & - & $3 \times 10^{-3}$ & 20 & $3 \times 10^{-3}$ & 20 \\
\hline 22 & - & - & - & - & $1.7 \times 10^{-1}$ & - & $1.7 \times 10^{-1}$ \\
\hline 23 & - & - . & - & - & - & - & - \\
\hline 24 & - & - & - & - & - & - & - \\
\hline 25 & - & - & - & - & - & - & - \\
\hline 26 & - & - & - & - & $3 \times 10^{-3}$ & 20 & 20 \\
\hline 27 & - & - & - & - & - & $3 \times 10^{-3}$ & $3 \times 10^{-3}$ \\
\hline
\end{tabular}

(A) Includes dose from recirculation pump and related piping.

(B) Total includes dose from activated MSL given in the operating table.

(C) Located in pool on vertical center line. 


\subsection{REACTOR AND SYSTEM DYNAMICS}

The CRBR system analog simulator, which includes the reactor, external steam system, and controls, was completed. New void-vs-reactivity curves and improvements in the superheater simulation were incorporated. The simulator will now show the fuel hot-spot and exit steam temperatures during a transient.

A simplified block diagram of the simulator is shown in Figure 3.12. The purpose of each block was previously described. 14 Figure 3.13 shows the actual void-reactivity relationship used in the simulator. These curves were calculated from the physics and heat transfer characteristics of the reactor core and are now felt to be reliable for conditions about the full-power operating point. A detailed description of the simulator was written and will be published as soon as improvements and additions that have been planned are included.

Results of several system disturbances are shown in Figures 3.14 through 3.16. It should be kept in mind that the curves were taken with steam-line pressure regulation only. The pressure regulator was set at a typical adjustment, not necessarily the optimum adjustment. Figure 3.14 shows variations for the maximum rate of control-rod run-in. Figure 3.15 shows variations for the maximum rate of control-rod run-out. Figure 3.16 shows variations for recirculation pump failure and start-up with full. line voltage applied and butterfly valves wide-open.

The above curves show that the relation between reactor power and exit steam temperature is very nearly a constant. During a transient, however, a

\footnotetext{
14 Pathfinder Technical Progress Report, ACNP-5909, P. 44, 45.
} 
change in steam flow lags the reactivity change by the sum of the bioiler fuel time constant and time constants associated with the steam-dome pressure build-up and steam flow dynamics. At full power, this lag is approximately 10 seconds. A reactivity change produces an almost instantaneous change in superheater heat flux while a lag of about 4 seconds is present in the boiler core. Thus, the exit steam temperature initially rises upon a reactivity addition and initially falls when reactivity is decreased.

A straight forward scheme is being devised to simulate a known degree of by-pass and turbine stop and/or turbine-inlet valve mismatch during a turbine overspeed or during a turbine trip. Thus, studies will establish the maximum amount of valve mismatch permissible without severely affecting any part of the system. The pressure response to a sudden valve closing instantaneous with a reactor scram will also be determined.

Work is being done to analyze in detail the hydrodynamlc characteristics of the CRBR primary system. A function is being derived relating the variable core friction factor, butterfiy valve position, recirculation flow rate, feedwater flow rate, and steam quality at the core exit. This function will be placed in the simulator and will be used to 1) determine the damping, 2) any hydrodynamic oscillation, if present, of the primary loop, and 3) calculate the natural. frequency of oscillation of the primary loop as a function of power levels from full power to natural ci rculation power.

Recently started is a time dependent flux study. This investigation is intended to show the dynamic characteristics of the coupling between the boiler and superheater cores. Power stability and flux traveling will be studied for a variety of reactor disturbances. 


\subsection{CRITICAL EXPERIMENTS}

The erection of most of the Allis-Chalmers Critical Facility was completed during the last quarter. The dump tanks, ion exchange tank, support structure, and reactor tank are now installed permanently with all the associated pumps, piping, and valves. The grid plate and other core structures were partially assembled. Most of the control rod drives were mounted on the control roddrive mounting bridge. Alignment of the drives, rods, and guide tubes will be completed early in the next quarter. With the exception of a few control rods, all the components for the assembly were received.

All the electrical circuits from the console to the reactor were installed during the quarter, except the circuits to the neutron and gamma detectors. Ninety-four per cent of the boiler fuel has been received. 


\section{THIS PAGE}

\section{WAS INTENTIONALLY LEFT BLANK}




\section{CHEMISTRY}

\subsection{CORROSION}

Efforts are being made to make the eddy current gage a more precise laboratory instrument for measuring corrosion rates. The gage used on the dynamic corrosion test loop was dismantled, and a new null-measuring meter will be incorporated. A test was designed to determine the effects of ambient and component temperatures on operation of the gage. These tests will be conducted to determine how much the accuracy will be improved by better control of temperature, as soon as the null-measuring meter is incorporated. Significant increases in stability and accuracy of the gage must be obtained for measurement of corrosion rates.

\subsection{RECOMBINER, RADIOACTIVE GAS REMOVAL AND STORAGE SYSTEM, ION EXCHANGER, AND CHEMICAL PRDCESSING}

\subsubsection{Radioactive Gas Removal System}

The gas removal system presently consists of a long delay pipe that provides approximately 6 minutes of additional delay time in the system before available atmospheric dispersion is made. Estimates of the off-gas activity levels indicate that this system will be adequate for continuous plant operation under normal operating conditions.

Design calculations on a liquefaction system that may be used as an alternate are being made. Design of such a system will be emphasized only if initial plant testing shows a need for further gas decontamination. Space in the Fuel Handling Building is available for quick installation of this system should the need arise.

\subsubsection{Liquid and Solid Waste Handling System}

The report on liquid and solid waste handling requirements for the 
Pathfinder 15 was reviewed and evaluated. The review and analysis were based on the following criteria: economics, safety to plant and operating personnel, flexibility, feasibility, reliability, the quantity of water available for dilution, the quantities and types of wastes to be treated, corrosion product contamination, fission product contamination, and discharge of wastes at less than maximum permissible concentrations.

A preliminary conceptual design of a liquid waste disposal system was completed on the basis of the evaluation. Evaporation, demineralization, decay, and dilution are the methods proposed. Evaporation is the major method proposed. Treated water will be reused in the system where possible. Certain types of liquid wastes will be discharged directly into the river. 4.2.3. Reactor Water Purification System.

4.2.3.1. System Design. Design Status. A diagram of the reactor water purification system is shown in Figure 4.1. The conceptual design phase for the system is nearly complete assuming that no major changes in the design requirements are made.

The tentative requirements for interlocks, annunciators, and controls were written and are described below. The superheater draining procedure (section 4.2.3.2.) was revised and expanded.

The reference design for the purification system flash tank is shown in Figure 4.2. Moisture separation requirements are presently being investigated in more detail to determine if the separating equipment may be simplified.

$15 \mathrm{M}$. Armando, et al, Pathfinder Atomic Power Plant Study of Liquid and Solid Waste Disposal Requirements, ACNP-5916, 1959. 
Tests of various filters are continuing, since results of tests with cotton-wound "Fulflo" filter elements were not encouraging. Details of these tests and of tests with other filter materials are given in Section 4.2.3.3.

Automatic Controls, Annunciators, and Inter locks. The list of general control and instrumentation requirements for the reactor water purification and superheater draining system was revised and will supersede any previously published list. The revised list will serve as a reference for writing detailed equipment specifications. It does not include requirements for reșin sluicing systems, filter backwashing systems, or radiation monitoring equipment. These systems and equipment will be considered separately.

The shut-down pump requirements are as follows:

1) The pump will be remotely operated from the control room.

2) Electrical interlocks between valves $P-1$ and $P-2$ (see Figure 4.1.) and the pump starting circuit are required. The interlocks will cause the valves to open simultaneously with pump starting and close with pump stopping.

3) Pressure actuated inter locks between valves $P-1$ and $P-2$ and the reactor are required to prevent the valves from opening when the reactor pressure exceeds a set pressure less than the maximum design working pressure of the shut-down pump. Two separate interlocks should be provided. Each one should receive its signal from a separate sensing element located between the recirculation loops and the inlet to the shut-down pump. One interlock can cause air to be bled from valve operators. The second interlock can cause electrical contacts to open the pump starting circuit so that the pump 
cannot be started from the control room. There should be no means available for by-passing these interlocks. (The interlocks discussed above will be required only if the shut-down pump is not designed for full reactor pressure.)

4) A motor load monitor on the control panel is required to indicate the load on the shut-down pump. An ammeter may be used for this purpose. It will be used to determine when superheater draining is complete.

5) Lights on the control panel are required to give a positive indication of the open position for valves $P-1$ and $P-2$. A light will also be required to indicate when the shut-down pump is operating.

6) Electrical contacts will be required for the pump pressure-relief valve P-9. An alarm and a light that are initiated on closing of the contacts will be required on the control panel to indicate that the valve has 1 ifted.

The superheater draining system requirements are as follows:

1) Interlocks between valve $P-4$ and valves $P-5$ and $P-6$ are required so that P-5 and P-6 open while P-4 closes, and so that P-5 and P-6 close while P-4 opens. This operation will be sequenced so that P-4 does not open until P-5 and P-6 are closed.

2) Lights will be required on the control panel to give a positive indication of the open position of valves $P-4, P-5, P-6$, and $P-8$.

3) A pressure sensing element will be installed in the buffer zone between P-5 and P-6 and will be connected to a gage located so that leakage of a valve may be observed by an operator.

4) Valves $P-5$ and P-6 will be interlocked with the control rod "withdrawal permit" as a part of the reactor start-up interlock scheme. The 
rods cannot be withdrawn unless these valves are closed; the valves cannot be opened when the reactor is critical. This will prevent any unintentional draining of the superheater while the reactor is critical. Requirements for emergency isolation valve P-7 are as follows: The emergency isolation valve $P-7$ will be a quick-closing stop valve. It should close on any isolation scram signal. Valve closing time should be the same as is required for the main-steam isolation valve. Valve controls should be provided that permit closing of the valve by an operator in the control room. If leak detection equipment is installed between the containment vessel and valve $P-10$, valve $P-7$ may be required to close on a leak-detector generated signal.

Requirements for the blow-down control valve P-lo are as follows: A control system for the blow-down control valve P-l0 is required so that it may be remotely positioned at any point from shut to full open. A valve position indicator will be required for the control panel and will indicate the per cent of full stroke. The valve will be capable of automatic quick closing when certain undesirable system conditions are encountered. Conditions that will cause the valve to be closed by interlocks are: high flash-tark pressure and extremely high flash-tank water level. An operator should be able to by-pass the interlocks to permit normal procedures during start-up and shut-down.

The flash-tank control requirements are as follows:

1) Pressure will be maintained at the desired set-point by automatic control of valve P-12. The pressure sensing element will be installed in a pipe extension of the flash tank, probably in the some pipe used for the liquid level control. This pipe extends through the concrete biological shielding that houses the flash tank. 
2) Valve P-12 will be interlocked with the liquid level controller to cause it to positively shut when liquid level in the flash tank is high, regardless of pressure. A receding water level below the set-point will permit pressure control to be resumed.

3) On a pre-set high pressure in the flash tank, an inter lock feature wil! cause an alarm to sound and will cause valve $P-10$ to close.

4) A light will be provided to indicate the shut position of valve $P-12$.

5) Water level in the flash tank will normally be maintained at a set position by automatic control of valve P-46. A differential pressure control system will be used.

6) Valve P-46 should be capable of being opened or closed from the control room by an operator.

7) A level indicator should be located on the control panel. No recorder will be required.

8) Liquid level control system will incorporate the following additional safety features: a) an alarm will be required to sound at a pre-set high water level just under nozzle entrance elevation; b) an interlock will cause P-10 to quickly close at a pre-set extreme high water level; c) an independent interlock will cause $\mathrm{P}-12$ to close at the same level; d) means of by-passing both interlocks to permit continuous operation through transient start-up and shut-down stages will be provided; e) electrical contacts may be provided on the level indicator for interlock and alarm purposes.

Flash tank nozzle stop valves will be provided with electrical contacts so that the open position can be indicated by a light on the control panel. 
Steam by-pass valve $P-25$ and stop valve $P-48$ will be remotely operated stop valves. They will be interlocked so that one closes as the other opens. Their operation stiould be sequenced so that the opening valve operates sooner (faster) than the closing valve. Valve operation will consist of selecting one of two switch positions on the control panel. The positions will be designated steam to heater and steam to condenser.

Flow control requirements of conderisate and circulating water to purification coolers are as follows. The flow control valves will be actuated by thermal bulbs located in the cooler outlet or filter-inlet line. A pneumatic temperature controller-indicator will be used to maintain constant cooler outlet temperature.

A second temperature sensing element will be used to sound an alarm at a pre-set high temperature.

Two water flow meters are required in the system. One flowmeter will precede valve P-10, and the other will precede valve P-46. Both flowmeters will give a continuous indication of flow rate in the control room. No integrating or recording will be required.

Additional temperature and pressure indicators are required at various points throughout the system. The exact positions have not yet been established.

4.2.3.2. Superheater Draining. Design Status. The superheater draining system consists of the reactor water purification system (Figure 4.1.) plus a 4-inch drain line, three additional valves, and the interlocks and controls. 
During the quarter, the procedure for draining the superheater 16 was revised and expanded. The effect of equipment failure and/or human error during or prior to draining was partially evaluated.

Problems associated with maintenance of drain valves were considered, and procedures are in process of being formulated.

Superheater Draining Procedure. In formulating the superheater draining procedure, the following assumptions were made.

1) The reactor has been started-up after a normal shutdown for refueling and/or maintenance.

2) The reactor has been operating at a power level of $12 \mathrm{tmw}$ for approximately one hour, and the reactor pressure is about 100 psia saturated.

3) The temperature of the water between the bottom of the superheater and the main steam isolation valve is approximately $105^{\circ} \mathrm{F}$.

4) The purification system is being operated with the shut-down pump taking suction from the recirculation loops.

5) Two nozzles on the flash tank are open.

6) All filters and ion exchangers are operating in parallel, and the flow is assumed to be greater than $100 \mathrm{gpm}$.

7) Valves $P-5$ and $P-6$ are closed; valve $P-4$ is open. (Valves P-5 and P-6 are electrically interlocked with appropriate reactor controls so that they cannot be opened when the reactor is critical..)

8) Flash-tank steam is by-passed to the main condenser.

16 ACNP-5812,pp.36-38, 1958 
The superheater may be drained either with or without the shut-down pumps according to the following procedure.

1) The control rods are inserted to shut-down the reactor.

2) Flow to the flash tank is stopped by closing control valve

$\mathrm{P}-10$.

3). The flash tank liquid level controller is set at the lowest position. The flash tank will then drain almost completeiy if a vacuum exists in the main condenser.

4) All four nozzles on the flash tank are opened fully.

5) Valve $P-4$ is closed, and drain valves $P-5$ and $P-6$ are

opened. (These valves are interlocked so that P-4 closes before P-5 and P-6 are opened.)

6) If at least 5 minutes has elapsed since shut-down, control valve $P-10$ is opened to drain the system.

6a) If the shut-down pump is used, vaive $P-10$ is opened until a maximum flow rate of $270 \mathrm{gpm}$ is reached. The superheater is drained after about $3-i / 2$ minutes. The operator in the control room may determine that draining is complete by observing an ammeter that is connected in the circuit of the shut-down pump motor. When the current falls off and is steady, draining is complete, and the pump is stopped. Valves $P-1$ and P-2 are automatically closed through interlocks. - The operator may also determine when draining is complete by observing flow meter indications.

6b) If the shut-down pump is not used, a flow rate of about $170 \mathrm{gpm}$ may be expected when valve $\mathrm{P}-10$ is opened. The flow is a result of the presisure differential between the reactor and the main condenser. The operator may determine when diaining is complete by observing flow meter indications. Draining should be complete after about 5-1/2 minutes. 
7) Steam is allowed to blow through the drain line to the flash tank for approximately $1-1 / 2$ minutes after draining is complete.

8) The operator opens the main steam by-pass and then closes drain valves $P-5$ and $P-6$.

9) The remaining start-up procedure, in general, is as previously outlined. 17

Draining Time. Draining times with and without the shut-down pumps were calculated assuming that 950 gallons of water were to be drained and that the water between the bottom of the superheater and the main isolation valve is $105^{\circ} \mathrm{F}$. Heat transfer calculations indicate that the latter condition may be expected after a normal shut-down, i.e. When the reactor and shield pool have been maintained at $105^{\circ} \mathrm{F}$ for a number of hours. Should the temperature of the water be near or equal to the saturation temperature of the reactor water, the draining time will increase considerably. This is especially true when the shut-down pump is not used.

Unintentional. Draining. The only time the superheater is flooded and the reactor is critical, coincidentally, is during the initial phase of start-up. The maximum possible draining rate was calculated for accidental draining with the following conditions:

1) The reactor is critical and producing $12 \mathrm{tmw}$.

2) The reactor is at 100 psia saturated conditions just prior to shutting-down for draining.

3) Inter locks between valves $P-5$ and $P-6$ and the control rod "withdrawal permit" are inoperative and the valves are accidentally opened without resultant scramming of the reactor. Valve P-4 is closed.

4). The shut-down pump is operating.

17 ACNP-5812, Pp. 36,37 and 38 . 
5) Water in the main steam ! ine up to the superheater is at approximately $105^{\circ} \mathrm{F}$.

6) All flash tank nozzles are open.

7) The purification system filters and ion exchangers are operating in parallel.

8) All liquid valves including the control valves are open full. The maximum possible draining rate under these conditions is $304 \mathrm{gpm}$. Draining at this rate would empty the fuel section of the superheater in 11 seconds. If operating procedures previously outlined are followed, few of the outlined conditions should exist, and the possibility of draining at such a high rate of flow is therefore very remote.

4.2.3.4. Tests. Cotton-Wound Filter Elements. Testing of cotton-wound Fulflo filter elements was completed. The test conditions closely approximated the conditions anticipated in the Pathfinder reactor-water purification system. A simulated corrosion product, boehmite $\left(\mathrm{AL}_{2} \mathrm{O}_{3} \cdot \mathrm{H}_{2} \mathrm{O}\right)$, was used in the tests to determine various filter characteristics. Boehmite was selected for the following reasons: 1) corrosion calculations indicate that the greatest percentage of suspended corrosion products to be removed by the purification system will consist of aluminum; 2) spectrographic and X-ray diffraction analyses of corrosion products taken from the dynamic aluminum corrosion test loops (Section I.I.) show the major portion of the aluminum to be in the form of boehmite; 3) information from similar corrosion product analyses made at ANL indicate that most of the aluminum is in the form of boehmite.

Results of the cotton-wound filter tests are somewhat discouraging because of the poor load-up charactei-istiss and resulting rapid pressure-drop 
increase. The maximum mass load-up was such that at least 30 filter elements would be required for every pound of boehmite removed, assuming a maximum allowable pressure drop of 25 to 30 psi is the limiting factor. Load-up did not significantly vary with flow rates from 0.5 to $2 \mathrm{gpm} / \mathrm{element}$.

The rapid increase of pressure drop as shown in figures $4.3,4.4$, and 4.5 can be attributed to the method of filtration and the physical characteristics of the bcehmite. Dissection of used filters revealed the method of filtration to be one of surface caking with essentially no depth filtration; and the cake formed appeared to be a gelatinous, non-porous mass.

Test data was used to predict the yearly operating cost of cottonwound filters should they be used as pre- and after-filters in the reactor water purification system. Even the most conservative estimates appear high due to the low element capacity when filtering boehmite. Annual operating costs at a minimum are estimated to be $\$ 30,000$ if the filter elements are cast in concrete blocks as removed from service and shipped to the disposal site.

The problems associated with filtering large quantities of aluminum corrosion product with cotton-wound filter elements is considerable. The tests results represent a significant departure from what would be expected in a system where ferrous materials predominate. Literature surveys were made but liftle information has been found on this subject thus far. Information that has been published is in definite agreement with the test results. It was decided, however, that more reliable confirmation should be obtained before final conclusions are made. Therefore, the literature search will be continued as well as personal contacts with various organizations generating such information. Tests of other filter materials that may be more suitable are continuing. 
Micro-Klean Filters. Tests are presently in progress using MicroKlean, 5-micron rating, filters. These filters are identical in size to the fulflo filters. The type of construction is different and the elements may therefore have different filter characteristics. A comparison will be made between the Micro-Klean filters and Fulflo filters as soon as tests are complete.

Duolite 5-30. Two tests of Duol ite S-30, a phenolic resin, were completed. A flow rate of $6 \mathrm{gpm} /$ square foot was used with a 6 -inch diameter by 18-inch deep resin bed. The tests indicated the material to be completely ineffective for filtering aluminum corrosion product.

Nalcite HCR-W. Nalcite HCR-W in the 40- to 60-mesh size range was tested as a filter material. A flow rate of $6 \mathrm{gpm} / \mathrm{square}$ foot was used with a 6-inch diameter by 18 -inch deep resin bed. The moterial was very effective as a filter for the boehmite. Until break-through the resin removed almost 100 per cert of the corrosion product. The tine resin was not as sensitive to flow changes as was the larger 12- to 40-mesh resin previously tested. Load-up was considerably higher with the fine resin. 
THIS PAGE

WAS INTENTIONALLY

LEFT BLANK 


\section{INSTRUMENTATION AND CONTROLS}

\subsection{SPEC.IFICATIONS}

Preliminary specifications for the instrumentation and controls are being prepared by the architect-engineer. Several meetings were held to discuss detailed requirements. Preliminary proposals for the Pathtinder control system were received from potential suppliers.

\subsection{PENETRATIONS}

Various designs for the reactor-building electrical-cable penetrations were studied. Two of the designs are shown in Figure 5.1. Type A can be used for the control cables. Type $B$ penetrations can be used for the high voltage single conductor cables and for spares. All co-axial cables will be terminated at the vessel wall and commercially available connectors will be used to penetrate the wall.

A list of the start-up interlocks was prepared and is shown in Figure 5.2. The satety and alarm signal list is being revised to include the method of detecting and initiating the signal, the type of alarm, the effects on the system, and methods of correction.

\subsection{WATER LEVEL TESTS}

The water level test assembly was completed as shown in Figure 5.3. Tests were run to determine how well the assembly would perform during operation of the steam-separator test loop. Instruments were calibrated and checked out. Considerable trouble was experienced with air leaks at the valve connections and the reducing bushings. Some problems also arose due to the vibrations of the steam separator. loop and the turbulence of 
the air-water mixture inside the stand pipe. The fluctuations in the manometer readings were dampened out by small orifices in the connecting tubing. The instability of the liquid level indicator was solved by the use of small pressure snubbers in series with the transmitting tubing.

Several tests were run, and the data is being processed. The balance of the data will be collected during the fourth quarter of 1959 . The manometer readings for the pressure taps indicate need for more damping, and some data may therefore be retaken after this modification is made. The test report will consist of three parts: water level prediction by calculation and tests; correlation of actual and indicated water level, and applicability of test results to controlled recirculation boiling water reactors. 


\section{PLANT SAFETY ANALYSIS}

Reactor safeguards analyses and studies of plant safety are continùing as the plant design progresses. A supplement to the preliminary safeguards report was submitted to the Division of Licensing and Regulation early in July. Subsequently, meetings were held with the Hazards Evaluation Branch and the Advisory Committee on Reactor Safeguards. Review of the Safeguards Report by the AEC is continuing. 
THIS PAGE

\section{WAS INTENTIONALLY LEFT BLANK}




\section{FEASIBILITY STUDIES}

\subsection{ELIMINATION OF VAPOR CLOSURE}

The Internuclear Company experienced considerable difficulty in putting the IBM-704 code into operation, and the entire project was therefore reviewed. Internuclear was requested to study the feasibility of containment elimination using engineering judgment and hand calculations and to submit a final report. 
THIS PAGE

WAS INTENTIONALLY

LEFT BLANK 


\section{STEAM PLANT AND REACTOR AUXILIARY SYSTEMS DESIGN}

Detailed design and arrangement of the various components associated with the steam and feedwater system (Figure 8.1) is progressing in step with plant and piping layout work at Pioneer Service and Engineering Company. Preliminary specifications were written for most of the major equipment by PS\&E and were reviewed by Allis-Chalmers. Revised system piping schematic drawings were also submitted and reviewed.

The reactor safety valve and relief piping system is being analyzed to determine the required capacities, set points, blow-down limits, effect of back pressure, superheater protection, and valve maintenance.

Reactor operating procedures are being expanded to cover abnormal conditions. A procedure was established for removing reactor decay heat without using the main condenser or condensate pumps for an unlimited period beginning approximately 30 hours after shutdown. This is made possible by using the stand-by cooler of the reactor water purification system. The new procedure will permit facilitete major condenser maintenance.

Design requirements for instrumentation and interlocks for the steam plant and auxiliary systems under start-up and shut-down conditions are being prepared and will be used to write instrumentätion and control specifications. 
AVERAGE CORROSION RATE OF 800 I ALUMINUM ALLOY IN DYNAMIC TESTS

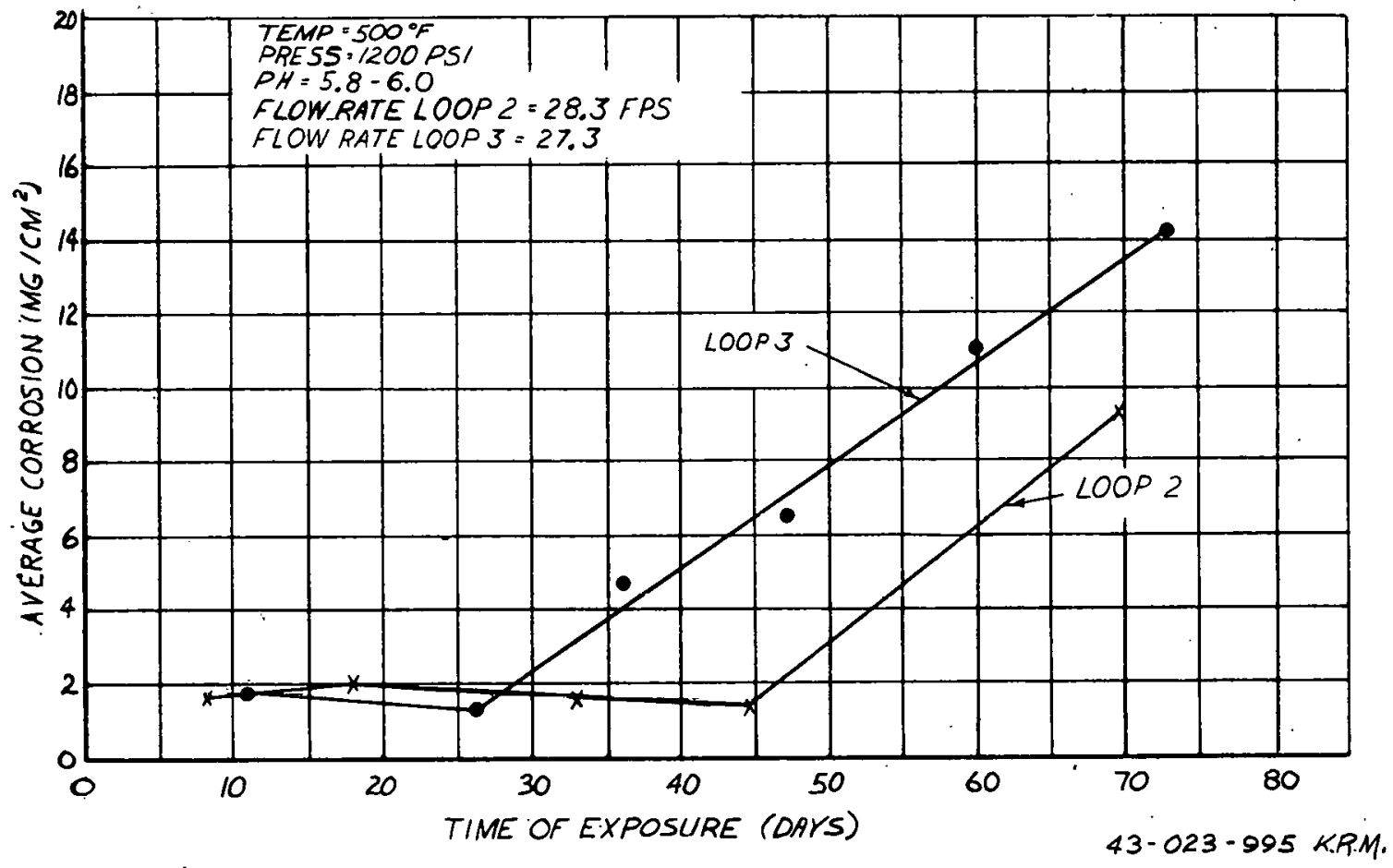

AVERAGE CORROSION RATE OF 800 I ALUMINUM ALLOY IN STATIC TESTS

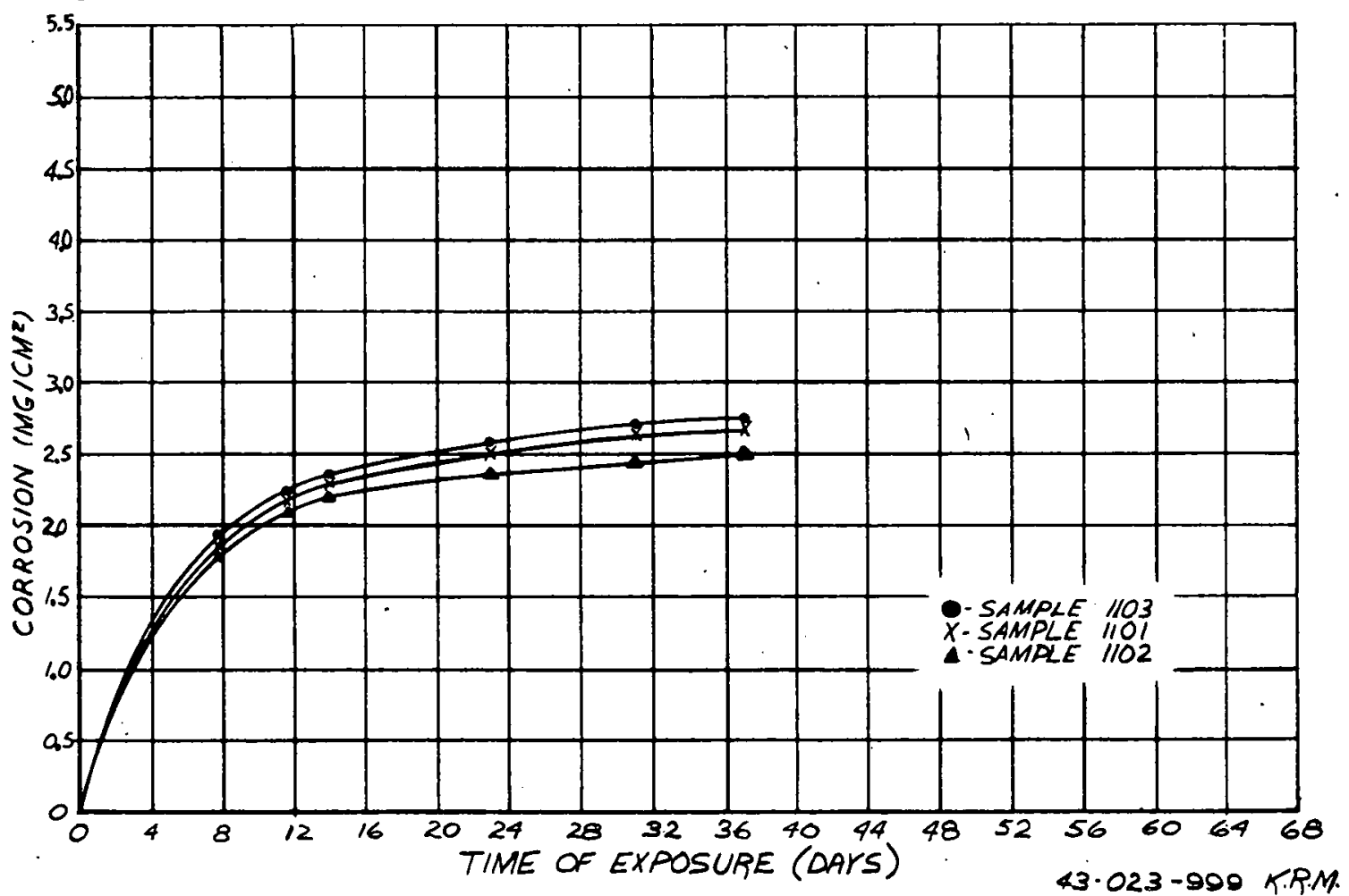

Figs. $1.1 \& 1.2$ 


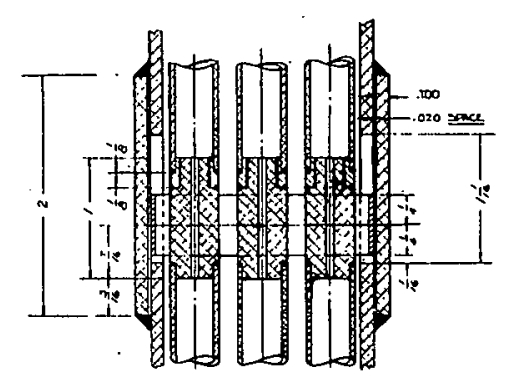

$\frac{\text { SECTION } C \cdot C \text {. }}{\text { SAIE } 2+12}$

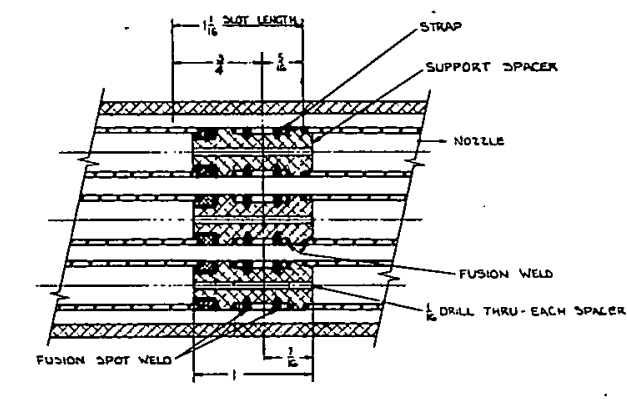

$\frac{\text { SECTION } B-B \text { : }}{\text { SCANE } 2 \cdot 1 \cdot 2}$

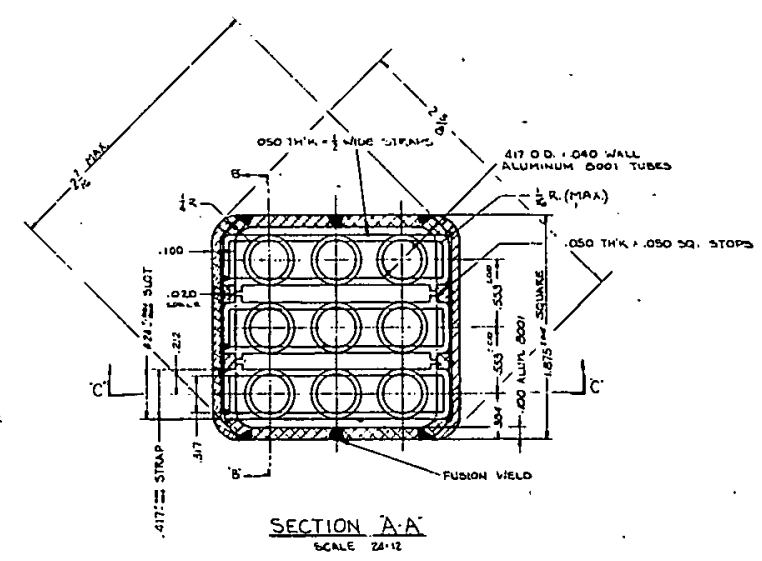

$\frac{\text { SECTION }}{\text { SCAEE }} \frac{A \cdot A}{2 \cdot 12}$

\&

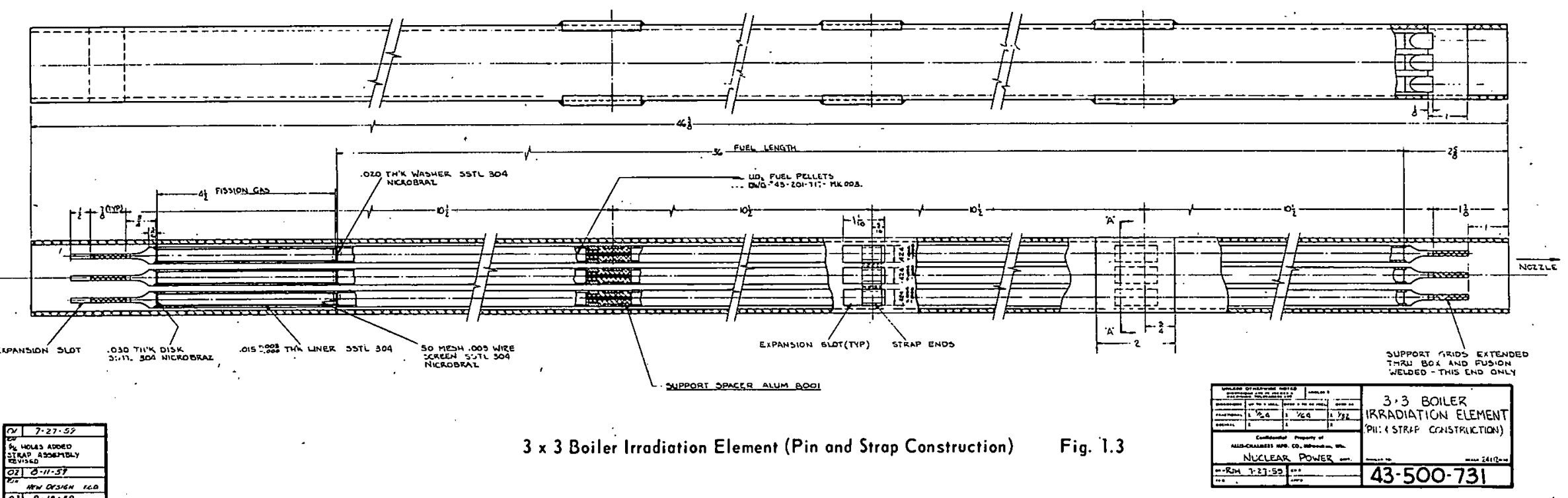



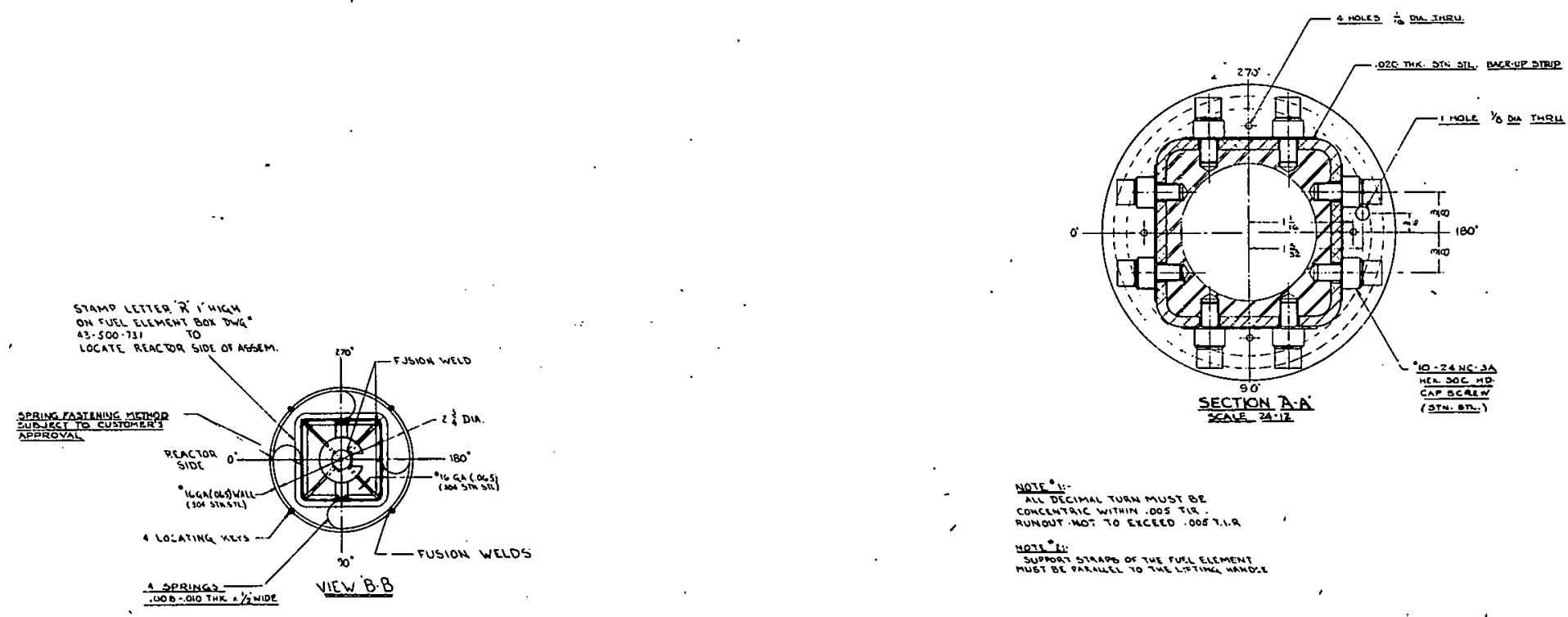

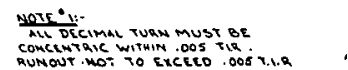

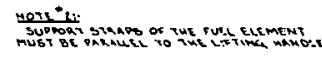

$\$$

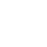
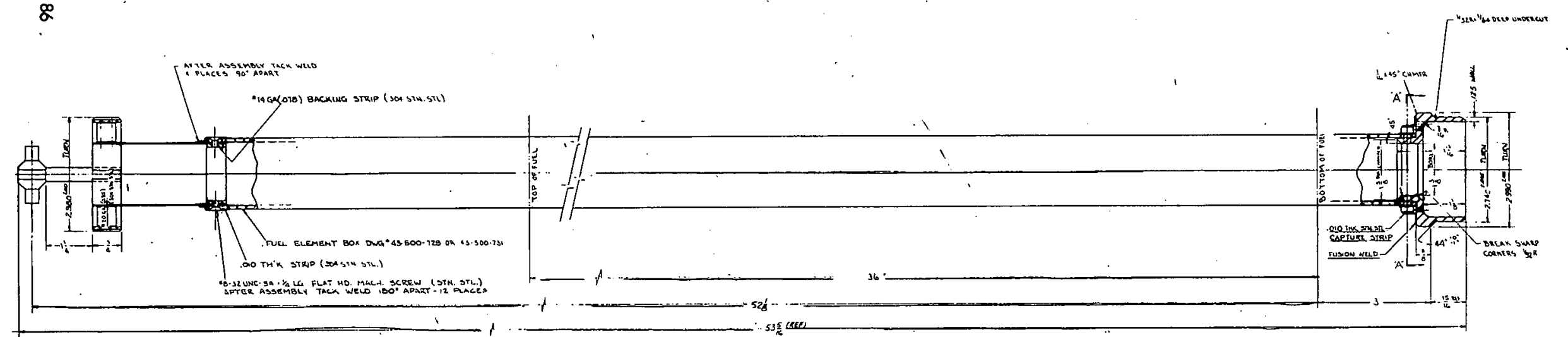

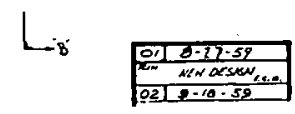

Boiler Irradiation Assembly

Fig. 1.4

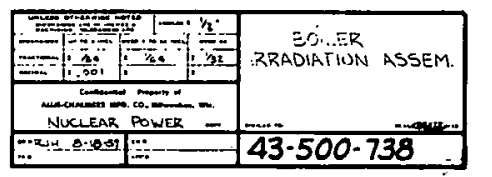




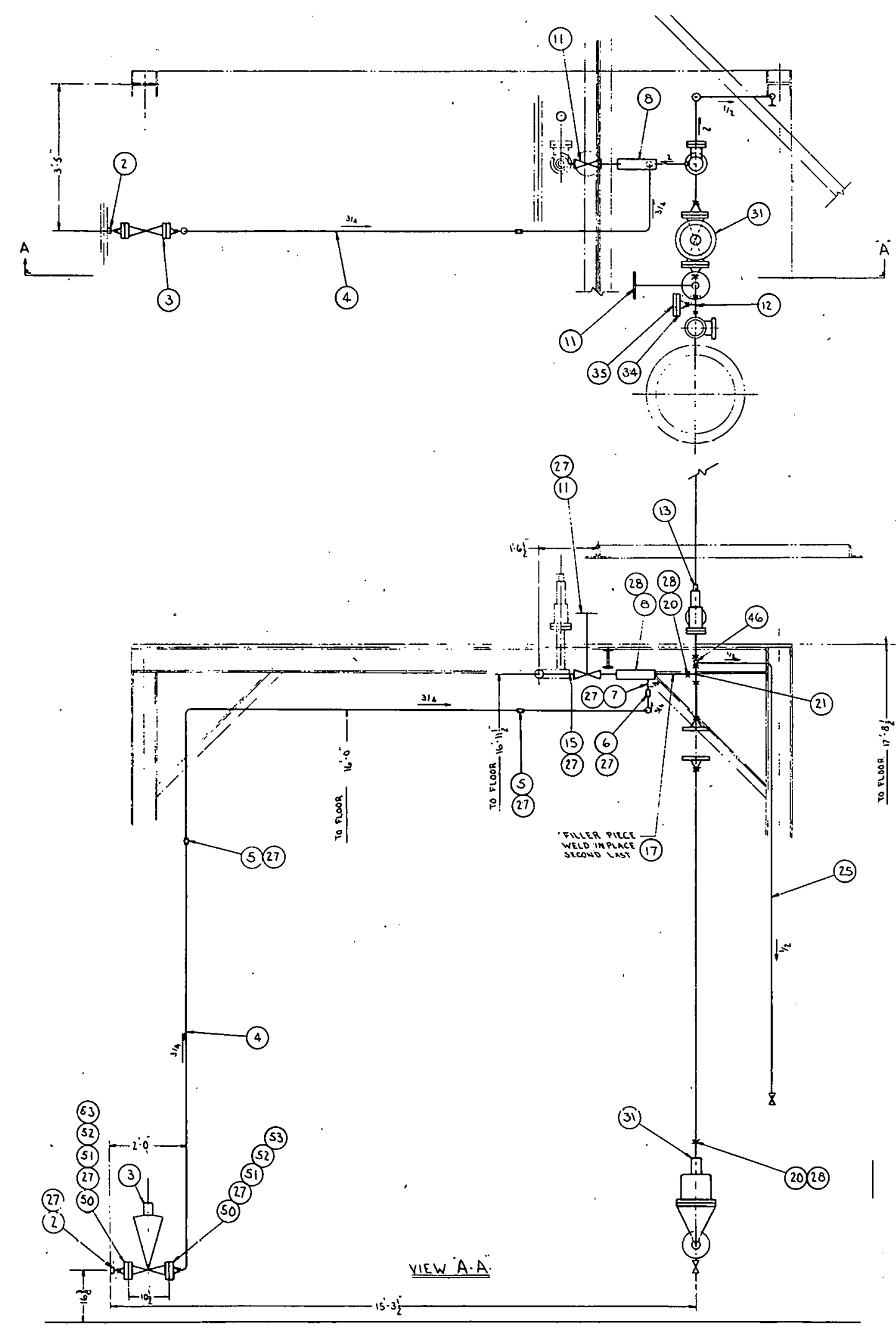

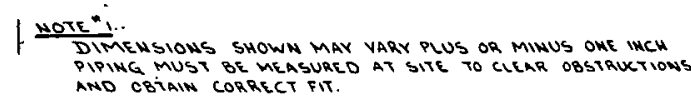

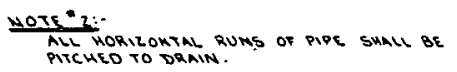

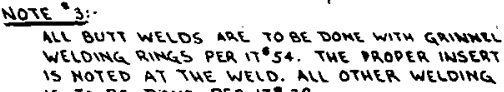

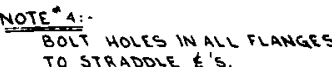
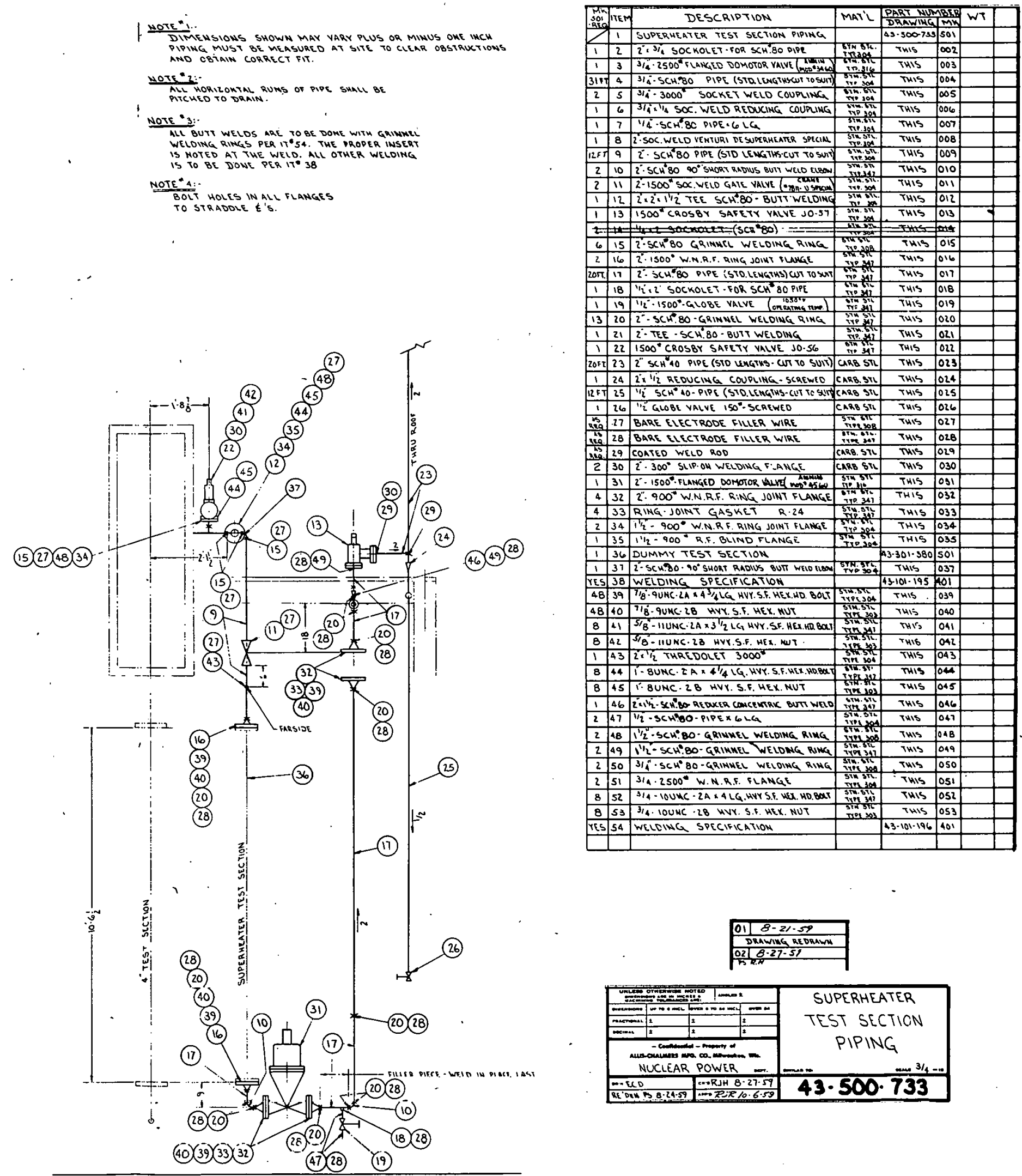

Superheater Test Section. Piping

Fig. 1.5

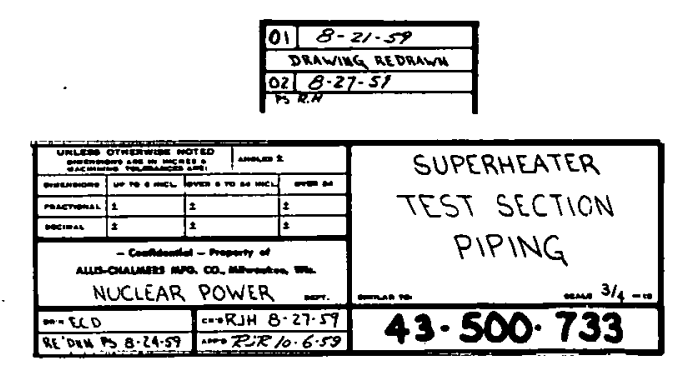

87 
10.8.

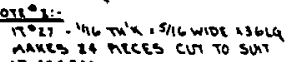

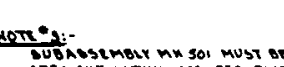

tont

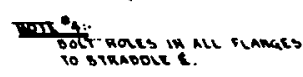

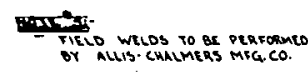

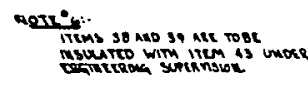
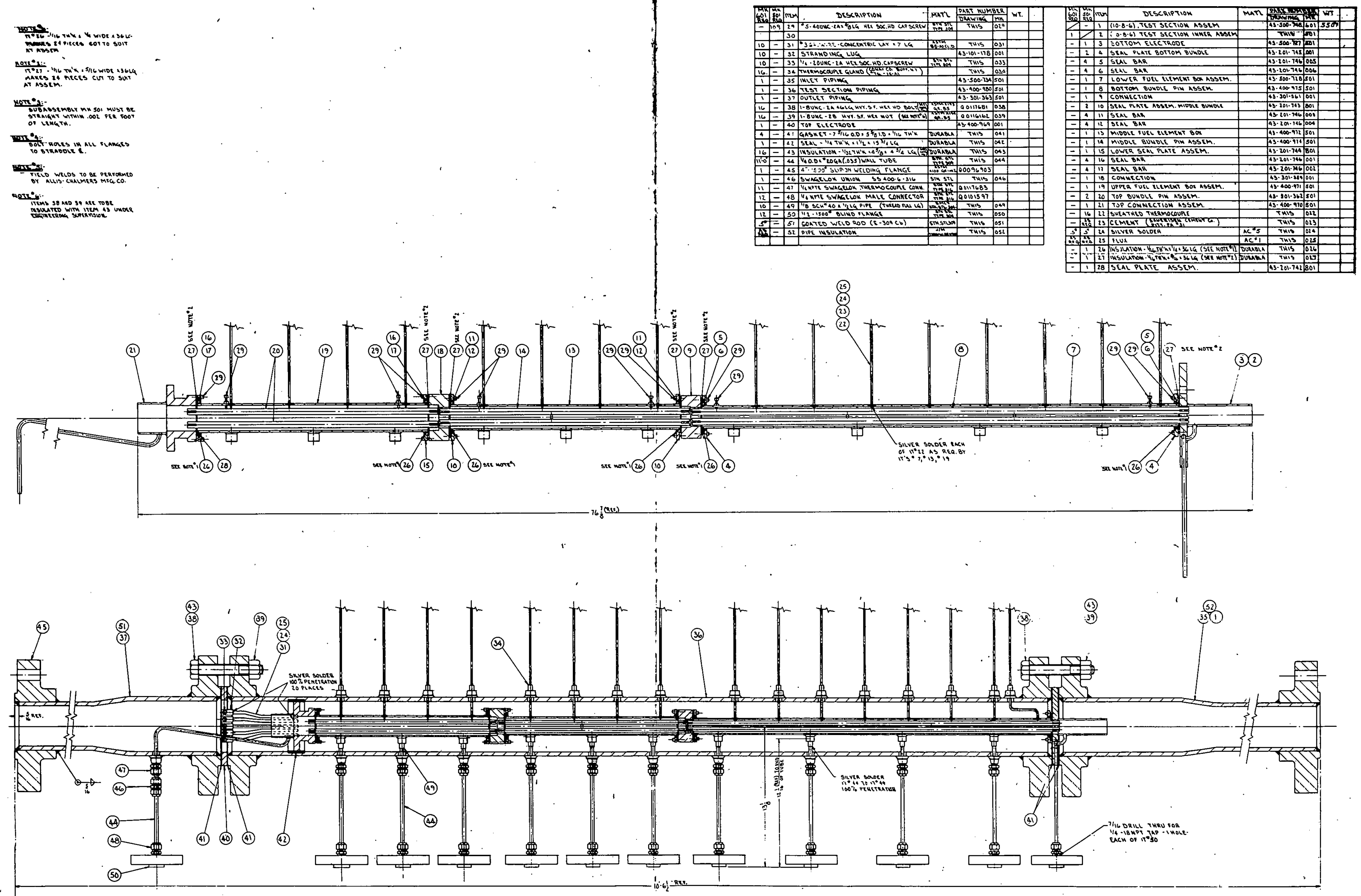

10-8-6 Pin Test Section Assembly ${ }^{\prime} \quad$ Fig. 1.6 


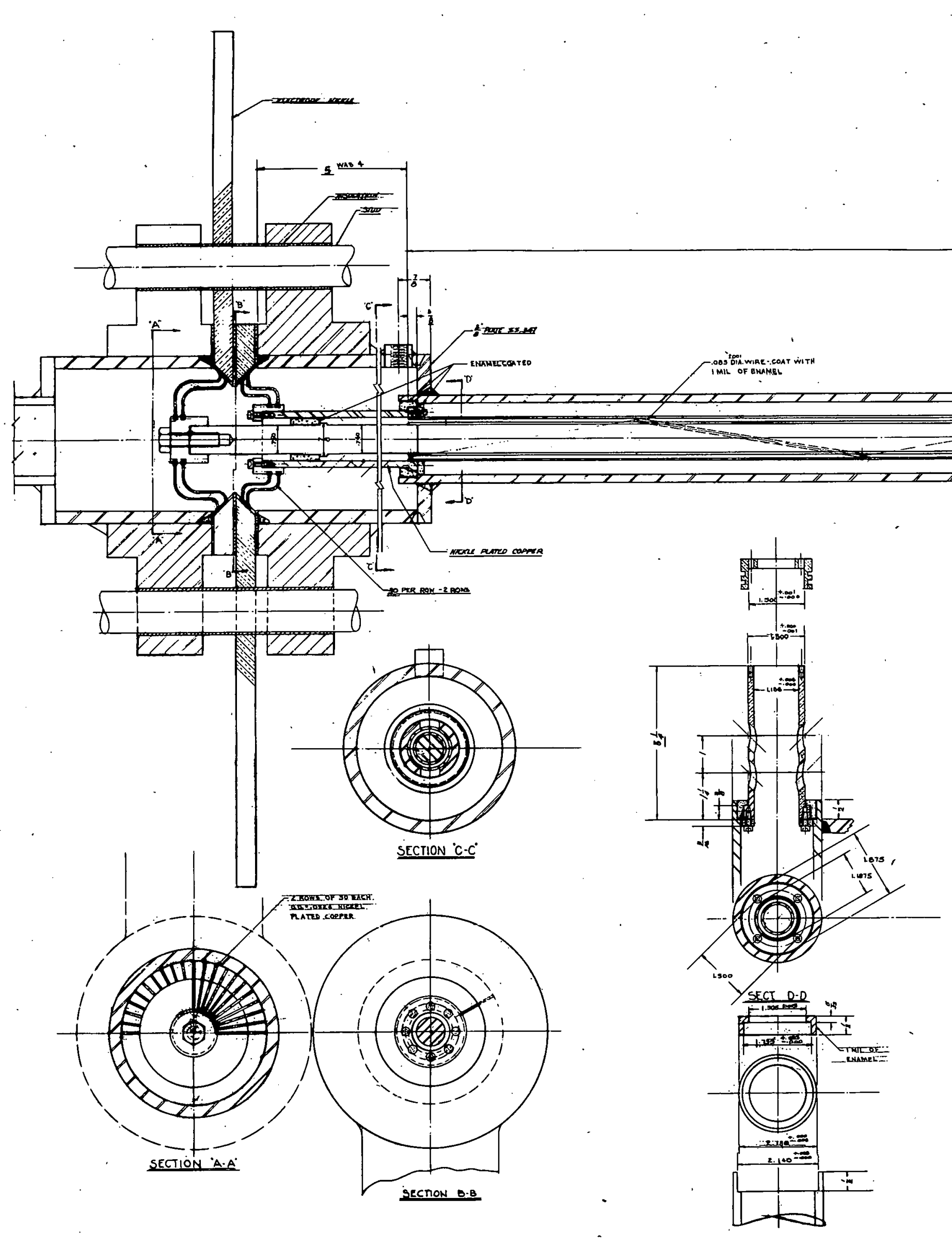

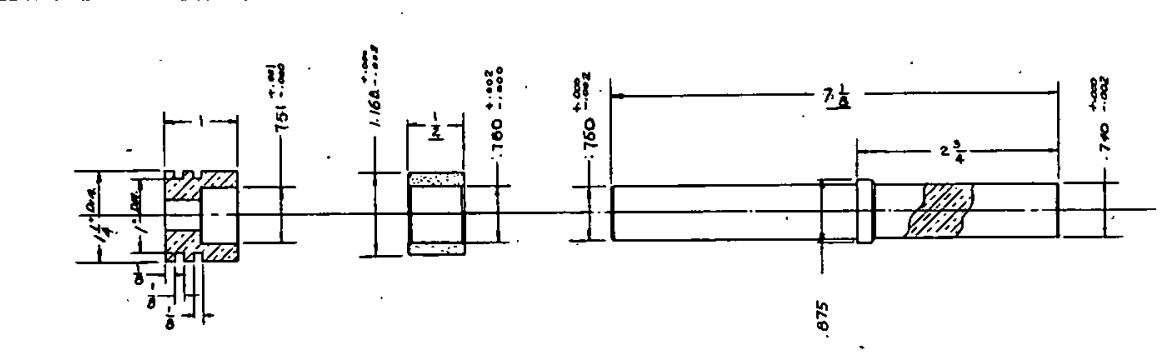

.
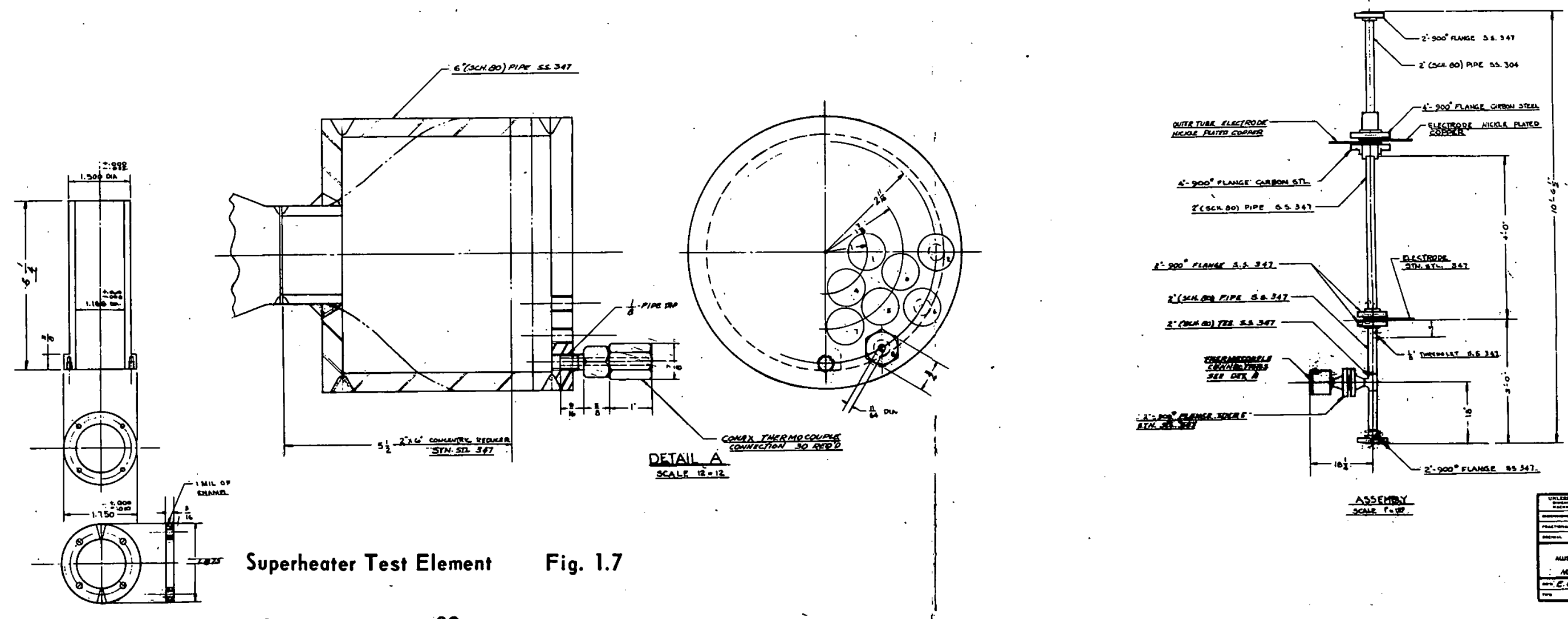

每senar

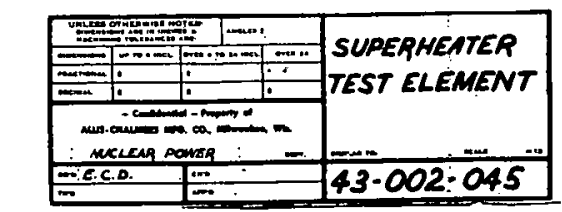


THIS PAGE

\section{WAS INTENTIONALLY LEFT BLANK}


HEAT BALANCE

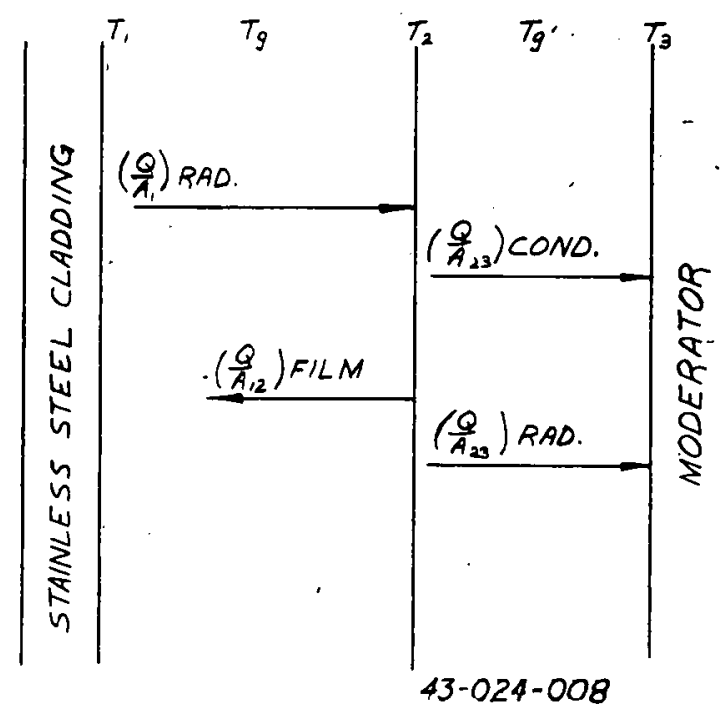

HEAT LOSS TO MODERATOR

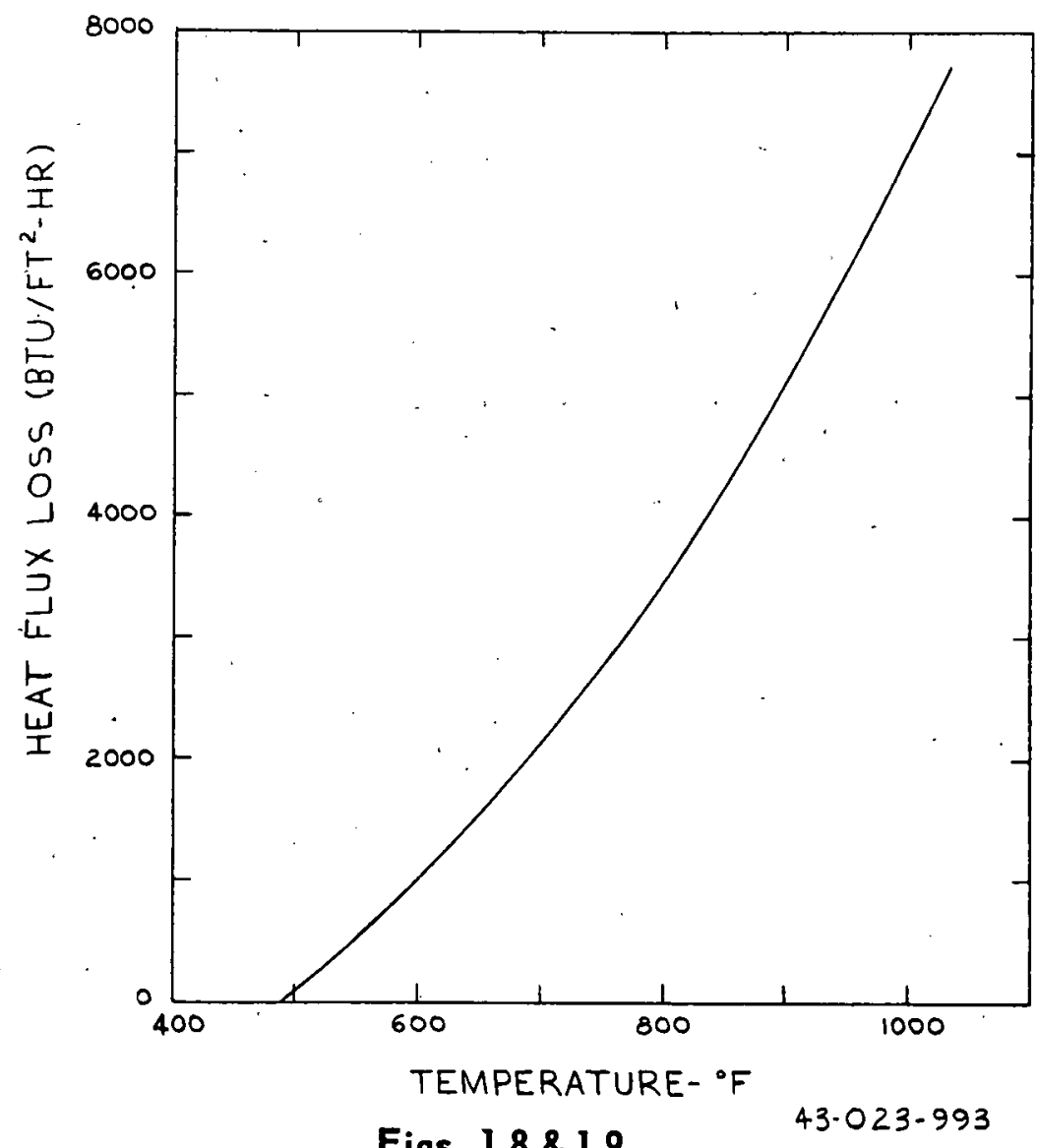

Figs. 1.8 \& 1.9 


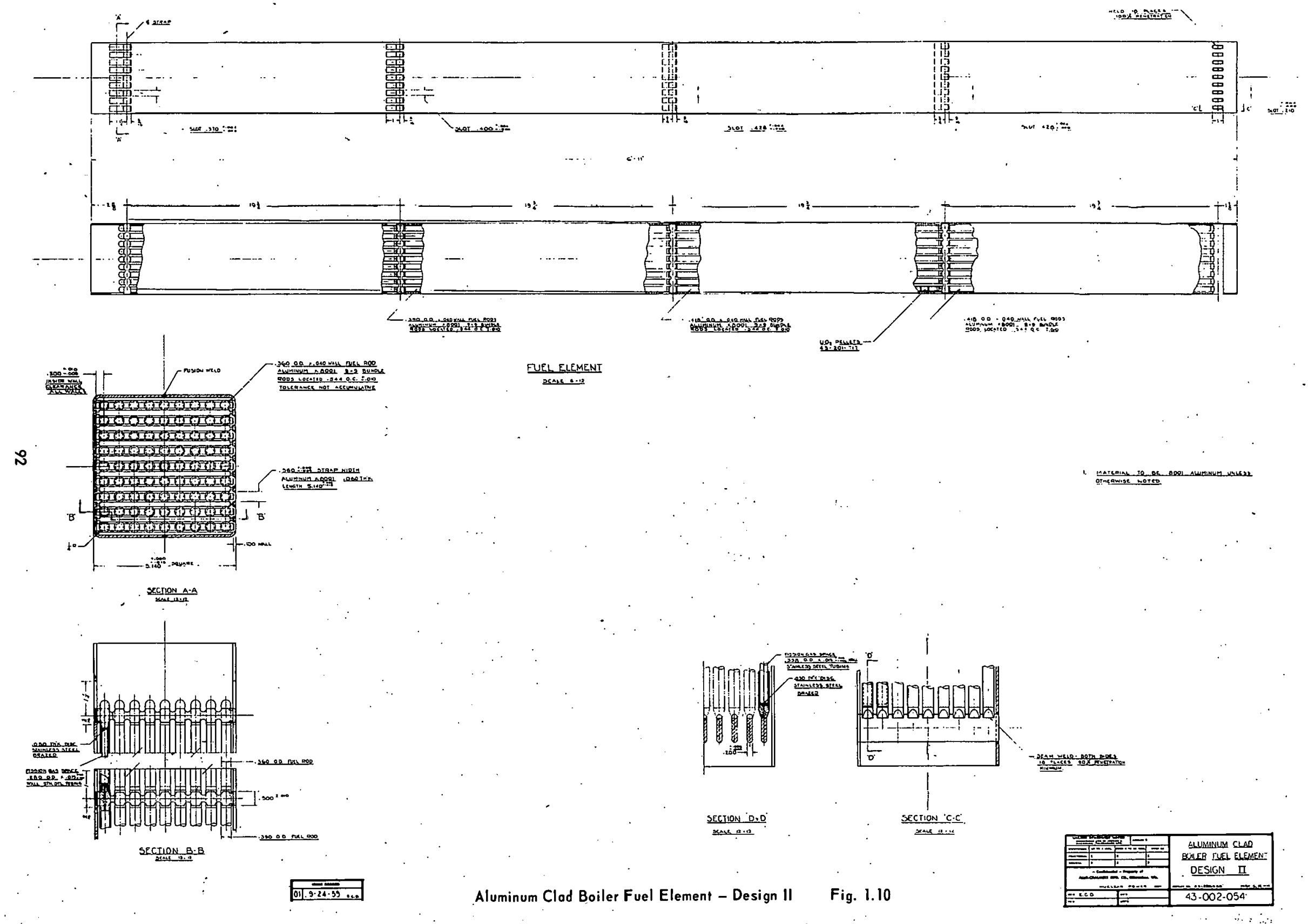



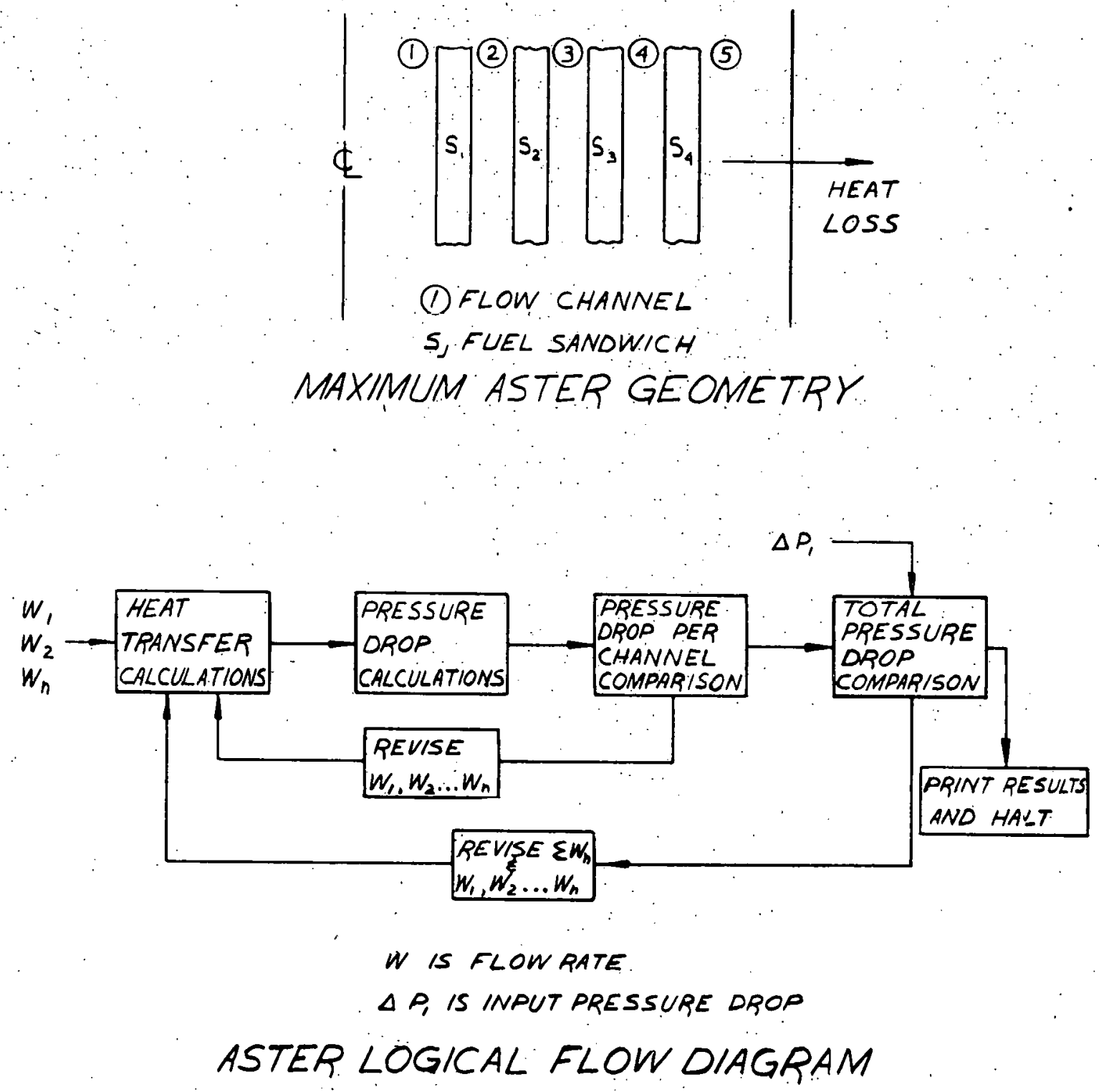

43-024-007 K.R.M

Figs. $1.11 \& 1.12$ 

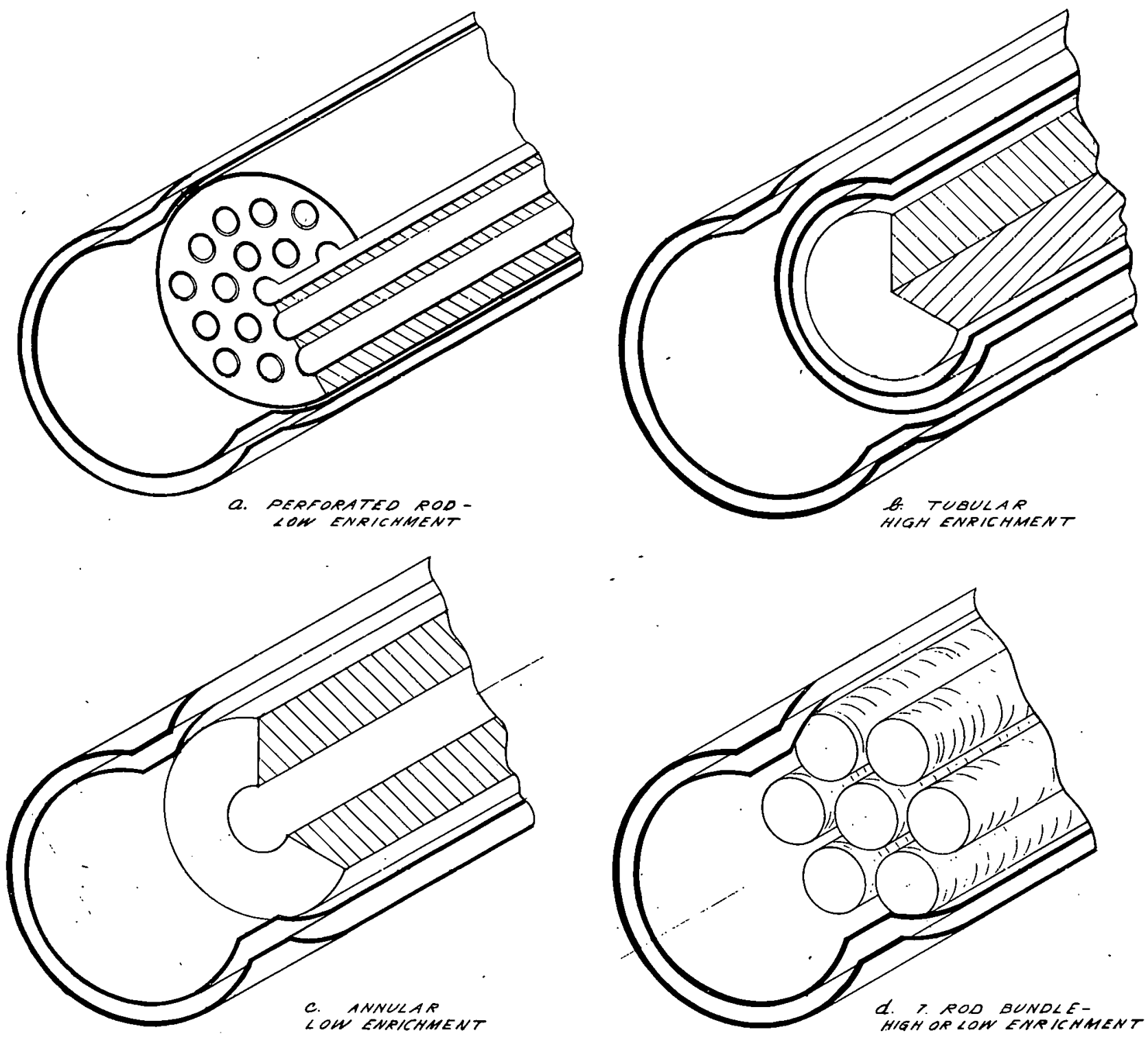

Superheater Element Concept Fig. 1.13

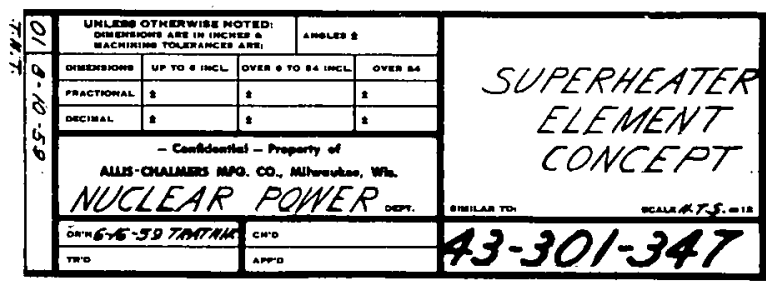




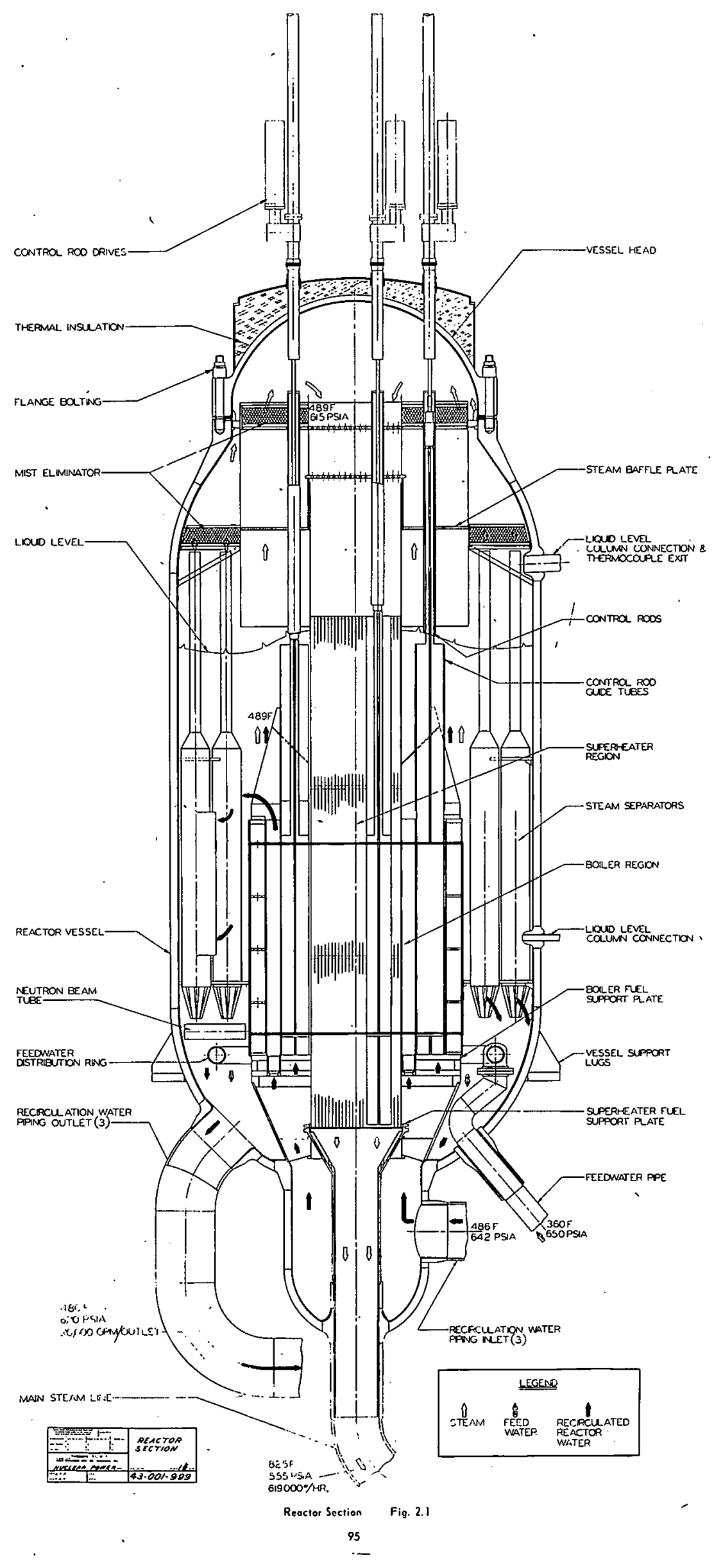




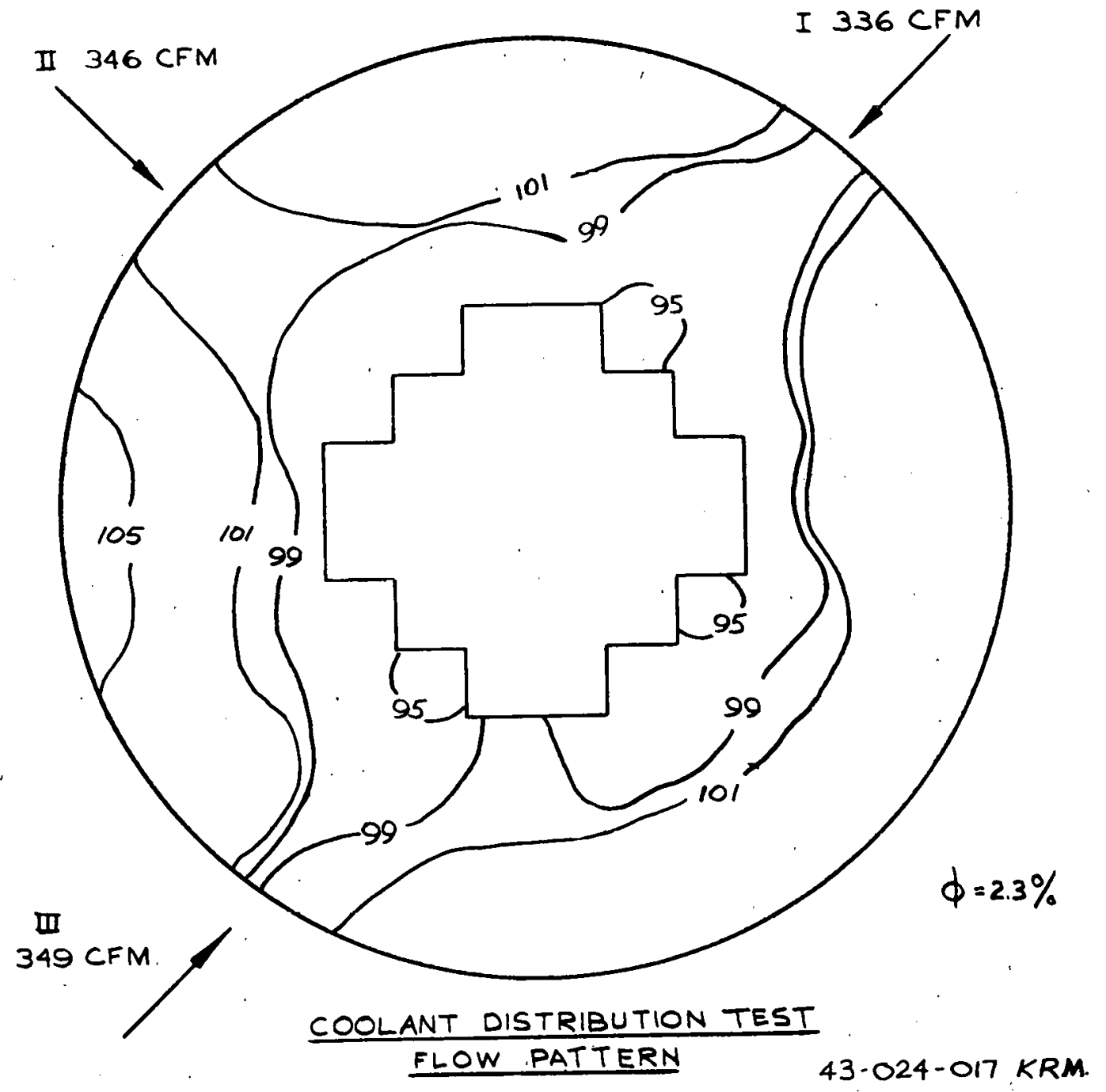

Typical Flow Distribution Pattern Through Grid Plate

Fig. 2.2 

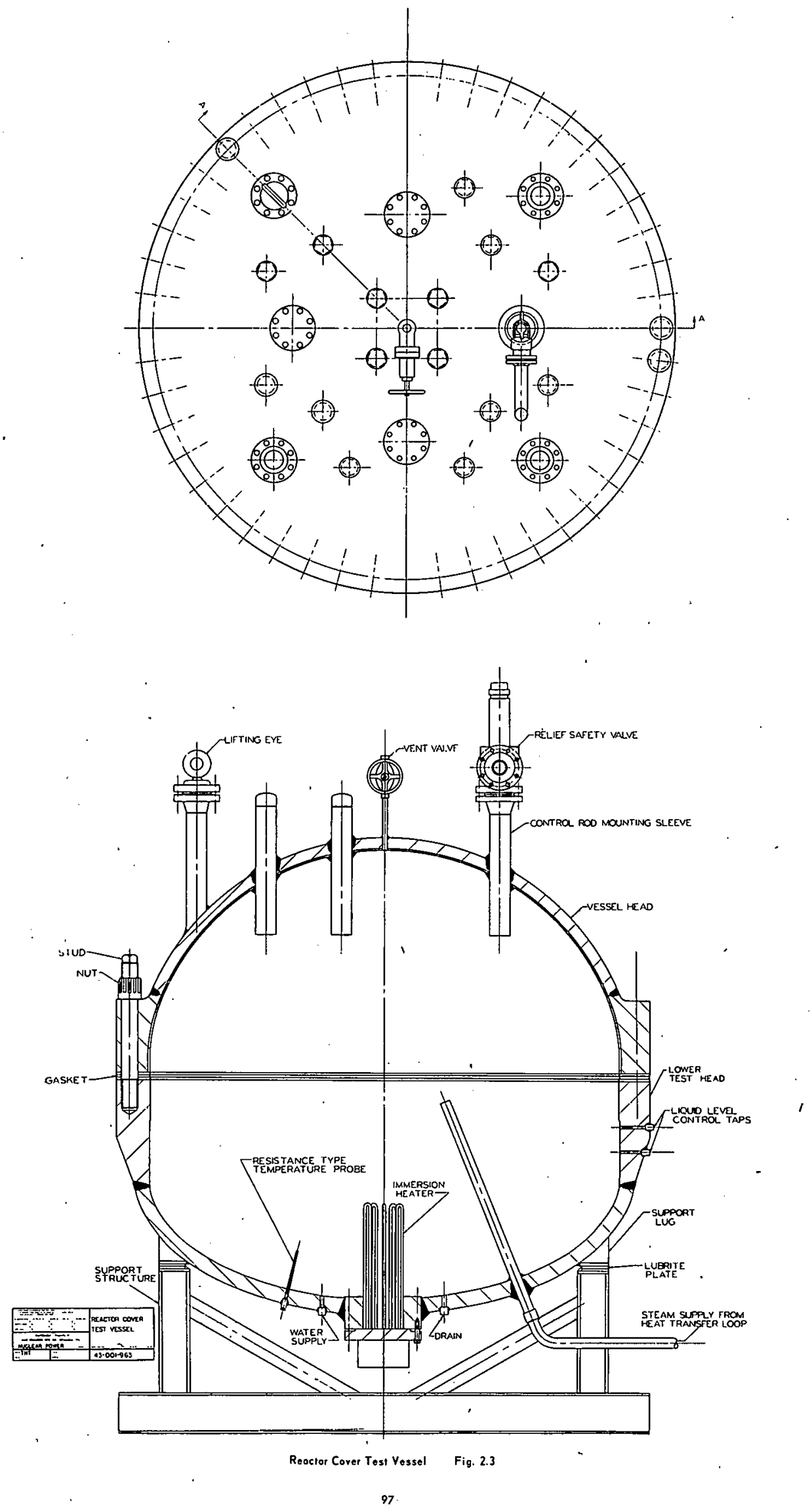


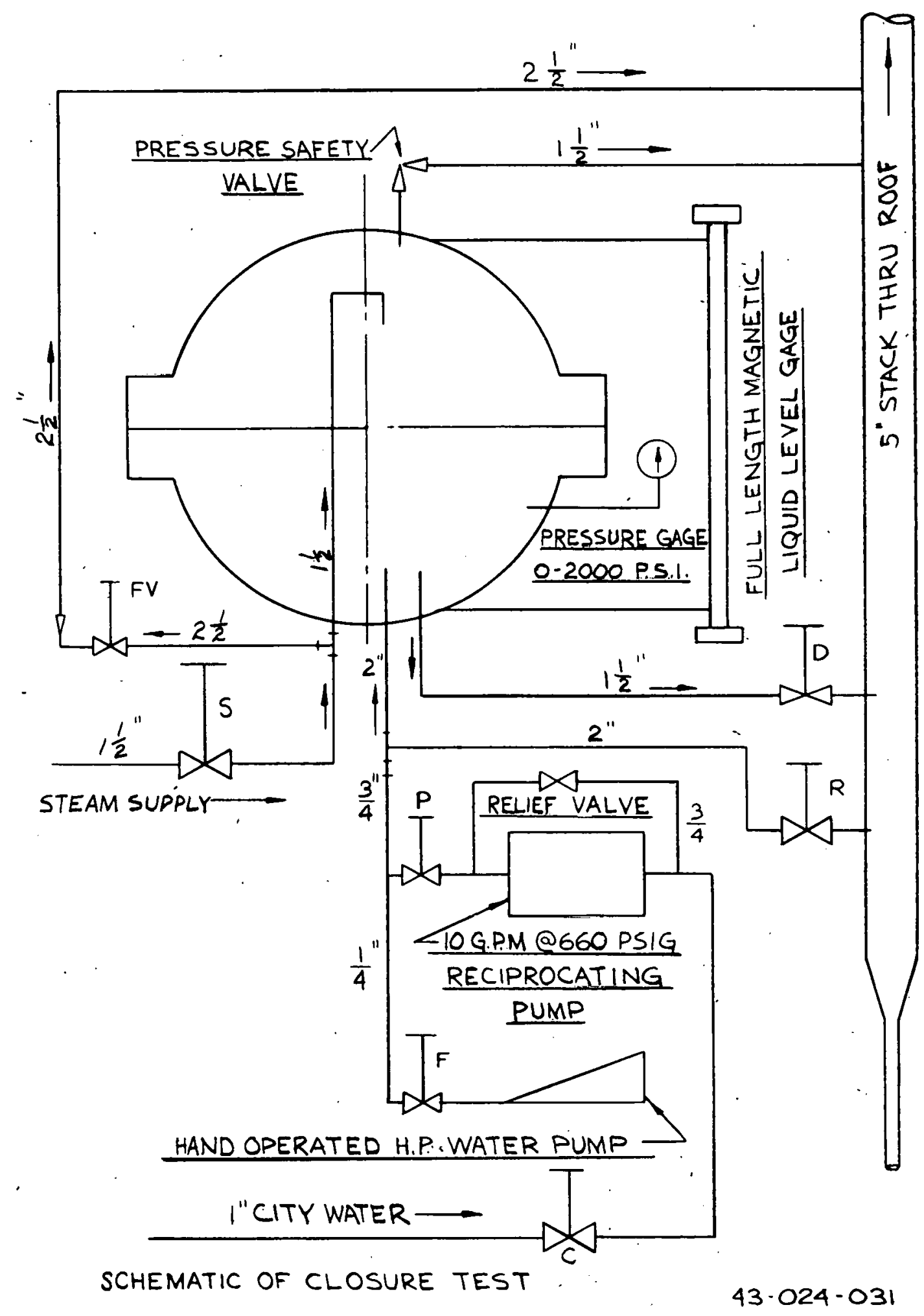

Schematic of Closure Test Fig. 2.4 
Full Scale Closure Test

- Upper Head Tack Weld
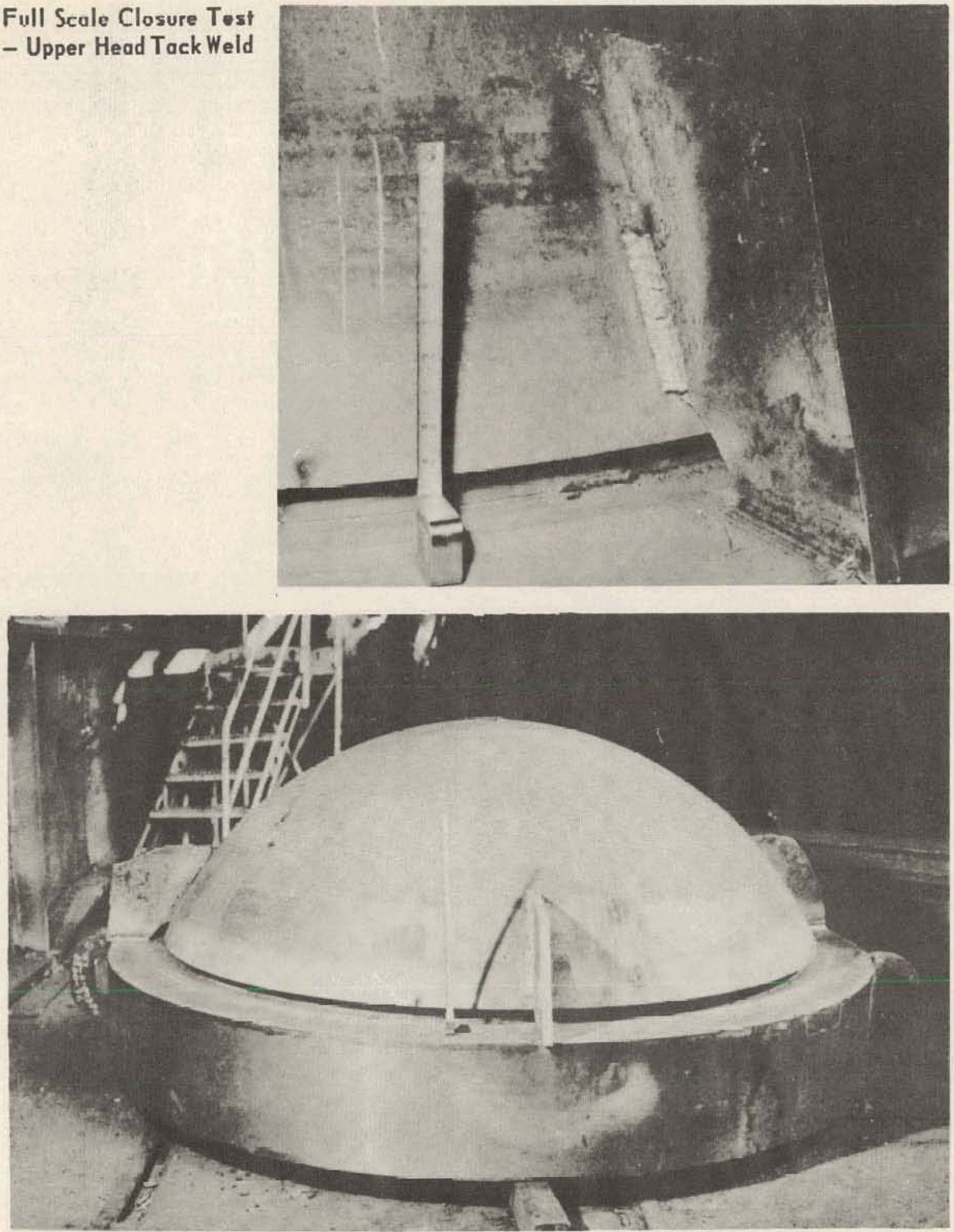

Full Scale Closure Test - Upper Head With Initial Tack Welds

Figs. $2.5 \& 2.6$ 


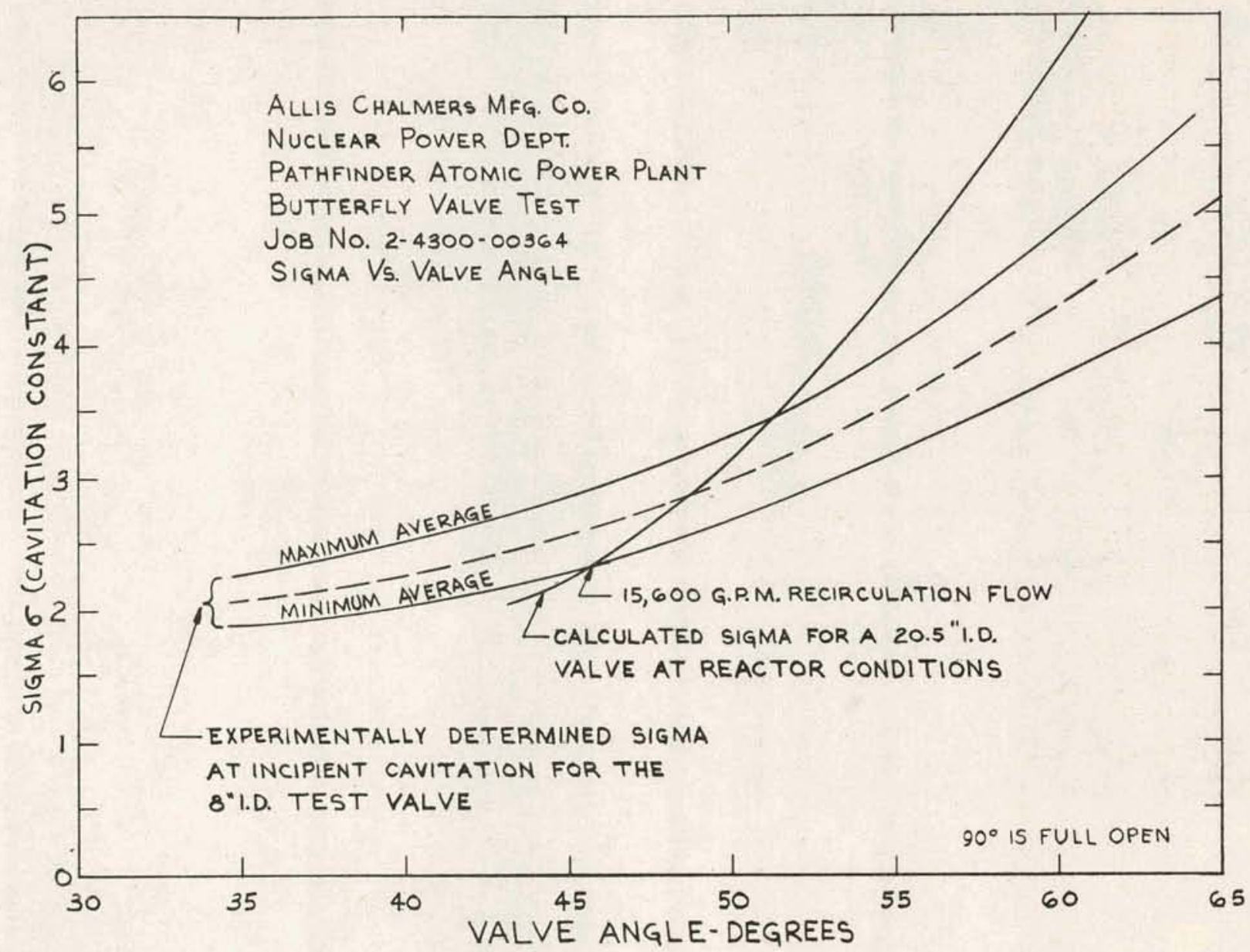

Butterfly Valve Test - Sigma vs Valve Angle

Fig. 2.7

43-023-984 


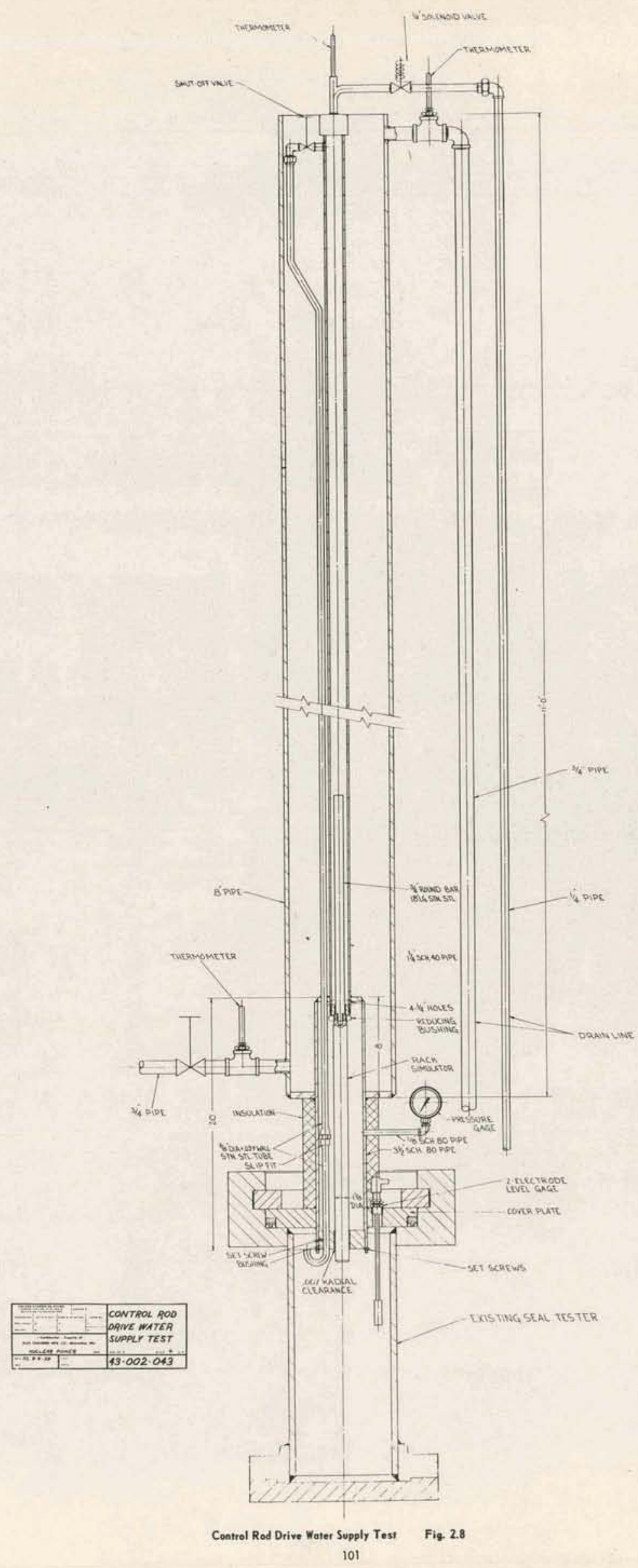




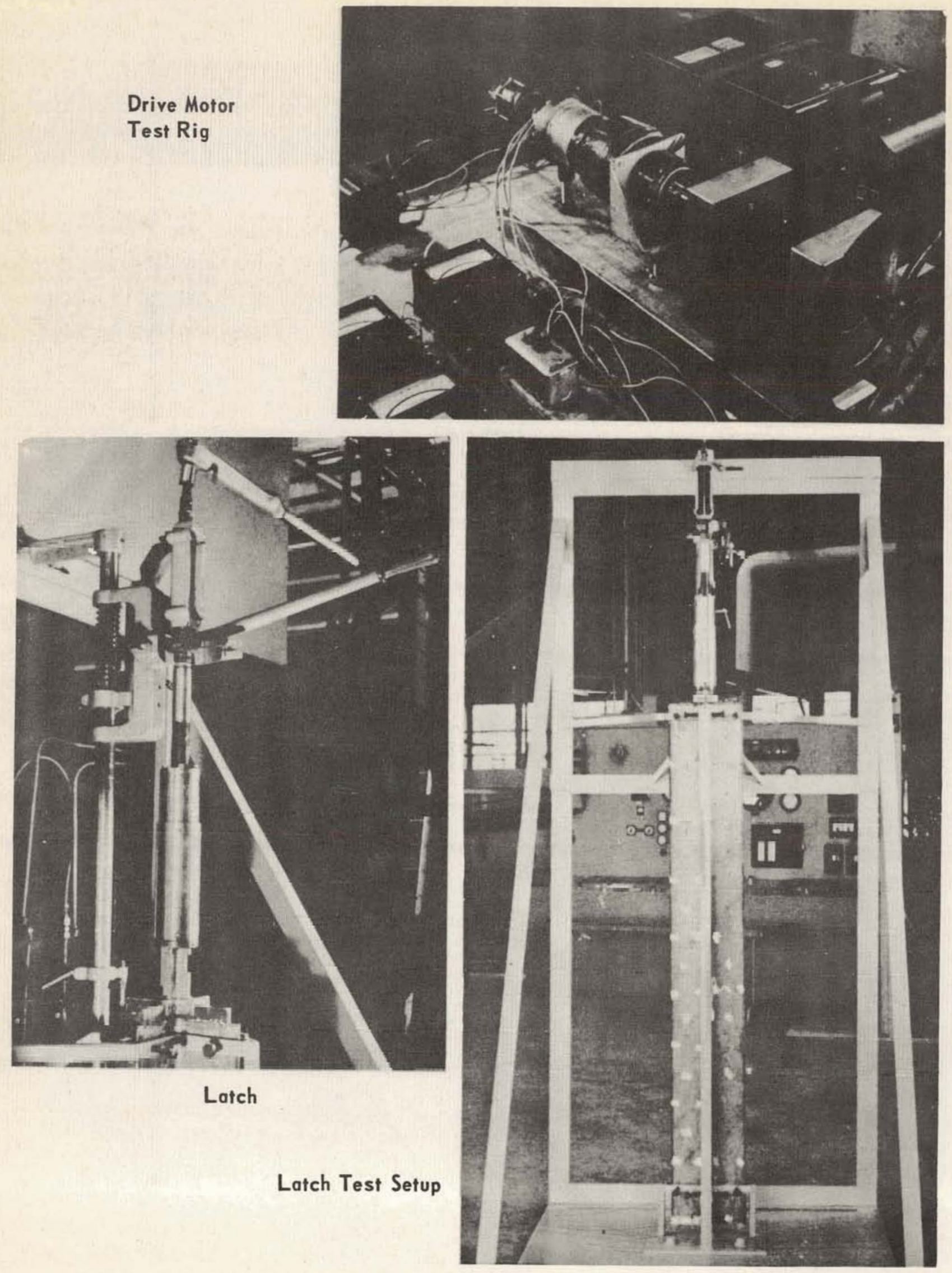

Figs. $2.9-2.11$ 

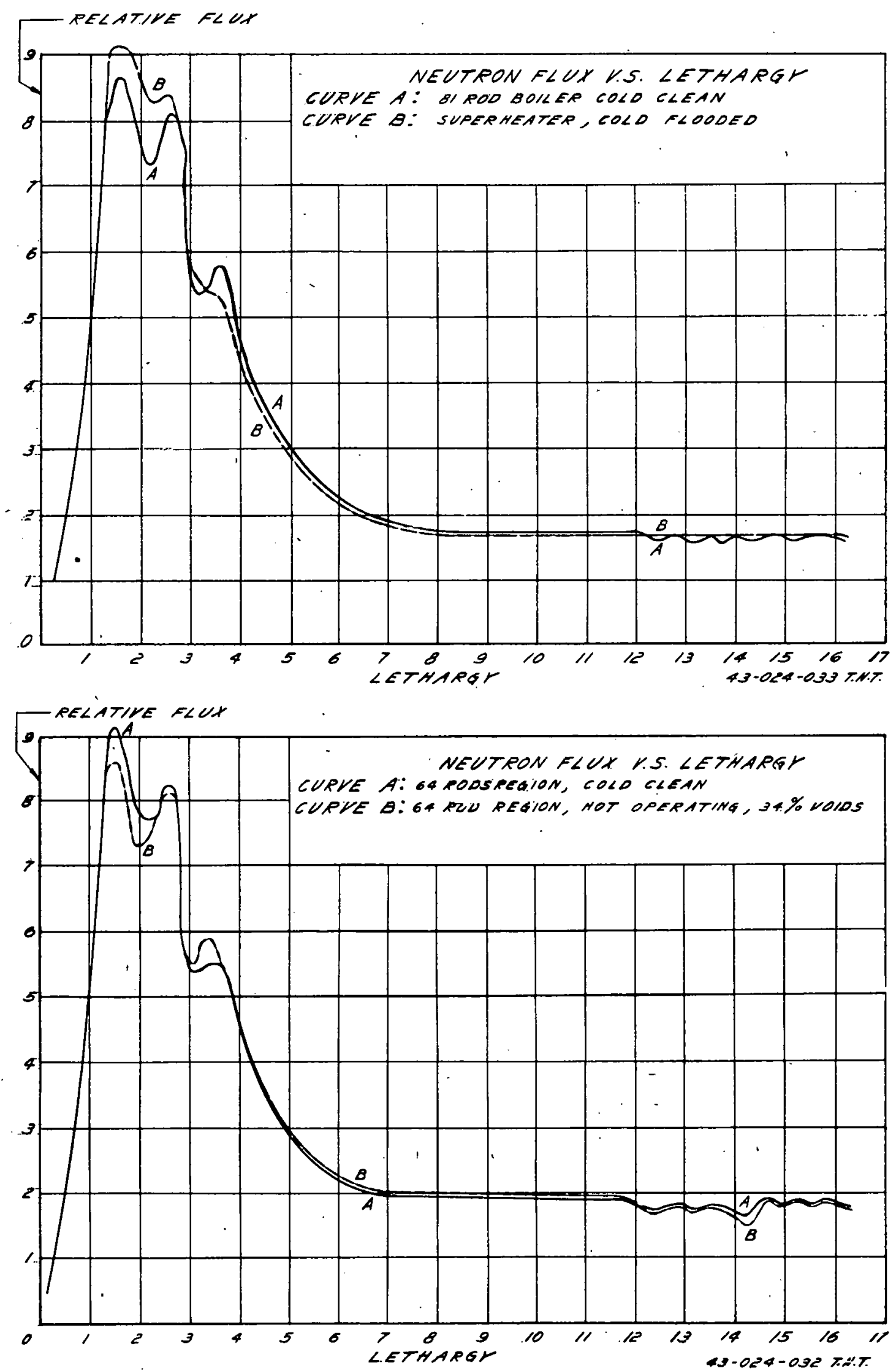

Figs. $3.1 \& 3.2$ 


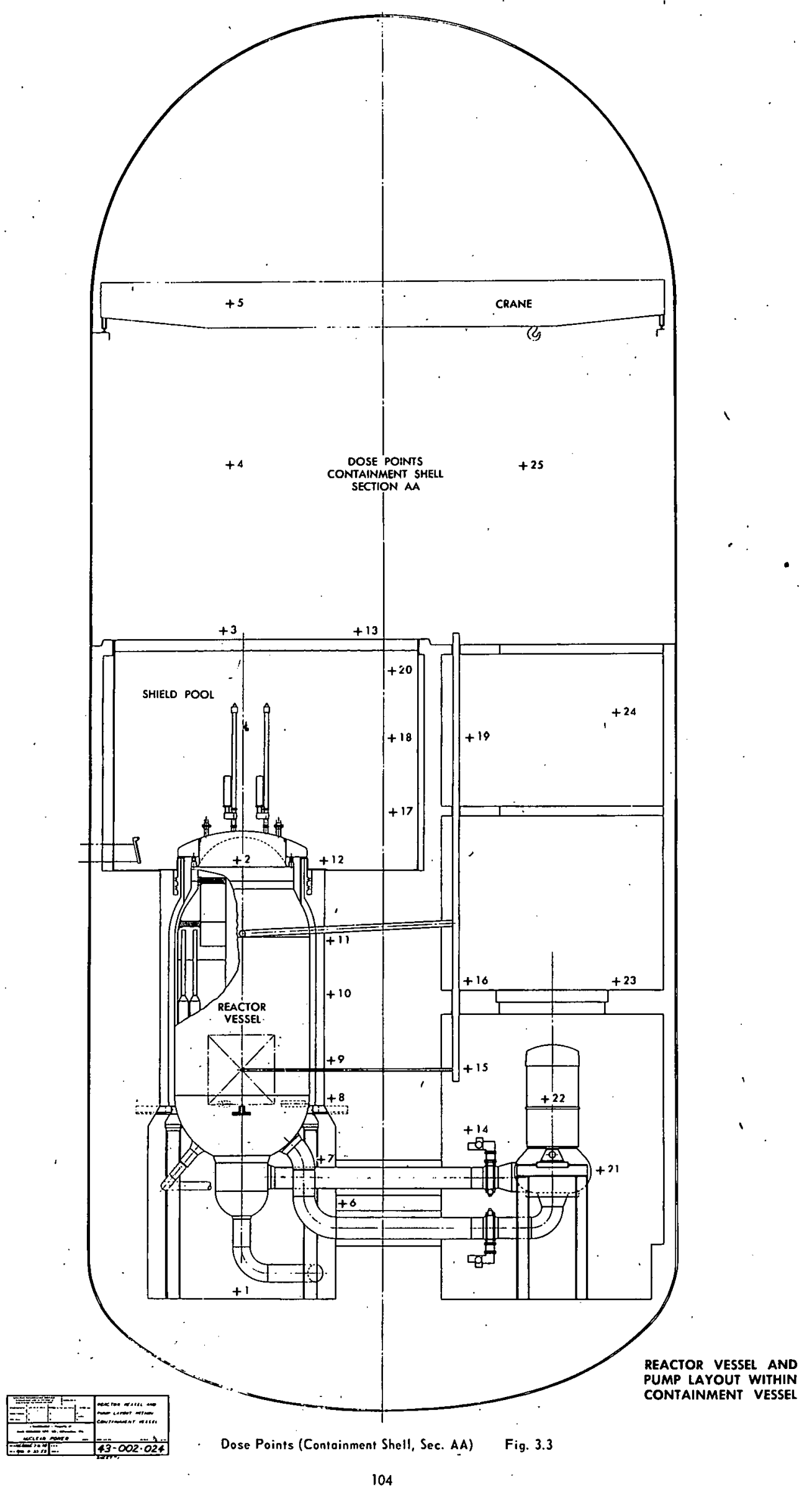




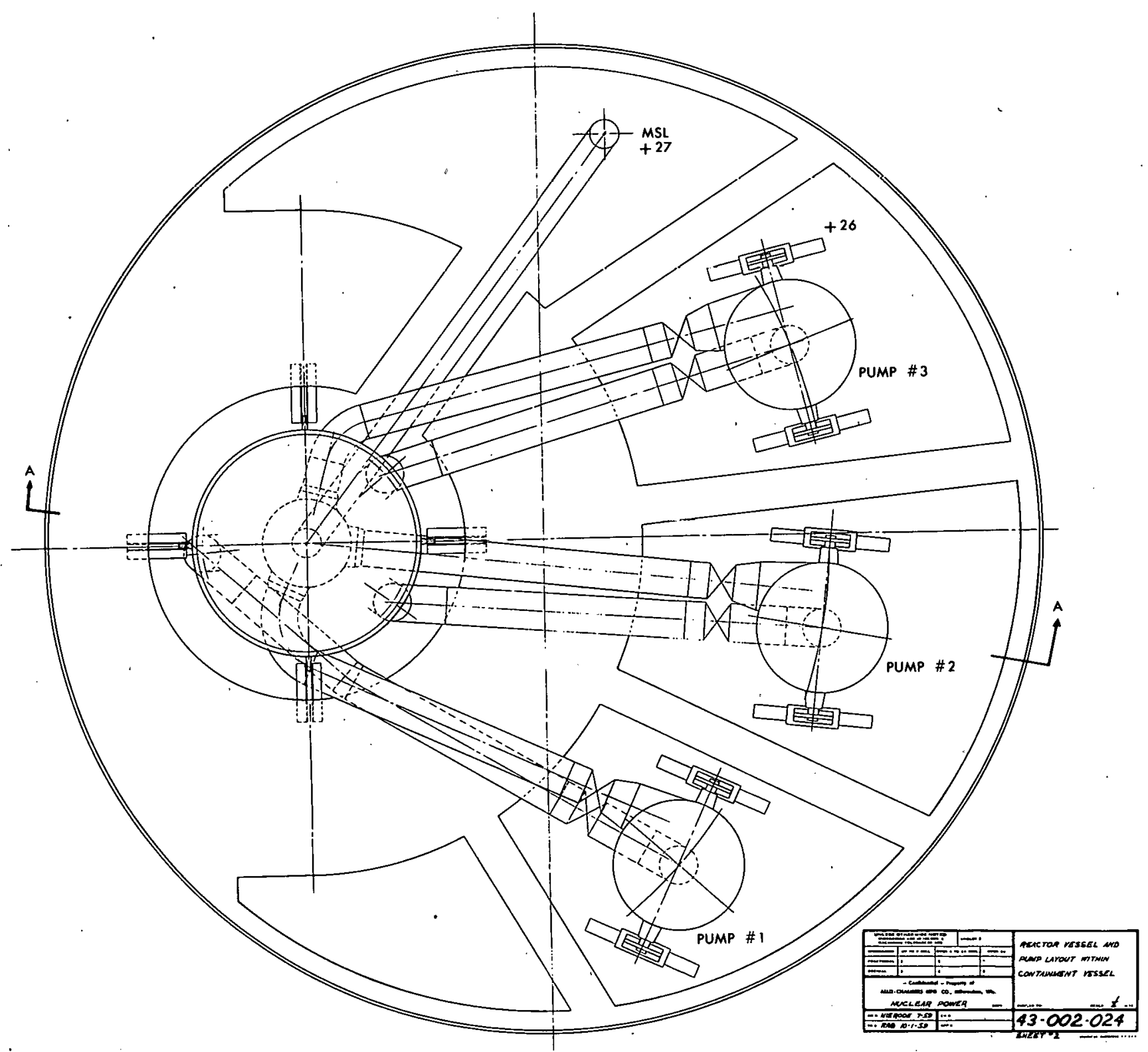

Dose Points (Recirculation Pump Floor Containment Shell)

Fig. 3.4 

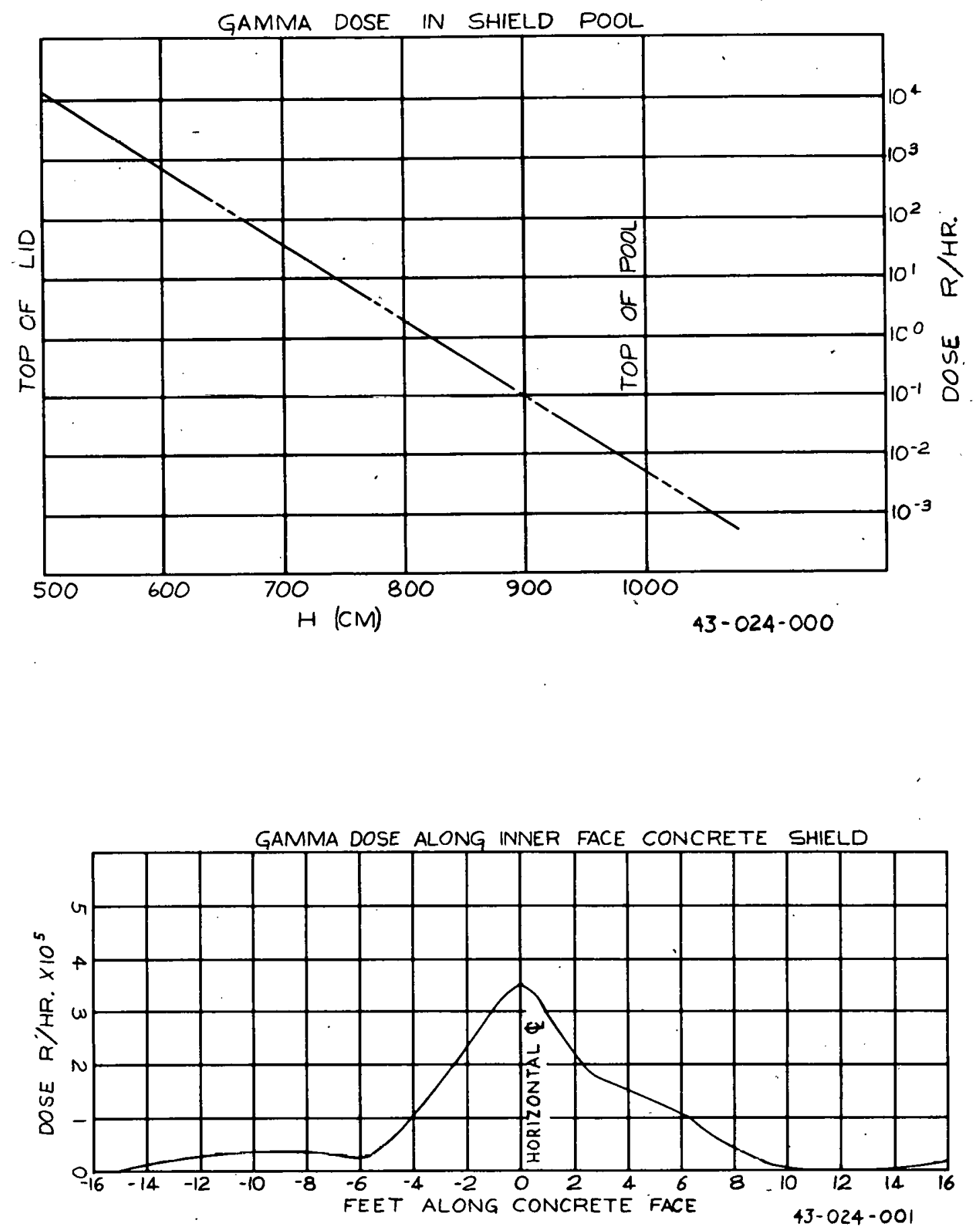

Figs. $3.5 \& 3.6$ 

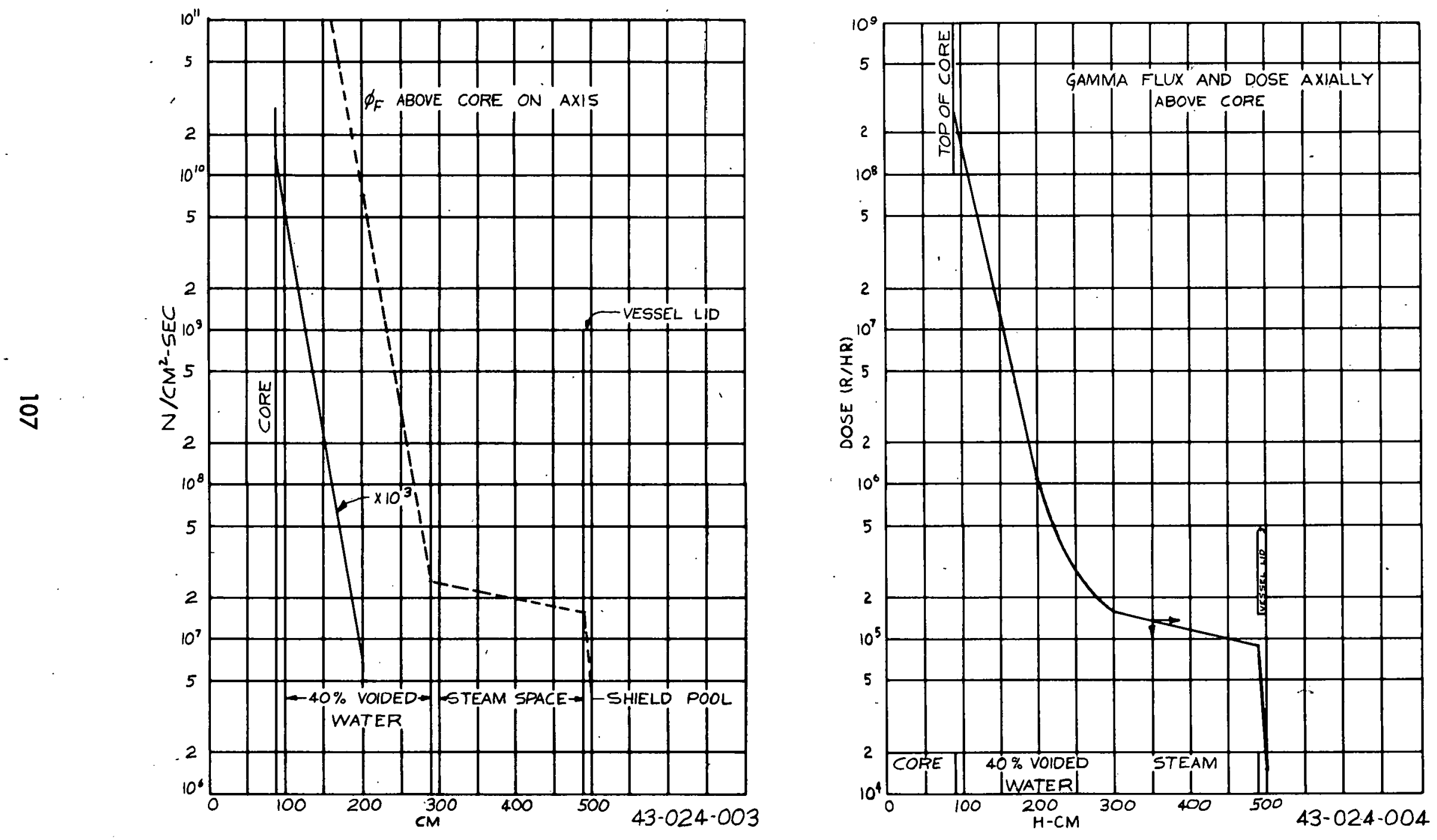

Figs. $3.7 \& 3.8$ 


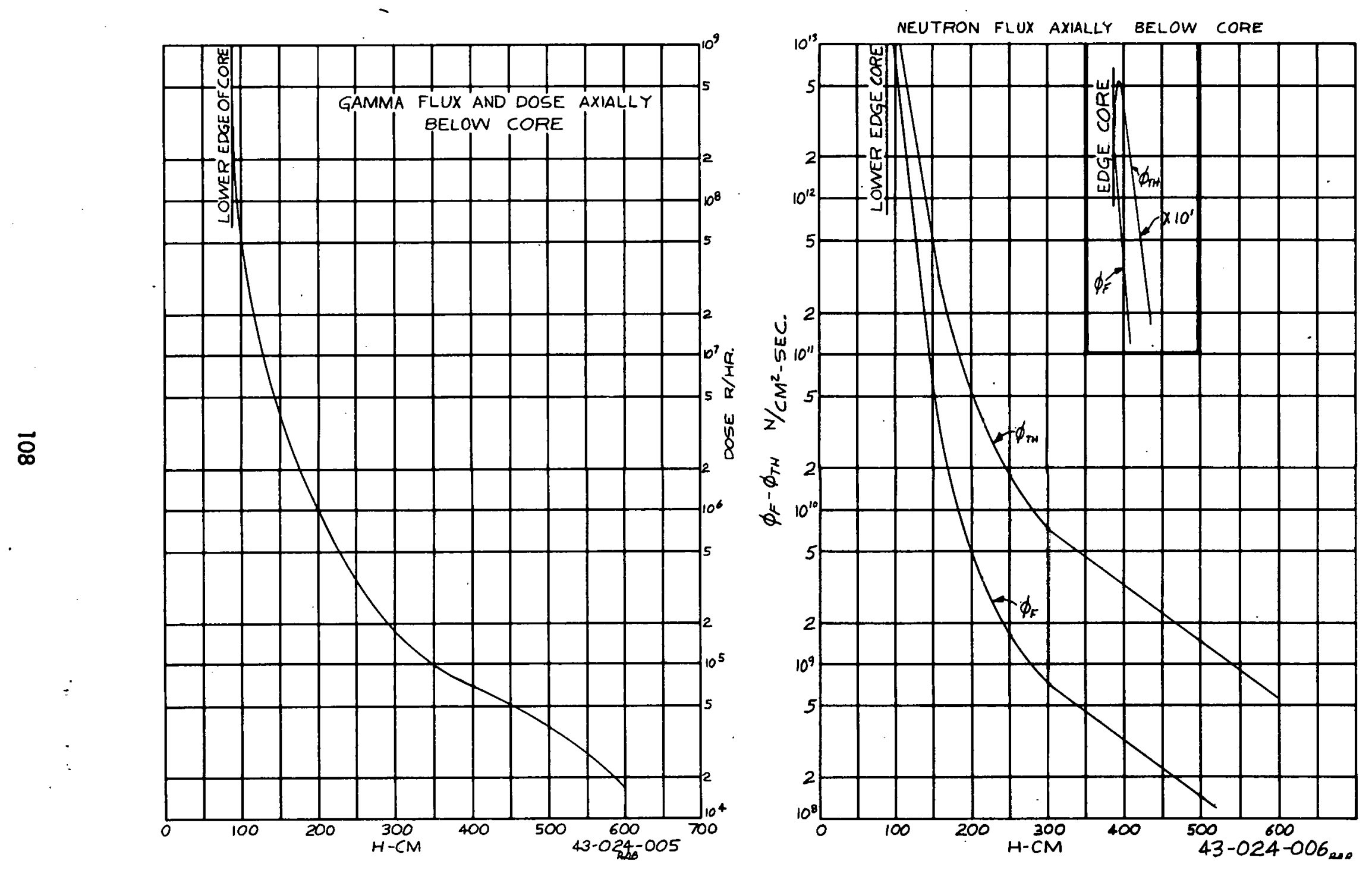

Figs. $3.9 \& 3.10$ 


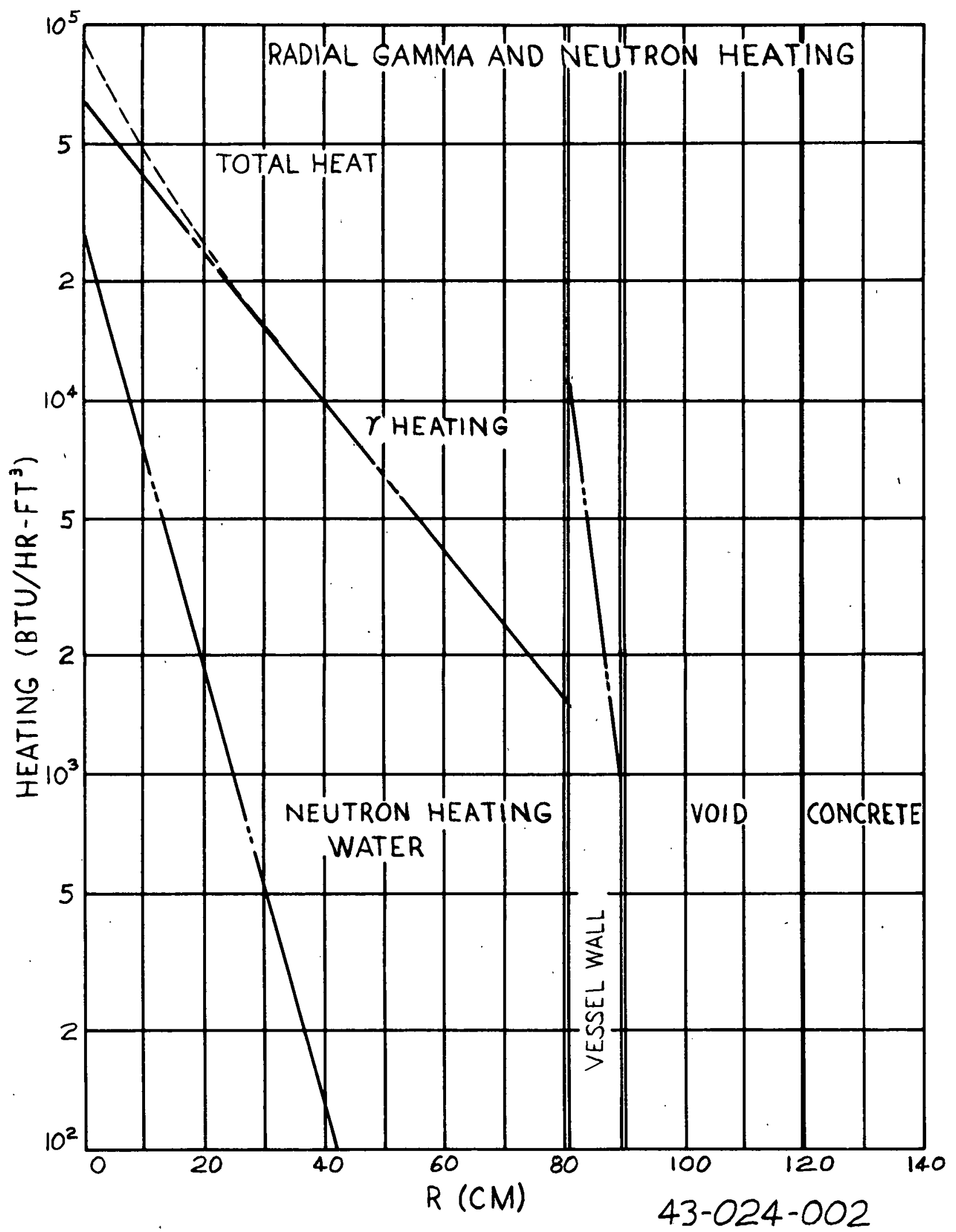

Radial Gamma and Neutron Heating Simulator

Fig. 3.11 


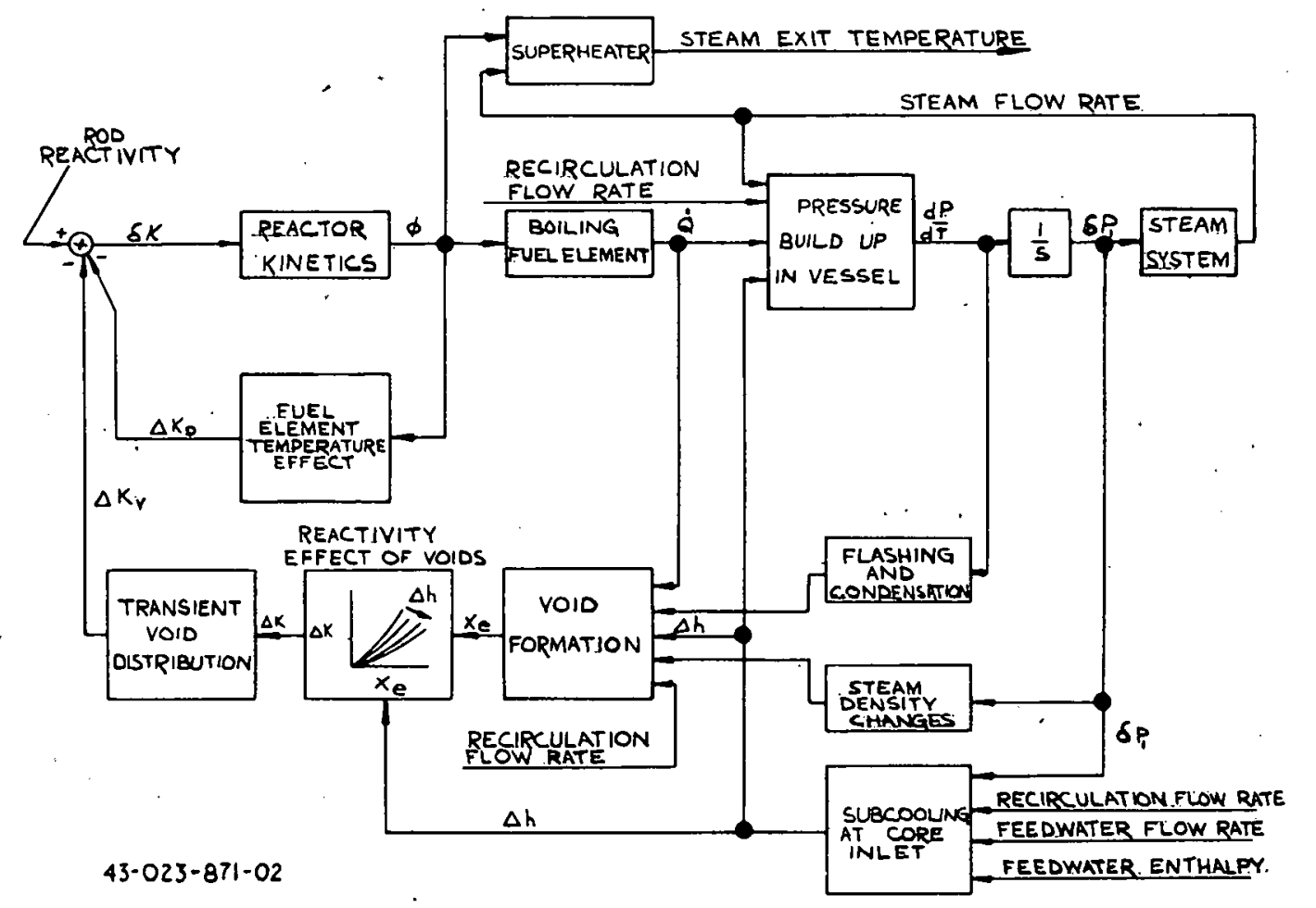

System Block Diagram

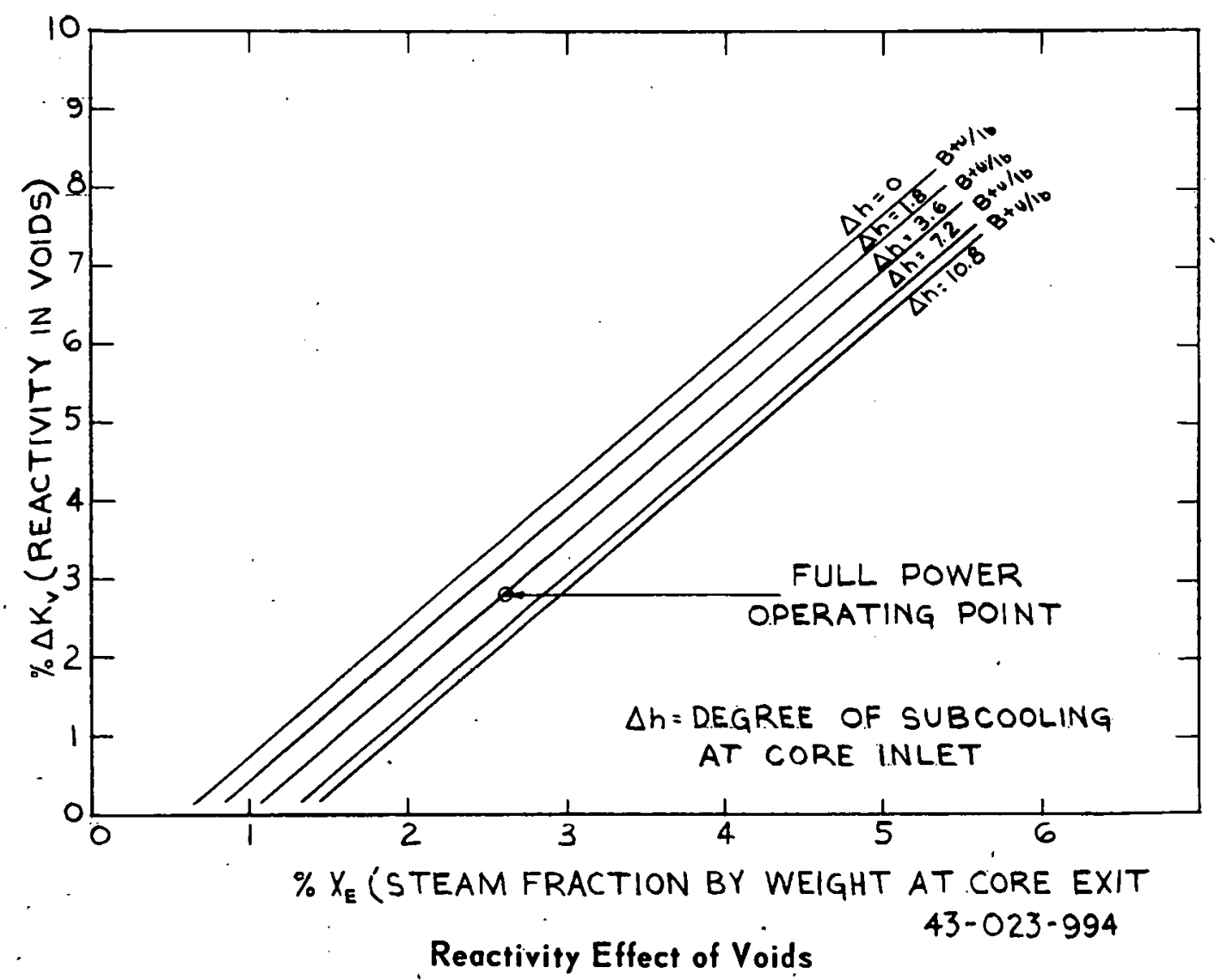

Figs. $3.12 \& 3.13$ 


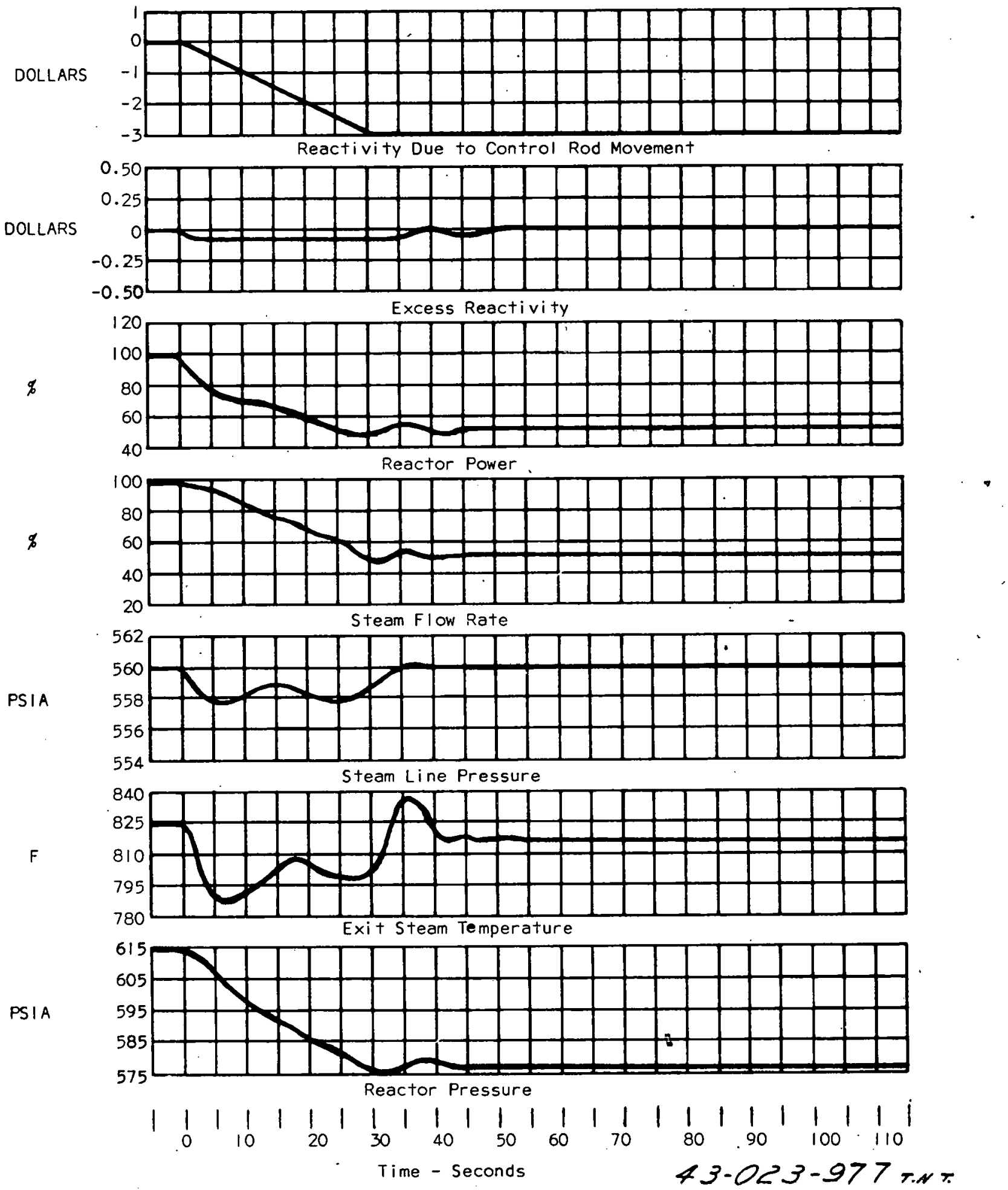

Control Rod Run-In Fig. 3.14 
CONTROL ROO RUN-OUT

Operation at 50\% Power, Continuous Rod Withdrawal for

60 Seconds Results in Addition of 3 Dollars Reactivity

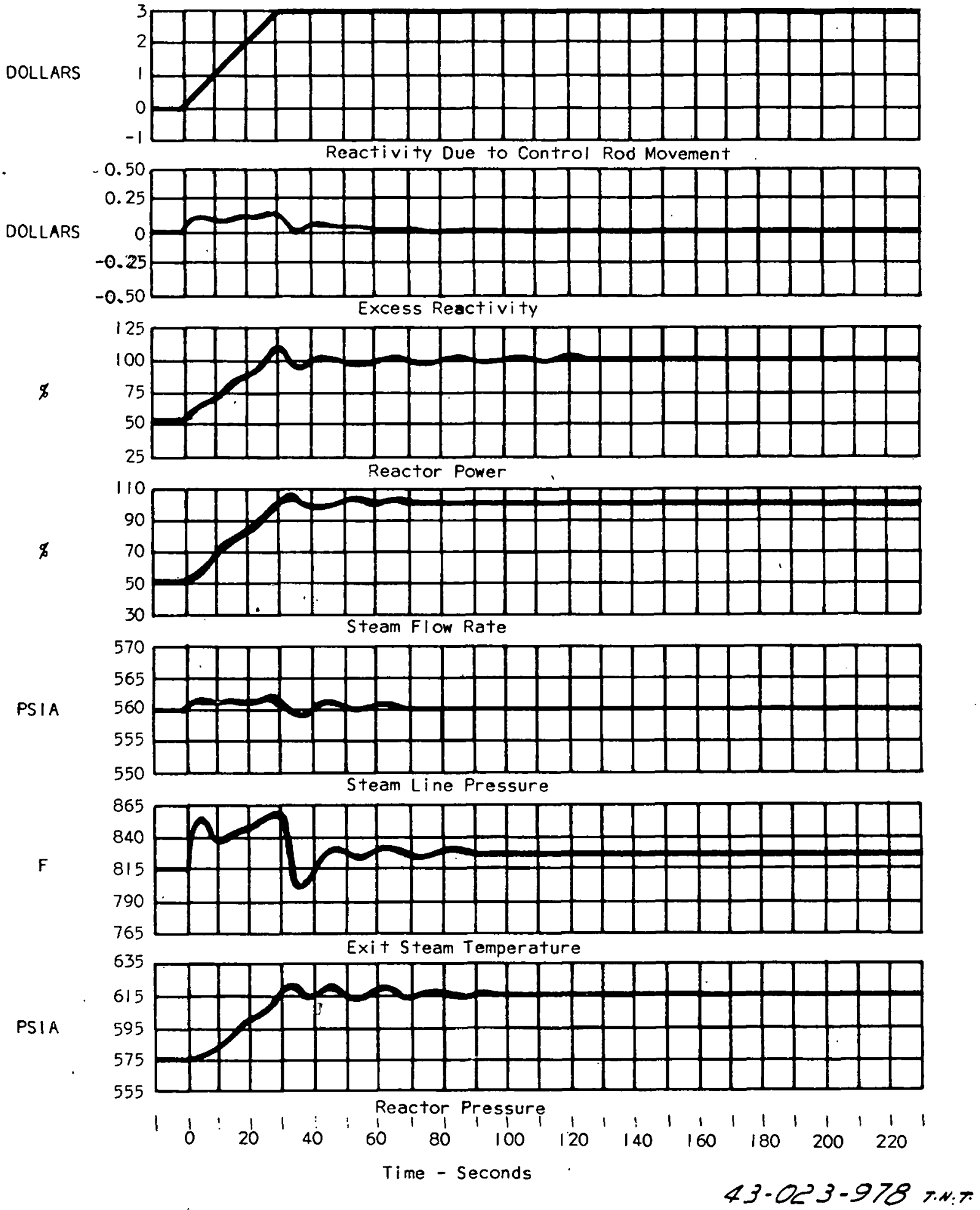

Control Rod Run-Out Fig. 3.15 
STARTING AND STOPPING RECIRCULATION PLMP

Operation at 100\% Power, One Recirculation Pump Suddenly Losses

Its Power, and I Minute Later Suddenly Comes Back.

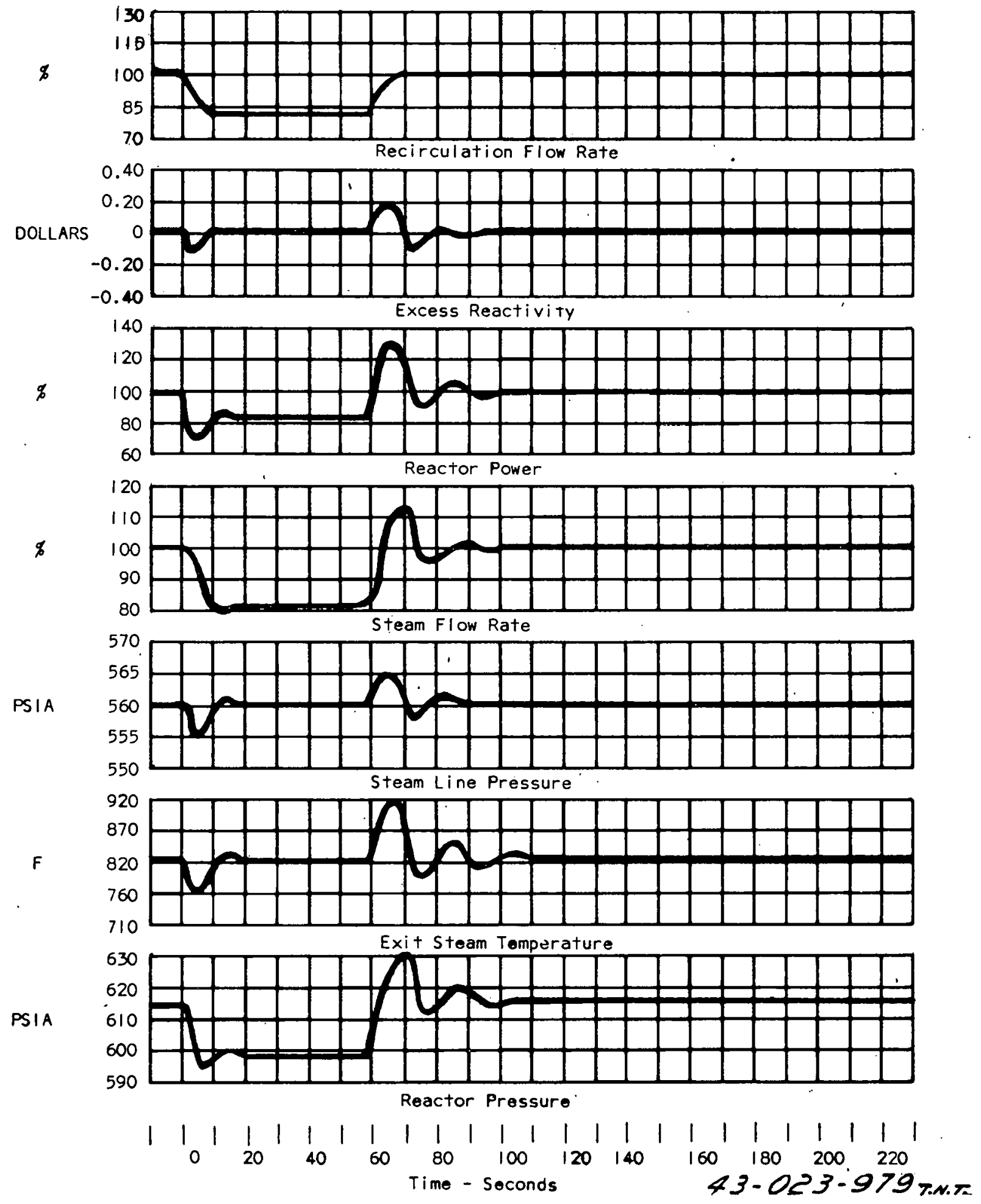

Starting and Stopping Recirculation Pump Fig. 3.16 


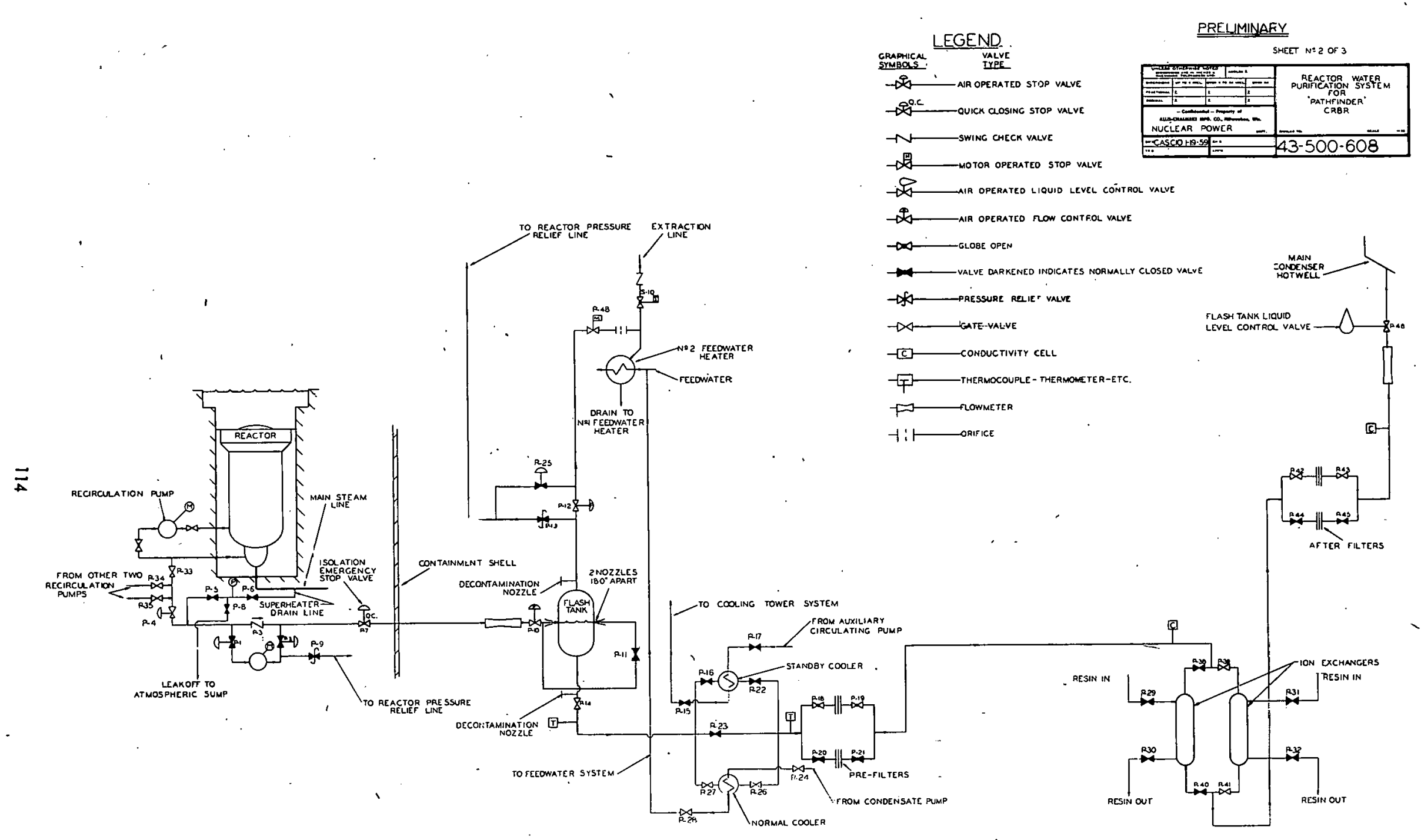

Reactor Water Purification System Fig. 4.1 


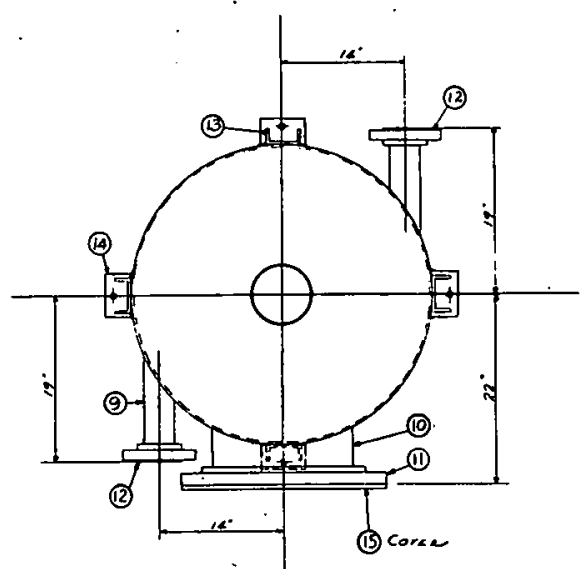

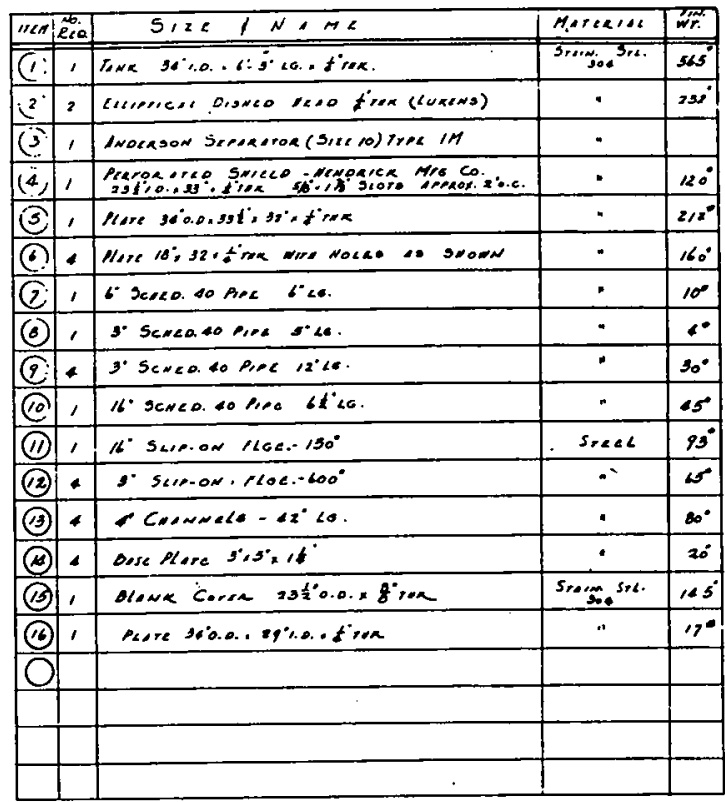

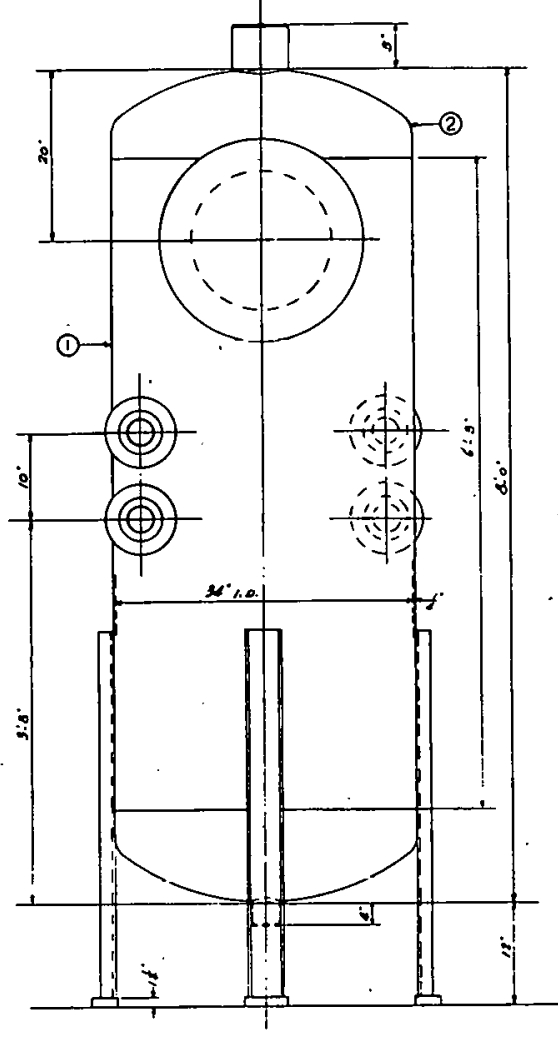

Flash Tank for Pathfinder Station
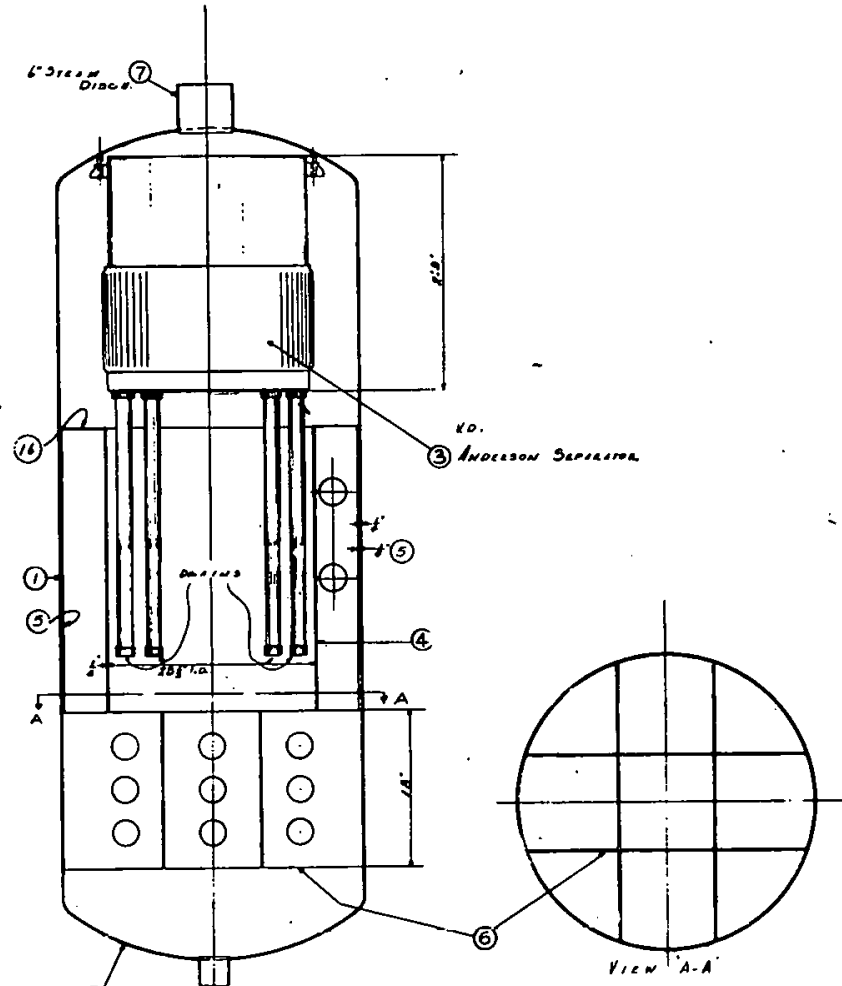

Desien press. 100 Psi Desian trme $3 / 2^{\circ}$ (Ne)

Fig. 4.2

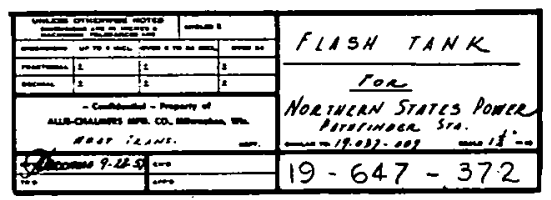


FILTER TEST - 39RIOCV - COTTON

2GPM PER ELEMENT

WATER AT 80 $80^{\circ} 130^{\circ} \mathrm{F}$ : BOEHMITE, $\mathrm{AL}_{2} \mathrm{O}_{3} \cdot \mathrm{H}_{2} \mathrm{O}$
CORROSION PRODUCT : BOHM

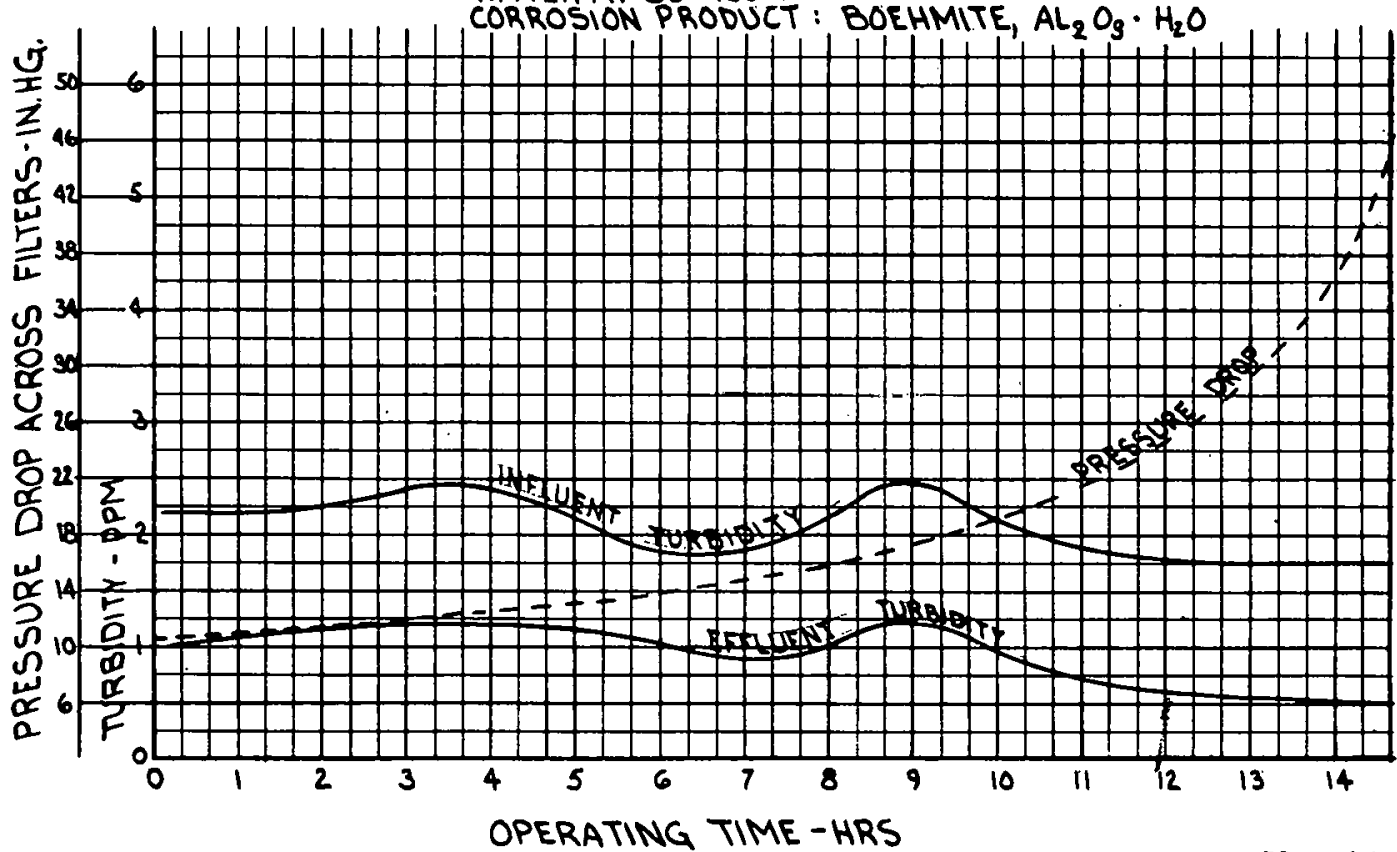

14 JULY59 KGG

43. 023.996

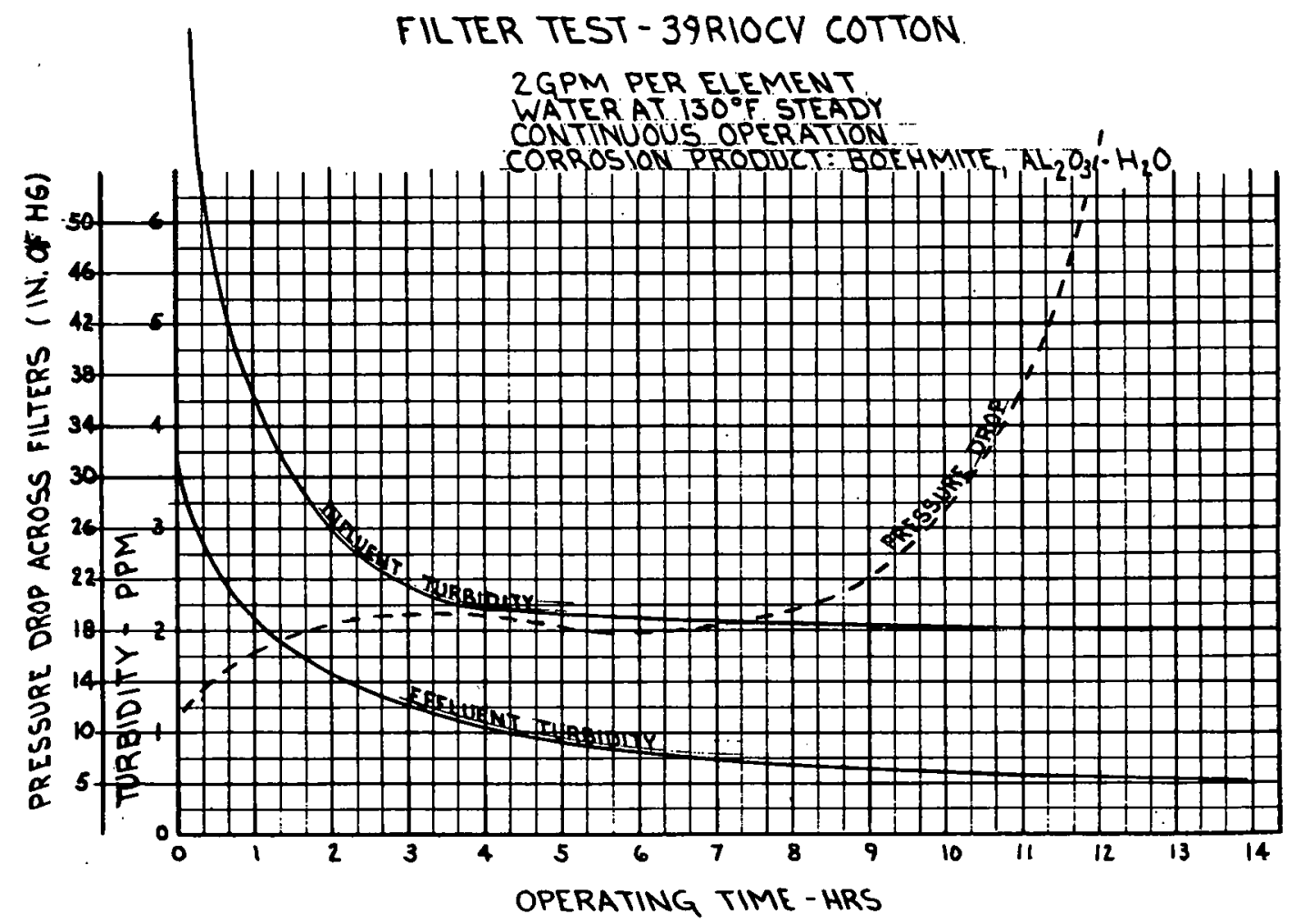

Figs. $4.3 \& 4.4$

15 JULY 59 KGG

$.43-023-997$ 


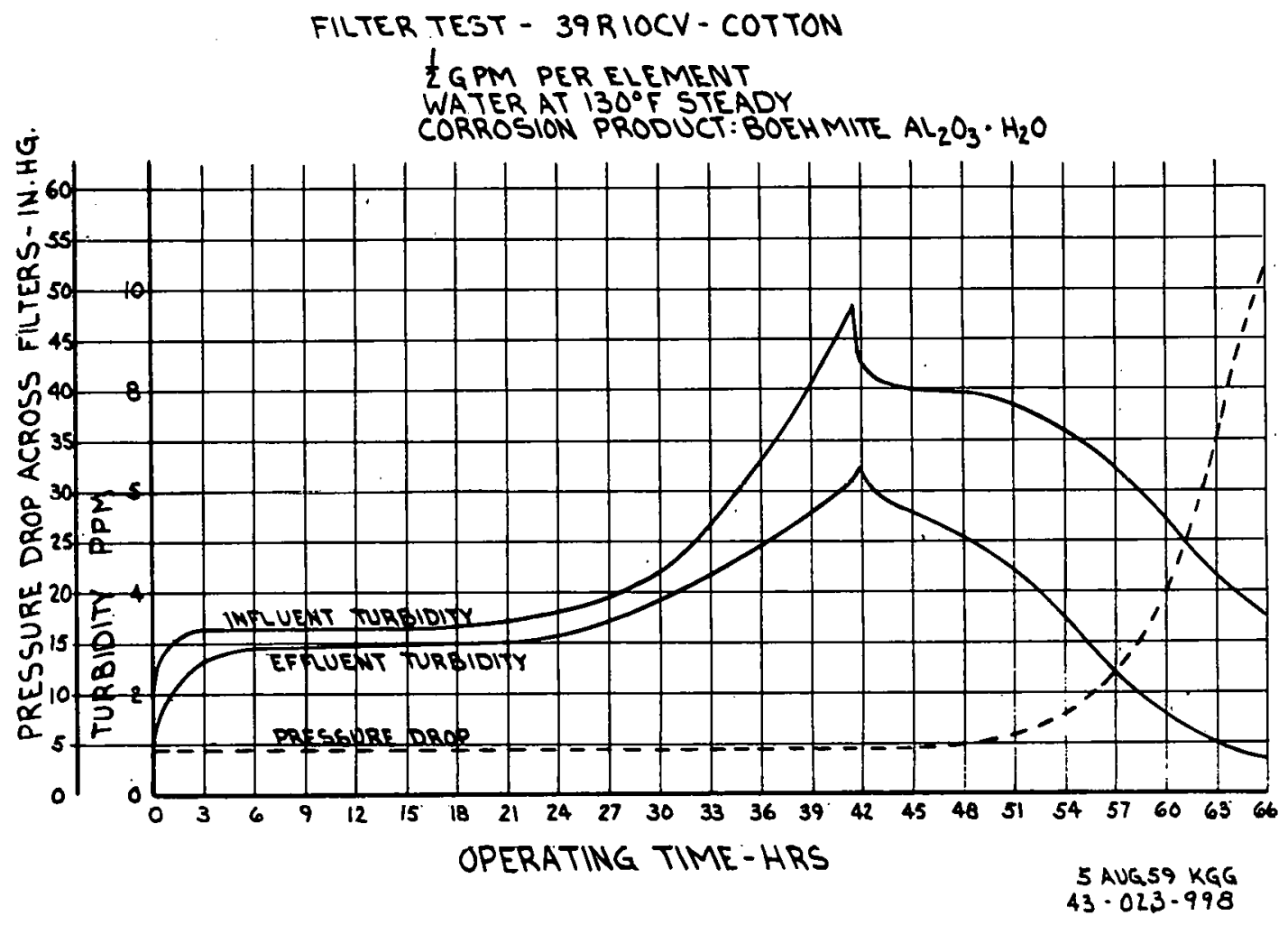

Pressure Drop Across Filters vs Operating Time,

Fig. 4.5

Filter Test - 39R10 CV - Cotton

117 
PEAGTOP BUILDING

ELECTRICAL CABLE PENETRATIONS

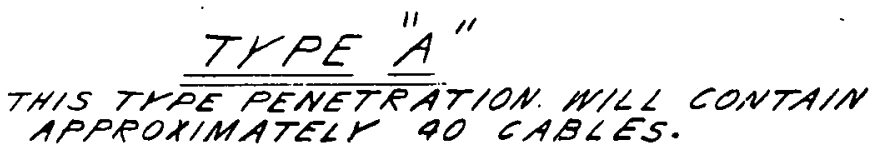

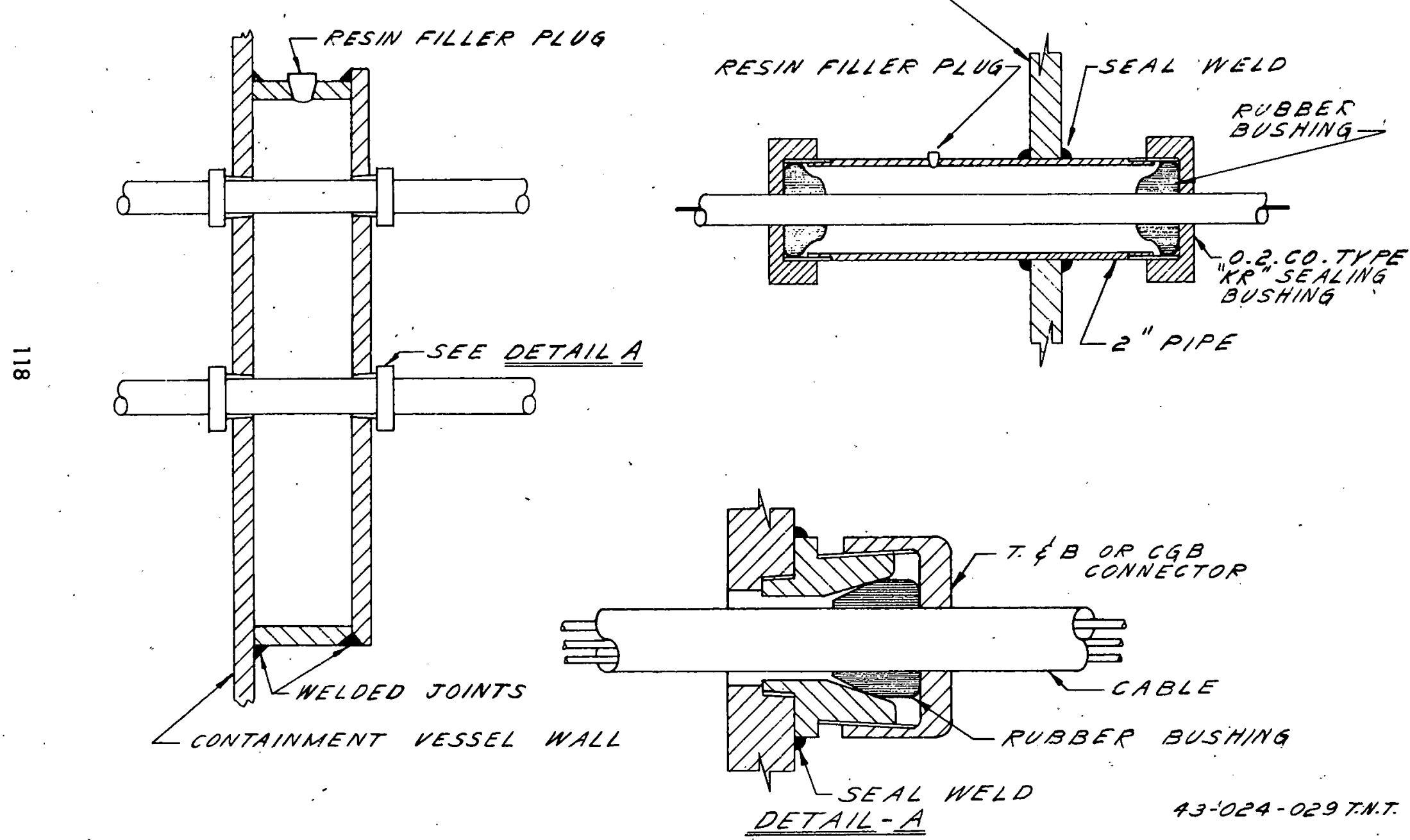

Reactor Building Electrical Cable Penetrations

Fig. 5.1 
PRÓPOSEO

PEACTOR START-UP INTEPLOCKS

VALVE NUMBERS REFER TO DWG"43-500-608

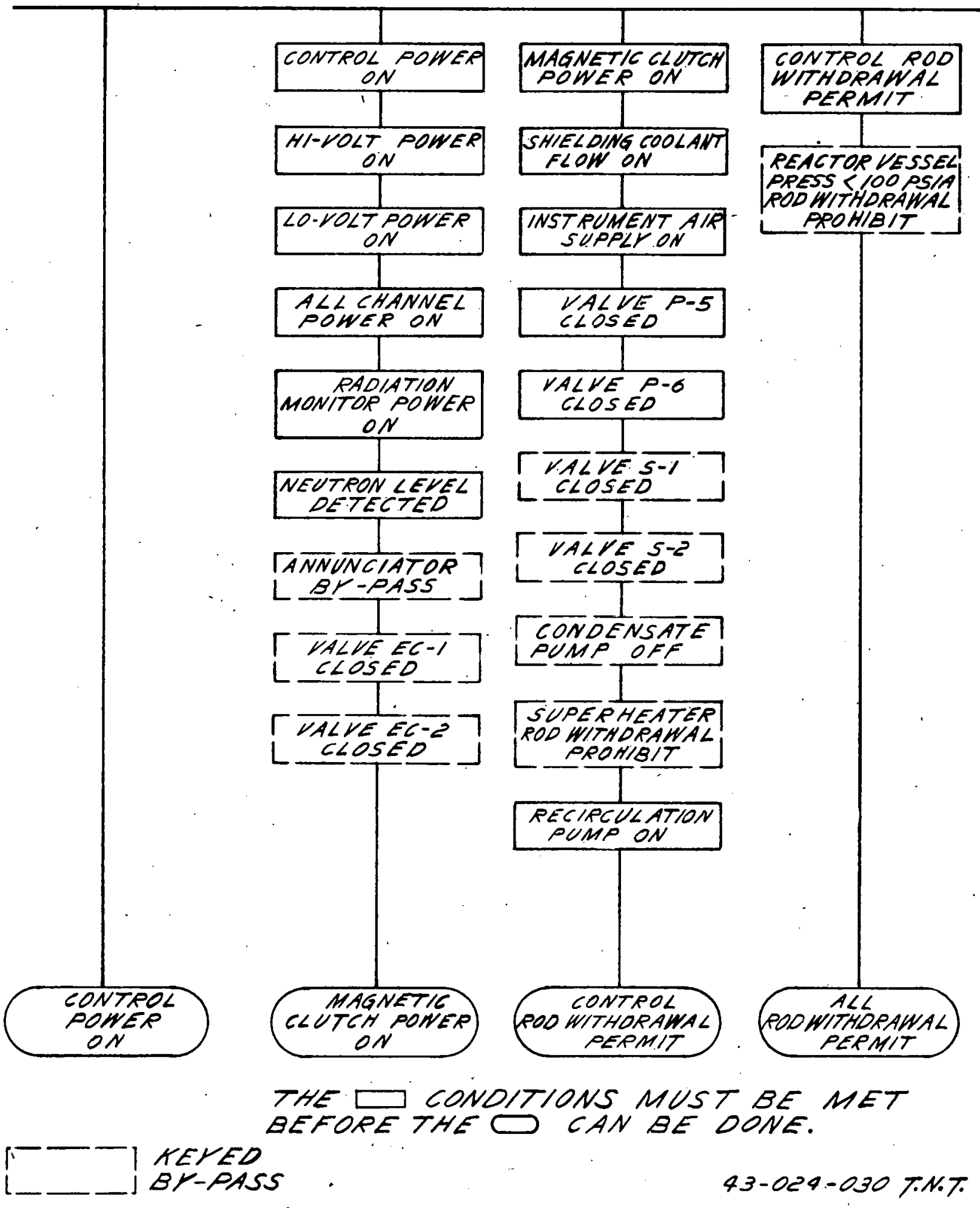

Proposed Reactor Start-up Interlocks

Fig. 5.2

119 


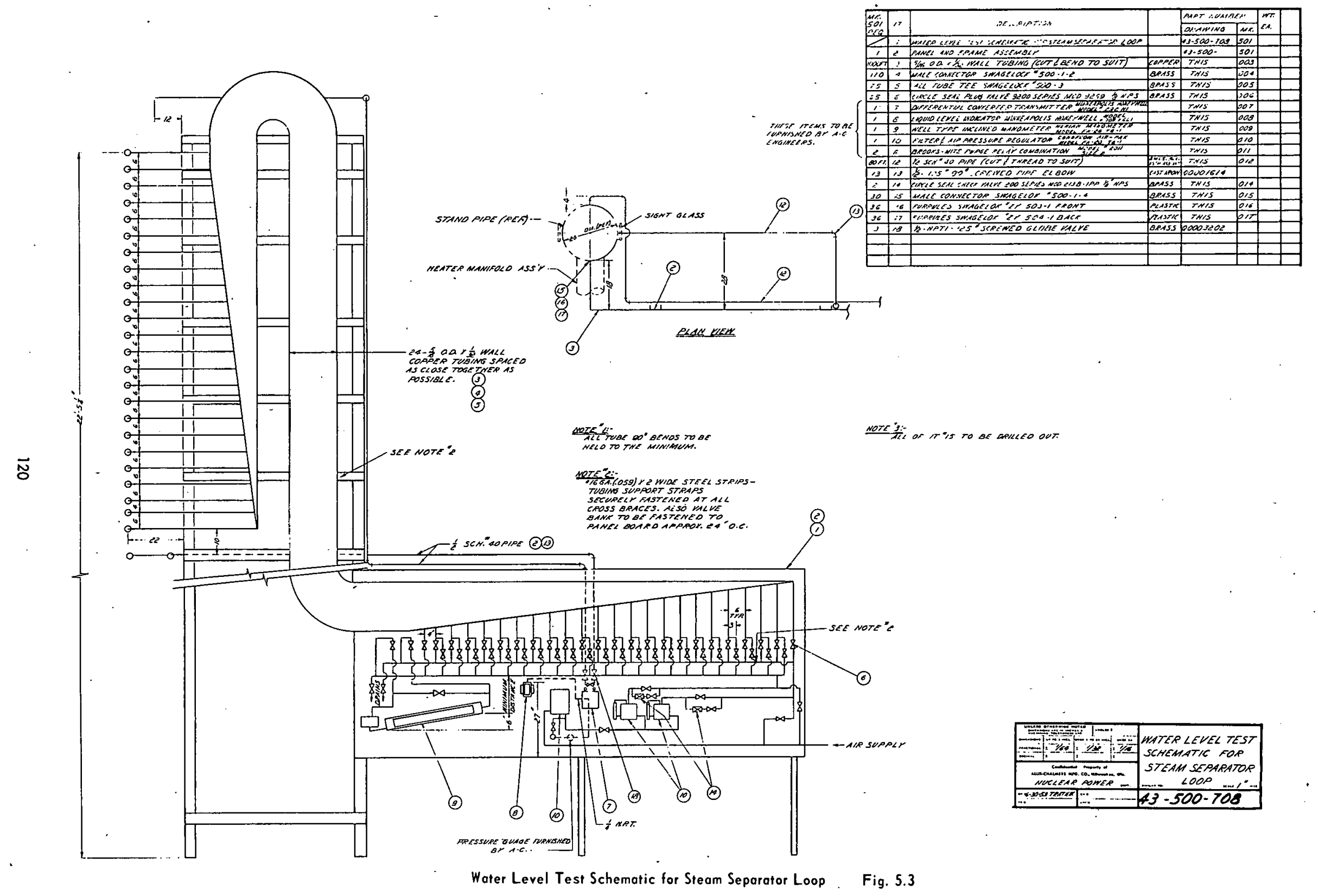




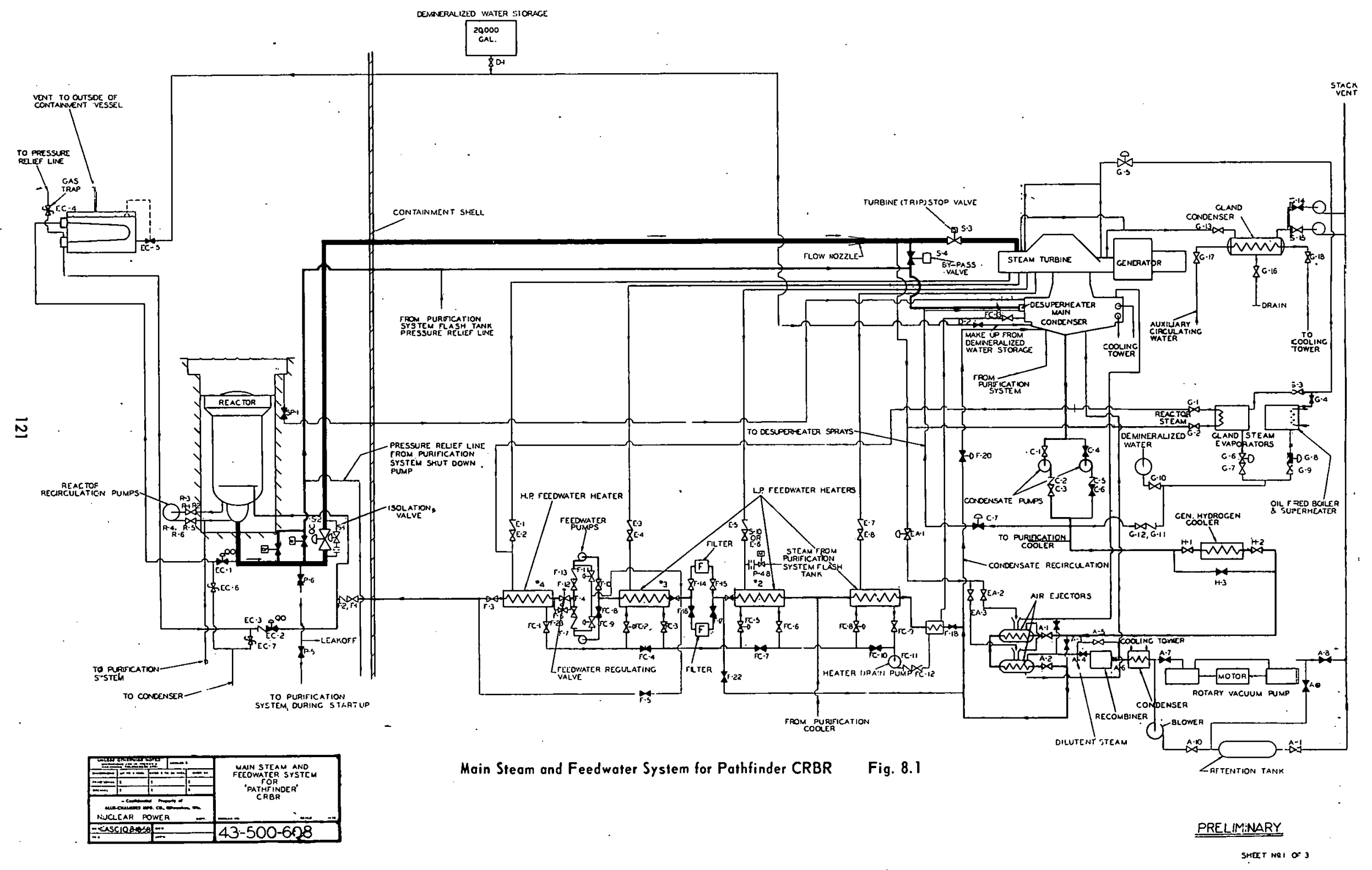


